Present-Day and late Quaternary

Crustal Deformation along the southern Dead Sea Fault System, Jordan

A Thesis
Presented to
the Faculty of the Graduate School
at the University of Missouri-Columbia
In Partial Fulfillment
of the Requirements for the Degree
Master of Science
by
Wr. Francisco Gomez, Thesis Supervisor
MAY 2013


The undersigned, appointed by the dean of the Graduate School, have examined the thesis entitled:

Present-day and late Quaternary crustal deformation along the southern Dead Sea Fault System, Jordan

Presented by William Cochran

A candidate for the degree of Master of Science

And hereby certify that in their opinion it is worthy of acceptance.

Dr. Francisco Gomez

Dr. Eric Sandvol

Dr. Randall Miles 


\section{$\underline{\text { ACKNOWLEDGEMENTS }}$}

I would like to thank my thesis advisor, Dr. Francisco Gomez, for his encouragement and support throughout this research process. I would also like to thank my thesis committee members, Dr. Eric Sandvol and Dr. Randall Miles, for their assistance in improving the quality of my writing. I would like to thank our collaborators at Hashemite University, Dr. Eid al-Tarazi and Jafar abu Rajab, for their assistance with collecting our GPS data in Jordan, the National Science Foundation (NSF) for the funding of our GPS survey, the MU Department of Geological Sciences for TA and scholarship support, and UNAVCO and SOPAC for supplying regional GPS data. Finally, I would like to thank my family and friends for their love and support throughout my collegiate career, and Brooke for her patience and love through the writing process. 


\section{TABLE OF CONTENTS}

Acknowledgments

List of Figures.

List of Tables.

Abstract.

Chapter 1 (Introduction)

1.1 Introduction

1.2 Scientific Goals

Chapter 2 (Geologic Background)

2.1 Tectonic Setting

2.2 Volcanism

2.3 Lithospheric Structure

2.4 Seismicity

2.5 Kinematics of southern DSF

Chapter 3 (GPS Theory, Processing, \& Modeling)

3.1 What is GPS?.

3.2 GPS Data Collection

3.3 GPS Data Processing

3.4 Resulting Velocity Field

3.5 Modeling GPS velocities

3.5.1 1-D Elastic Dislocation Models

3.5.2 2-D Elastic Block Model.

3.6 Discussion 
Chapter 4 (Statistical Analysis of Quaternary Slip Rates)

4.1 Introduction.

4.2 Observational Data.

4.3 Statistical Analysis.

4.4 Results

4.5 Discussion

Chapter 5 (Discussions and Implications)

5.1 Short-term vs. Long-term Slip Rates.

5.2 Seismic Hazard Implications

5.3 Conclusions

References

Appendix A: Tables of GPS velocities

Appendix B: Tables of Raw Observations and Statistical Analysis 


\section{LIST OF FIGURES}

Figure 1.1: Regional Tectonic Map of Eastern Mediterranean Region...........(2)

Figure 1.2: Earthquake Cycle Model and strike-slip deformation cycle...........(3)

Figure 2.1: Seismicity along the southern Dead Sea Fault......................(10)

Figure 2.2: Regional GPS map from Reilinger et al. (2006)....................(15)

Figure 3.1: Survey-mode and continuous GPS site locations...................(19)

Figure 3.2: Fixed-height mast with Zephyr antennae installed at DBUS........(21)

Figure 3.3: Post-rotational residuals from reference frame transformation.......(23)

Figure 3.4: GPS velocities processed in this study............................(24)

Figure 3.5: GPS velocities including Sadeh et al. (2012) and Le Beon et al. (2008).

Figure 3.6: 1-D elastic dislocation model for the JVF, DSB, and WAF.

Figure 3.7: 1-sigma confidence limits on slip rate and locking depth for JVF, DSB, and WAF.....

Figure 3.8: Elastic block model for the southern DSF

Figure 4.1: Site locations for Quaternary slip rate studies statistically analyzed.

Figure 4.2: Interpreted alluvial surfaces from Le Beon et al. (2010).

Figure 4.3: Interpreted alluvial surfaces from Le Beon et al. (2012).

Figure 4.4: Quaternary slip rates for SDSF (zero erosion rates).

Figure 4.5: Quaternary slip rates for SDSF (maximum erosion rates)

Figure 5.1: Comparison among GPS and late Quaternary slip rates

Figure 5.2: Field photograph of offset aqueduct at Qasr Tilah site....

Figure 5.3: Orthorectified photo of offset aqueduct with scarp profile.

Figure 5.4: 3-D surface model of offset aqueduct.

Figure 5.5: 3-D slip vector of aqueduct showing vertical and horizontal offsets 


\section{LIST OF TABLES}

Table 2.1: Documented paleoseismicity along the SDSF

Table 2.2: Previously reported late Quaternary slip rates along SDSF

Table 4.1: Comparison among previously reported late Quaternary slip rates and uncertainties with statically reported slip rates from this study........(40) 


\title{
Present-Day and Late Quaternary Crustal Deformation along the southern Dead Sea Fault System, Jordan
}

\author{
By William Joseph Cochran \\ Thesis Supervisor: Dr. Francisco Gomez
}

\begin{abstract}
Theoretical models of the earthquake cycle predict that crustal rheology may lead to differences between short-term crustal deformation rates (decadal time scales) and long-term fault slip rates (Holocene to late Pleistocene time scales). This study investigates fault kinematics along the southern Dead Sea fault using tectonic geodesy and late Quaternary slip estimates. The Dead Sea fault is the left-lateral transform bounding the Arabia and Sinai plates in the eastern Mediterranean region. Two main segments comprise the southern DSF: the Wadi Araba and Jordan Valley faults. These two main fault branches are separated by a left step-over that forms the Dead Sea basin. This study incorporates new GPS measurements in Jordan (survey-mode and continuous), as well as recently published data within Israel. The application of elastic dislocation models produced slip rates of $4.8 \pm 0.1 \mathrm{~mm} / \mathrm{yr}$ and $4.7 \pm 0.1 \mathrm{~mm} / \mathrm{yr}$ for the Wadi Araba and Jordan Valley faults, respectively. Effective locking depths also varied along strike, ranging from $9 \pm 3 \mathrm{~km}$ and $16 \pm 6 \mathrm{~km}$ along the Wadi Araba and Jordan Valley faults, respectively. Previously published geologic slip rates range from 2-20 mm/yr. For a more robust comparison of short-term and long-term slip rates, this study re-evaluates published geomorphic data from six
\end{abstract}


sites along the southern DSF using a standardized statistical analysis. Our statistical analyses reduce the slip rate uncertainties, and suggest a slip rate of 4.5-5.0 mm/yr for the past $100 \mathrm{ka}$. In addition to implications for regional earthquake hazard, the consistency of the slip rates suggests that of a relatively stiff lower crust. 


\section{Chapter 1}

\section{Introduction}

\subsection{Introduction}

The Eastern Mediterranean region is composed of many tectonic

environments, including an active collisional zone (Bitlus/Zagros Suture) between the Arabian Plate and the Eurasian plate, escape tectonism via strike-slip faulting (e.g. North and East Anatolian faults) of the Anatolian plateau, and the Red Sea oceanic spreading system generating new ocean floor through extension (Figure 1.1). Within this region, the left-lateral Dead Sea Fault system (DSF) accommodates the differential convergence of Arabia with the Sinai (Africa) plate with Eurasia. The DSF traces for roughly $800 \mathrm{~km}$ and connects the Red Sea spreading center with the East Anatolian Fault in southern Turkey. Pull-apart basins (e.g. Dead Sea Basin) and transpressional settings (e.g. Lebanese Restraining Bend) are documented along the entire DSF, giving evidence that motion along the fault is not purely strike-slip.

Current earthquake recurrence models show that the build-up and release of elastic strain in the upper crust have implications on lithospheric deformation (Figure 1.2). Elastic strain energy is stored in the elastic upper crust during the interseismic period (i.e. between earthquakes) and is quickly released during coseismic slip (e.g. Thatcher, 1993). This interseismic strain is related to the depth of the seismogenic crust (i.e. locking depths) and the rheological properties of the lower crust/upper mantle (e.g. Thatcher, 1993). Therefore, comparing 


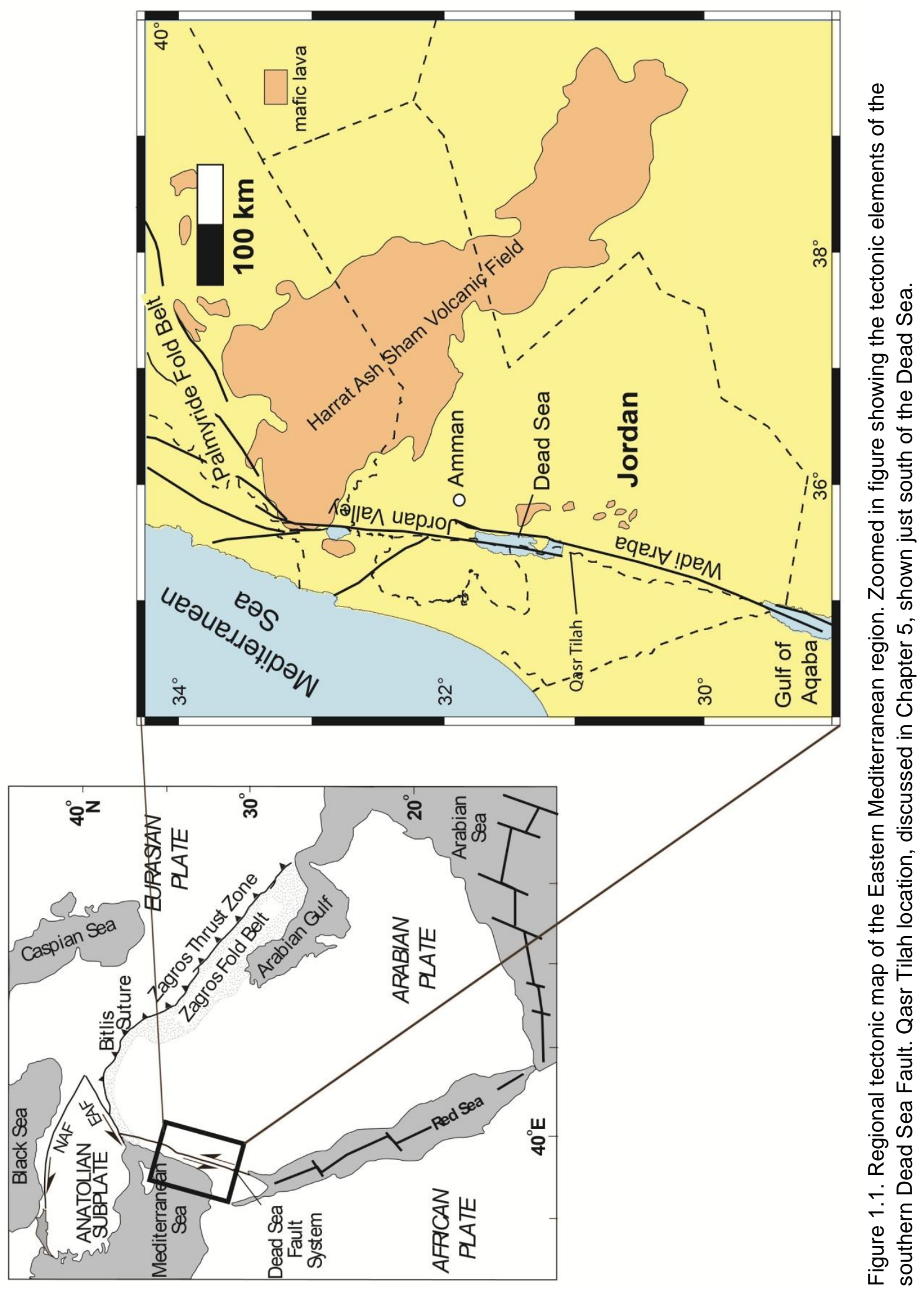




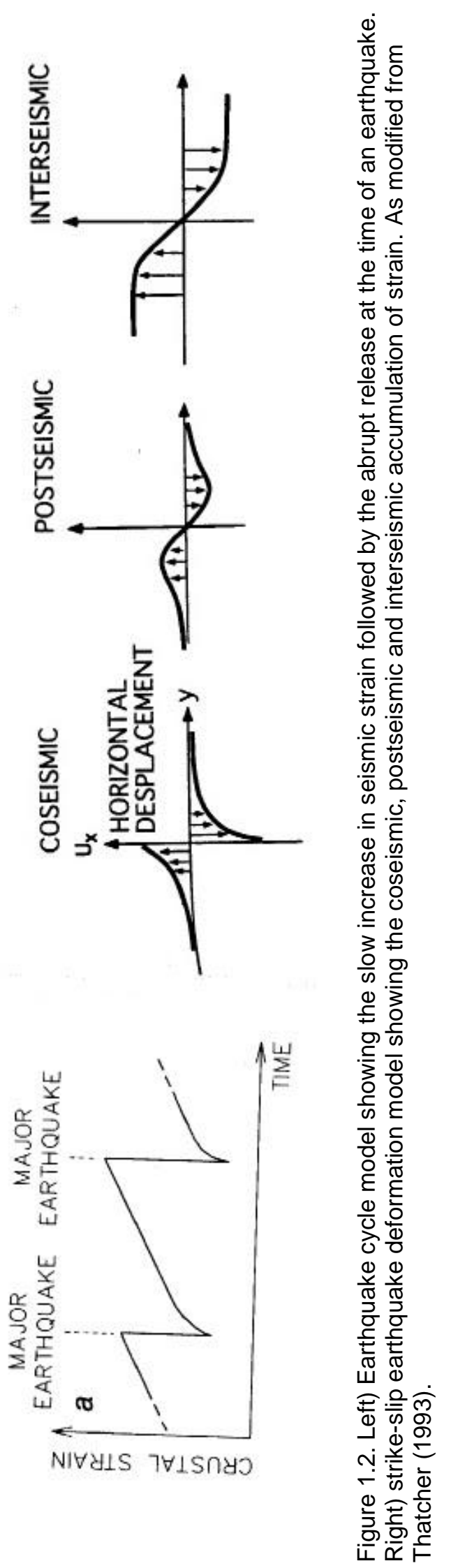


long-term and short-term fault kinematics has implications on lithospheric properties.

\subsection{Scientific Goals}

The goals of this study are to assess late Quaternary kinematics along the southern DSF using both Global Positioning System (GPS) and geologic observations (i.e. short-term vs. long-term fault kinematics). GPS measurements acquired during surveys from 2005-2012 in Jordan are combined with other available GPS data of the region (e.g. Israel, Lebanon, and Syria). Late Quaternary slip rate values are found by re-evaluating previously reported offsets and ages for a statistically consistent assessment of the data. Therefore, comparison of the consistency/differences between short- and long-term slip rates has implications for earthquake cycle models and lithospheric structure.

Historical and paleoseismic records document multiple devastating earthquakes along the southern DSF (e.g. Ferry et al. (2011). Therefore, this study assesses a previously documented faulted site representing an incremental slip event using field photogrammetric methods. Comparison of our geodetically determined slip rates with paleoseismic, archeoseismic, and historical records of the most recent earthquake, address questions regarding the peak magnitude event which could occur today.

The scientific questions include:

1) Does the locking depth vary spatially along strike of the southern DSF; and what implications are there on the lithospheric structure? 
2) How does the late Quaternary slip rates compare to the GPS slip rates (short-term vs. long-term slip)?

3) What is the influence of lithospheric structure on fault kinematic parameters (i.e. fault slip and locking depths)

4) What are the effects of temporal and spatial earthquake clustering on the evaluation of temporal fault kinematics?

5) By comparing our geodetic results with the southern DSF earthquake history, what is the peak magnitude event that could occur along the Wadi Araba and Jordan Valley faults today? 


\section{Chapter 2}

\section{Geologic Background}

\subsection{Tectonic Setting}

The N-S striking, left-lateral Dead Sea Fault (DSF) accommodates the differential convergence between the Arabian plate and the Sinai sub-plate (Nubian) (Figure 1.1). The DSF consists of three main segments: 1) A northern section tracing along the Syrian Coastal Mountains for $\sim 250 \mathrm{~km}$ until it reaches the East Anatolian Fault; 2) a Central bend striking NNE-SSW for $\sim 200 \mathrm{~km}$ along the Mount Lebanon and Anti-Lebanon ranges; and 3) a southern segment striking N-S for $\sim 350 \mathrm{~km}$ from the Red Sea Rift to the Sea of Galilee. The southern section of the DSF consists of two main faults, the Wadi Araba Fault (WAF) and the Jordan Valley Fault (JVF), separated by a left step-over which forms the Dead Sea pull-apart basin. An additional fault, the Carmel fault, is an oblique-slip fault (normal and left-lateral motion) trending NW-SE which splays off the JVF.

Geologic observations suggest left-lateral displacement along the southern DSF of approximately $105 \mathrm{~km}$, with two phases of displacement occurring since the late Miocene (e.g. Quennell, 1958; Quennell, 1984; Freund et al, 1970). The first phase accounts for approximately $60 \mathrm{~km}$ of displacement, occurring from the middle to late Miocene (Quennell, 1958; Quennell, 1984; Freund et al., 1970). The second phase, beginning during the late Miocene or early Pliocene and continuing today (Quennell, 1958; Quennell, 1984), accounts for $45 \mathrm{~km}$ of displacement and is suggested to have began during the initiation of 
the Red Sea Rift (e.g. Hempton, 1987). Although no clear offsets are present, Freund et al. (1970) suggest $20-25 \mathrm{~km}$ of left-lateral displacement along the northern DSF. Based on balanced cross-section, Chaimov et al. (1990) have interpreted the $20-25 \mathrm{~km}$ of shortening to be accommodated by the Palmyride fold and thrust belt prior to the activation of the DSF (late Cenozoic). Geologic observations have also been used to constrain the timing of activation of the DSF, dating 20 Ma dikes offset by the fault (Eyal et al. 1981). Garfunkel and Ben-Avraham (2001) suggest that the basins along the fault (e.g. Dead Sea Basin) are the oldest structures at 17-18 Ma.

\subsection{Volcanism}

Late Cenozoic volcanic activity characterizes the Arabian region, having pulses of volcanic activity from $\sim 25 \mathrm{Ma}$ to the Holocene occurring within three main regions (e.g. Illani et al., 2001): 1) The Dead Sea rift/Jordan Valley rift zone, 2) along the eastern side of the rift, and 2) within the Harrat AI Sham volcanic field, which extends through northern and eastern Jordan into southern Syria (Figure 1.1). Within the Harrat Al Sham, there have been two pulses of volcanism between 26-22 Ma and $13 \mathrm{Ma}$, suggested to coincide with the volcanism around the Red Sea (Illani et al., 2001). The quiescent period from 22 Ma to $13 \mathrm{Ma}$ is seen throughout the aforementioned volcanic fields, as well as along the Red Sea volcanic zone (Illani et al., 2001). Furthermore, the geochemical signature of the mafic volcanism indicates a mixed source of both lithosphere and asthenosphere (Shaw et al., 2003). 


\subsection{Lithosperic Structure}

Seismological studies provide insight into the lithospheric structure throughout the Anatolian Plateau and Arabian Shield. Regional seismological models utilizing $\mathrm{Pg}$ attenuation, $\mathrm{Lg}$ attenuation, and $\mathrm{Pn}$ tomography suggest an increase in seismic attenuation and a decrease in seismic wave velocity from south to north along the southern DSF. Bao et al (2011) documents a low Pg attenuation in the south along the Wadi Araba fault and a high attenuation along the Jordan Valley fault, and suggests a correlation between the absence of crustal melting and mafic volcanism (i.e. Harrat Ash Sham). Bao et al (2011) also compared the $\mathrm{Pg}$ and $\mathrm{Lg}$ attenuation, updating the data set from Al-Damegh et al (2004), showing an increase in Lg attenuation from south to north. These results compare to Pn tomographic studies of the region by Al-Laski et al (2004), which suggests a low velocity zone beneath northwestern Arabia along the JVF. Chang and Van der Lee (2011) utilized S-wave tomography to propose a mantle plume beneath NW Arabia (i.e. beneath the Jordan Valley) DSF, seen by a lowvelocity anomaly around $150-300 \mathrm{~km}$ depth.

More locally, the DESSERT and DESIRE working groups (e.g. Laske et al. 2008; Paschke et al. 2012; Weber et al. 2011; Mechie et al. 2009), as well as others, have collected data throughout Jordan using a variety of geophysical methods. Al-Zoubi and Avraham (2002) documents an increase in Moho (Mohorovicic discontinuity) depths from north to south along the southern DSF. Using surface wave tomography, Laske et al. (2008) suggest an anomalously slow asthenosphere and a relatively thin lithosphere of $80 \mathrm{~km}$ along the WAF. 
Comparison among various transects across the WAF and Dead Sea Basin suggests an increase in Moho depths from west to east, with perturbations located beneath the DSF, as well as a decrease in the depth to the Moho from the WAF to the Dead Sea Basin (Mechie et al. 2009, Weber et al. 2011, ten Brink et al. 2006). A clear discrepancy in the lithospheric structure along strike of the southern DSF suggests variation in lower crustal/upper mantle properties, with implications on fault kinematics.

\subsection{Seismicity}

Seismicity along the southern DSF has been relatively sparse throughout the previous century, despite historical evidence suggesting this transform produces large, devastating earthquakes (e.g. Ambraseys and Jackson, 1998; Sbeinati et al., 2005; Ben-Menahem et al., 1991). Aside from the 1995 earthquake in the Gulf of Aqaba (Mw =7.4), the southern DSF has not experienced a large $(\mathrm{Mw}>7.0)$ earthquake for nearly 600 years (Ambraseys, 2006; Ambraseys and Jackson, 1998) (Table 2.1). However, moderate seismicity (Figure 2.1), such as the $2004 \mathrm{Mw}=5.3$ in the Dead Sea Basin, provide evidence for the present day activity (Al-Tarazi et al. 2006).

Paleoseismic studies have attempted to assess earthquake recurrence along the Dead Sea fault. Hamiel et al. (2009) compiled paleo-prehistoric, historical, and instrumental seismicity along three areas of the DSF (N. Jordan Valley, Dead Sea Basin, and S. Wadi Araba) to assess late Quaternary seismicity. Suggested recurrence intervals over the past 60,000 years for the Jordan Valley, Dead Sea Basin, and Wadi Araba are 1500 years, 2000 years, 


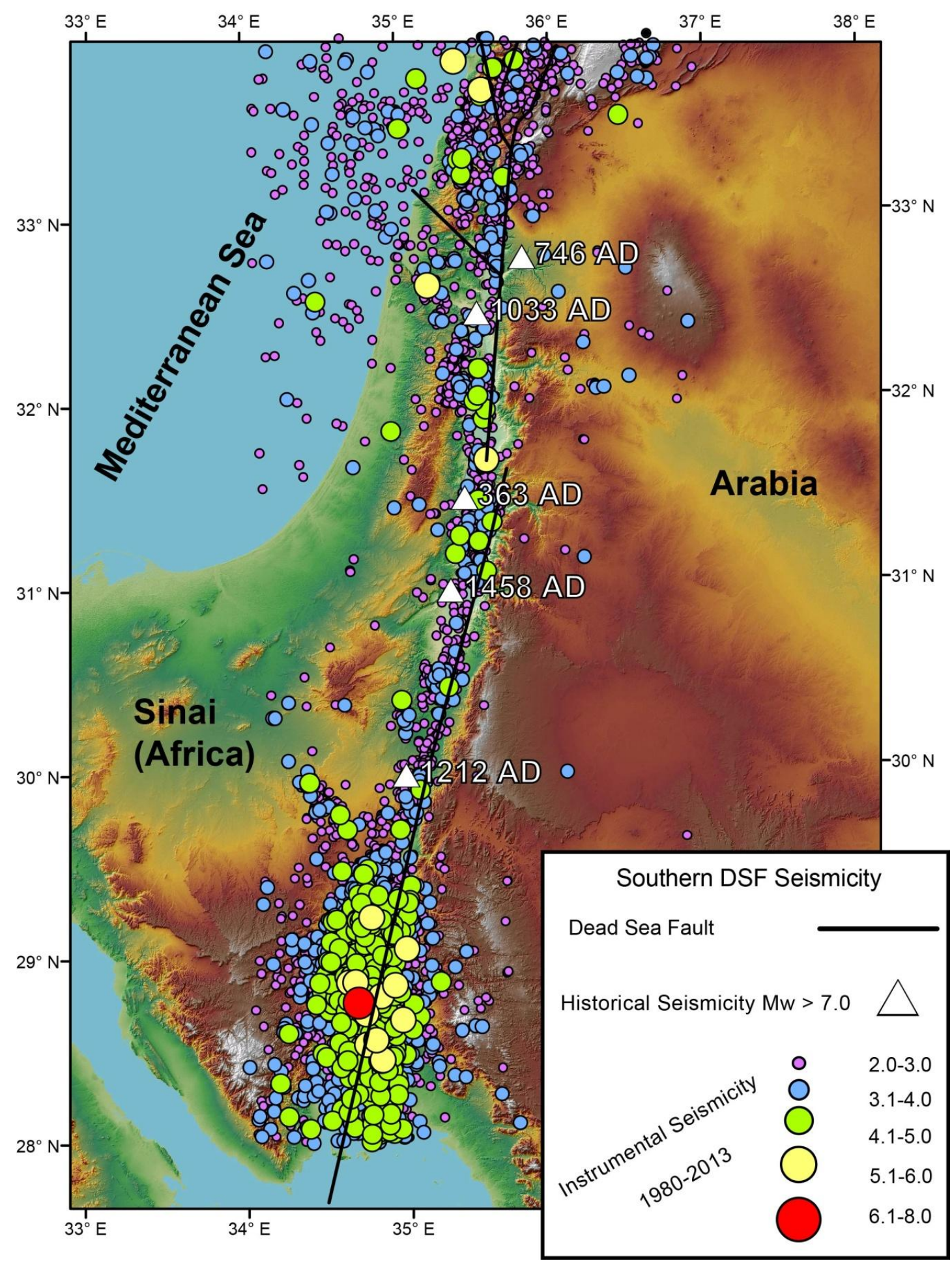

Figure 2.1. Seismicity along the southern DSF from the Geophysical Institute of Israel. The seismicity shown is complete down to $M_{w} \sim 2$, and spans from 1980-2013. 
Table 2.1. Summary of the paleoseismicity along the southern DSF for past 2000 years

\begin{tabular}{ccccc}
\hline Date & Fault Ruptured & \multicolumn{2}{c}{ Location } & Source \\
& & Latitude & Longitude & \\
\hline 363 & DSB & 31.5 & 35.4 & Ambraseys 2006* \\
551 & DSB & 33.9 & 35.9 & Haynes et al. 2006* \\
746 & JVF & 32.8 & 35.8 & Ambraseys 2006* \\
1033 & JVF & 32.5 & 35.5 & Ambraseys and Jackson, 1998* \\
1068 & WAF & 28.5 & 36.7 & Ambraseys and Jackson, 1998* \\
1212 & WAF & 30.0 & 35.0 & Haynes et al. 2006* \\
1293 & DSB/WAF & - & - & Haynes et al. 2006* \\
1458 & WAF/DSB & 31.0 & 35.3 & Ambraseys 2006* \\
1546 & DSB & - & - & Haynes et al. 2006* \\
1588 & WAF/Red Sea & 29.0 & 36.0 & Haynes et al. 2006* \\
1837 & DSB & - & - & Haynes et al. 2006* \\
1927 & JVF & 32.0 & 35.5 & Ambraseys and Jackson, 1998* \\
1995 & WAF/Red Sea & 28.9 & 34.2 & Ambraseys and Jackson, 1998* \\
\hline
\end{tabular}

* indicates that references therein are also referenced in this paper. 
and 1700 years, respectively (Hamiel et al. 2009). More recently, Ferry et al. (2011) used archeoseismology and paleoseismology and found 12 surfacerupturing events over the past 14 ka with an average recurrence interval of 790 $1160 \mathrm{yr}$, suggesting quasi-episodic slip behavior along the Jordan Valley segment. Owing to the uncertainties, these values are comparable to Hamiel et al. (2009). Additionally, Marco et al. (1996) used seismites (disrupted beds due to earthquake shaking) to suggest earthquake clustering to occur in 10,000 year intervals, followed by quiet periods of similar length. The paleo-magnitudes associated with the seismite formations to be $M_{L} \geq 5.5$, and suggest a 1600 year recurrence time for such events (Marco et al. 1996).

\subsection{Kinematics of southern DSF}

Quaternary slip rates along the southern DSF provide insight into longterm ( 350 ka) fault kinematics. These approaches assess geologically recent (Quaternary) features such as offset stream channels or alluvial fans (Table 2.2). Klinger et al. (2000a) estimated a slip-rate of 2-6 mm/yr along the Wadi Araba Fault section (south of the Dead Sea) by observing the displacement of a large alluvial fan with a depositional age of 44-170 ka. Niemi et al. (2001) also studied displacement along the Wadi Araba Fault by interpreting three alluvial fan deposits cut by the fault. These data suggest an average slip-rate of $4.7 \pm 1.3$ $\mathrm{mm} / \mathrm{yr}$ for the previous $15 \mathrm{ka}$. Ferry et al. (2007) used various offset drainages in the northern Jordan Valley, estimating a slip-rate of $4.7-5.1 \mathrm{~mm} / \mathrm{yr}$ for the last 47.5 ka. Recently, Le Beon et al (2010) evaluated late Pleistocene to early Holocene slip rates by looking at offset alluvial fans just to the north of the Red 
Table 2.2. Summary of late Quaternary slip rates along the southern DSF

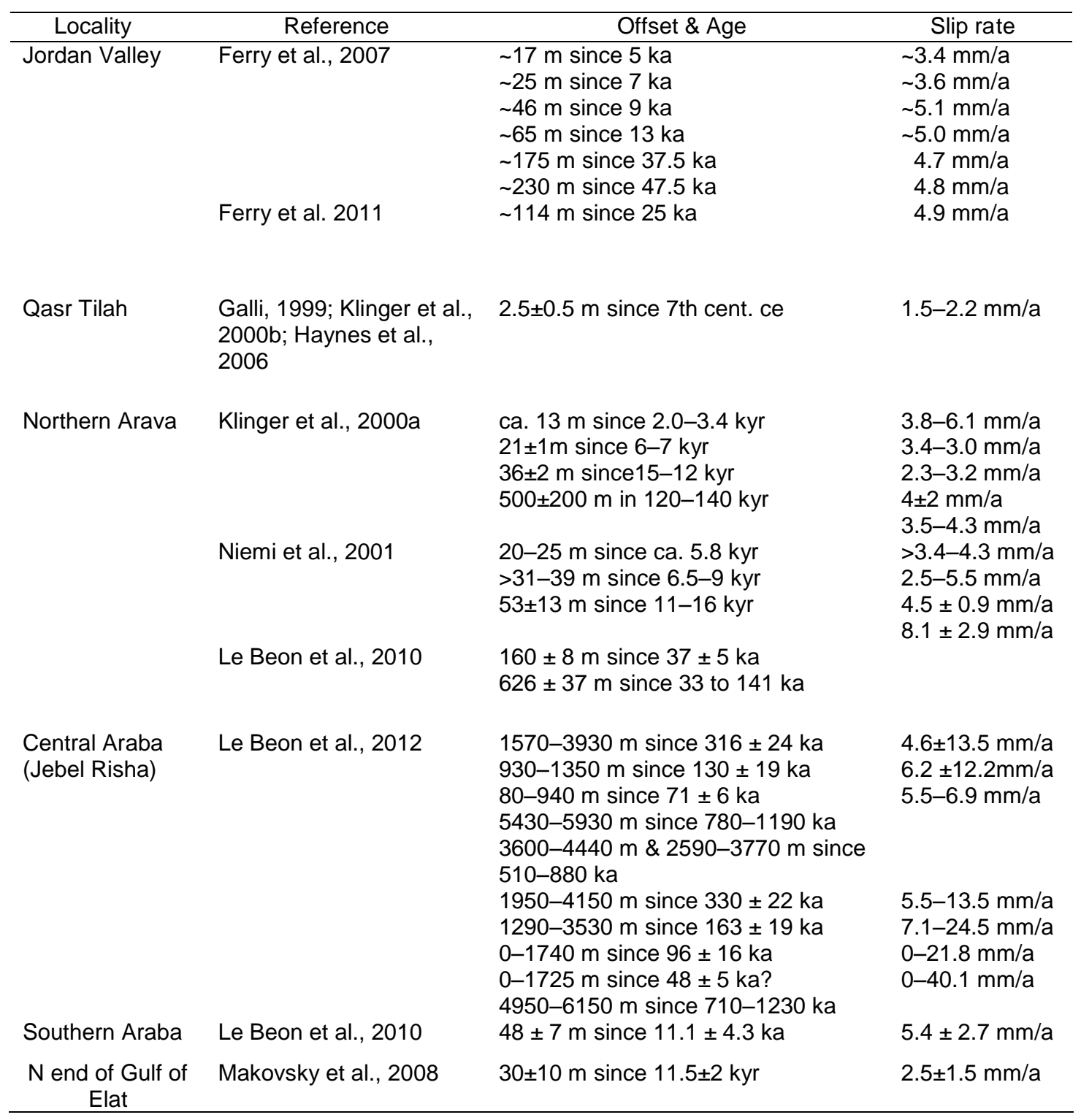


Sea along the Wadi Araba Fault. They suggest a broad range of slip rates using ${ }^{10} \mathrm{Be}$ exposure dating of $2-20 \mathrm{~mm} / \mathrm{yr}$. Further morphotectonic analysis by Le Beon et al. (2012) along the Wadi Araba fault using offset gullies and alluvial fans suggest of slip rate of $5-12 \mathrm{~mm} / \mathrm{yr}$ for the past $~ 350 \mathrm{ka}$. Additionally, the central DSF segment (i.e. the Yammouneh fault in Lebanon), shows comparable slip rates of $3.5-6.0 \mathrm{~mm} / \mathrm{yr}$ (Gomez et al. (2007a; Daeron et al. 2004). This attests to the conservation of slip between the southern and central DSF segments. An alternative method of estimating short-term fault slip involves the use of geodetic (Global Positioning System) techniques and the application of numerical models to relate the observed inter-seismic deformation to fault kinematics. GPS models for the Eastern Mediterranean region (Figure 2.2) suggest left lateral slip rates of $4-8 \mathrm{~mm} / \mathrm{yr}$ (e.g. Reilinger et al. 2006; McClusky et al. 2003). Along the southern DSF, Wdowinski et al. (2004) used a profile-based, elastic dislocation model to estimate a slip-rate of $3.3 \pm .4 \mathrm{~mm} / \mathrm{yr}$ and locking-depth of $12 \mathrm{~km}$ based on 11 GPS stations. Using the same type of model, Le Beon et al. (2008), found a slip-rate of $4.9 \pm 1.4 \mathrm{~mm} / \mathrm{yr}$ and a best-fit locking depth of approximately $12 \mathrm{~km}$ and an uncertainty of approximately $10 \mathrm{~km}$. More recently, Sadeh et al. (2012) utilized a dense network of GPS stations throughout Israel, suggesting a 3.1-4.5 $\mathrm{mm} / \mathrm{yr}$ slip north of the Carmel Fault, 4.6-5.4 mm/yr slip south of the Carmel along the Jordan Valley Fault, and a 4.7-5.4 mm/yr slip along the Wadi Araba Fault. Additionally, a $\sim 0.7 \mathrm{~mm} / \mathrm{yr}$ of left-lateral motion combined with a $\sim 0.6 \mathrm{~mm} / \mathrm{yr}$ dilatation was observed along the Carmel Fault (Sadeh et al., 2012). However, the uncertainties along the Carmel are large ( $>0.5 \mathrm{~mm} / \mathrm{yr}$ strike-slip and dip-slip). 


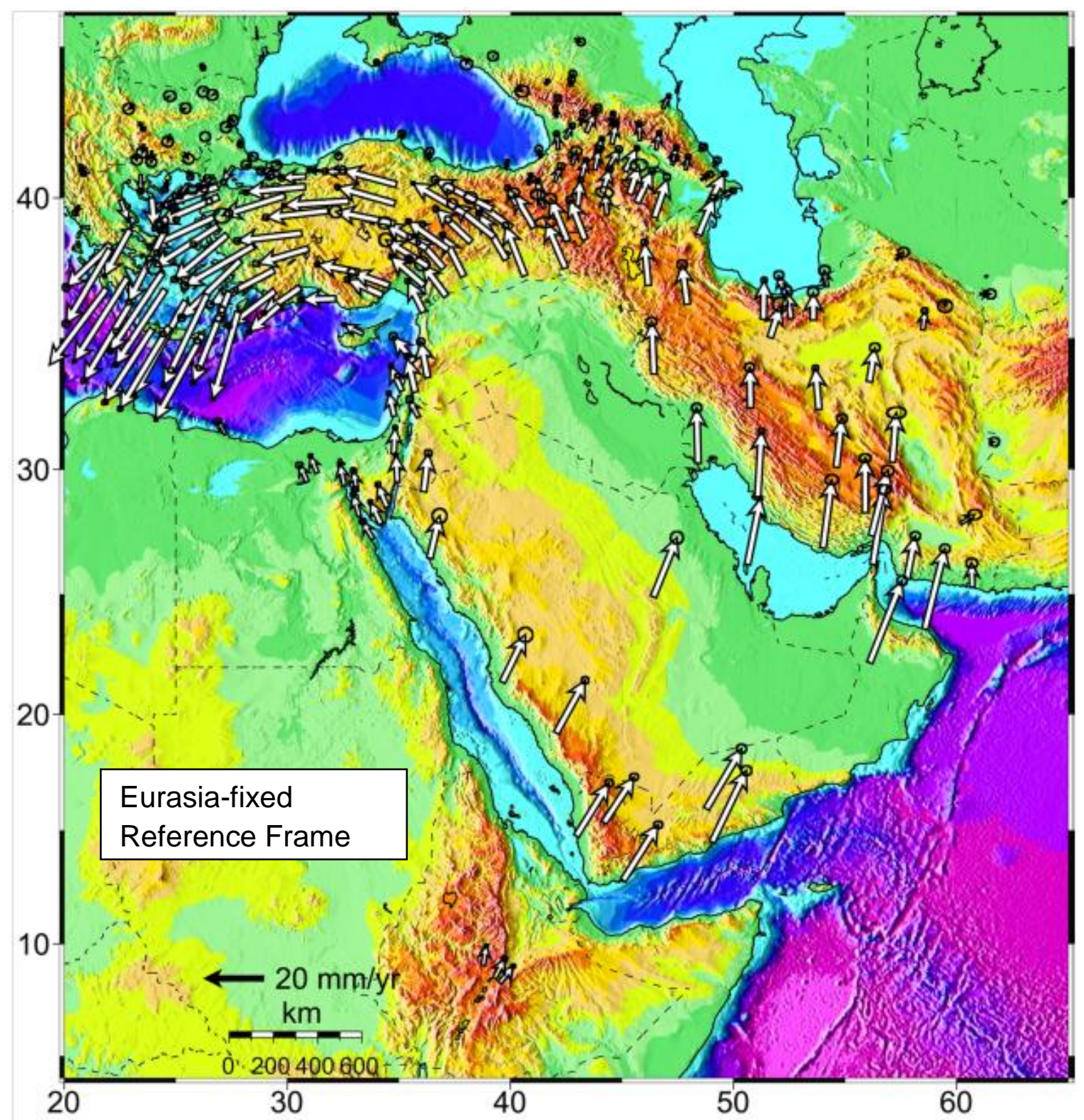

Figure 2.2. Regional GPS velocity map as modified from Reilinger et al. (2006) relative to Eurasia with $1-\sigma$ uncertainties. 
A preliminary analysis of the network used here (Al Tarazi et al. 2011) suggest slip rates of $4.9 \pm 0.4 \mathrm{~mm} / \mathrm{yr}$ and $4.7 \pm 0.4 \mathrm{~mm} / \mathrm{yr}$ for the WAF and JVF, respectively. From the above work, this broad range of GPS fault slip rates (3-8 $\mathrm{mm} / \mathrm{yr}$ ) can be reduced by increasing the spatial resolution of the GPS sites and by collecting higher quality data. 


\section{Chapter 3}

\section{GPS Theory, Processing, and Modeling}

\subsection{What is GPS?}

Global Positioning System (GPS) is a network of satellites and ground control stations designed by the Department of Defense to track the threedimensional position of GPS receivers down to $\mathrm{mm}$-scale. GPS is officially known as the Navigation Satellite Timing and Ranging (NAVSTAR), and can be utilized to study different geologic phenomena, including the motion of tectonic plates, movement along faults, the swelling of volcanoes before eruptions, and any change of motion of materials along the Earth's surface. More detailed information about the GPS system and processing is provided in Herring et al. (2006) and Segall et al. (1997).

GPS consists of four main components: Space Constellation, GPS control Segment, Satellite signal properties, and the user segment which includes the GPS receivers, the GPS survey network, and GPS processing. Also, within the GPS system there exist systematic errors such as atmospheric delays and multipath delays, which will be discussed further later in the section. The space constellation consists of 32 satellites with the orbital path information, orbital path orientations, and repeat times of the satellites consisting of 12 hours. The GPS Master Control Station (MCS) is responsible for pre-calculating the satellites ephemerides, navigation data, and clock information (e.g. Herring et al. 2006). Also, each satellite sends out data to the users at frequencies of $L 1=1575.42$ $\mathrm{MHz}$ and $\mathrm{L} 2=1227.60 \mathrm{MHz}$, while signals sent to the MCS equal frequencies of 
1783.74 MHz. The L1 band contains various satellite information including predicted GPS satellite orbits and clock corrections, while the L2 band is a selfcalibration signal for more precise measuring. For precise GPS positioning, the two "L-band" frequencies collectively reduce ionospheric effects on the signal. Displacements are calculated using the time-delay between the satellite and the receiver called the pseudorange (e.g. car and hiking navigation GPS), while highprecision (mm-scale) displacements are derived from the difference in the carrier phase received versus the phase generated in the oscillator within the GPS receiver (Herring et al. 2006). Although millimeter precision is obtained by calculating the "carrier beat phase", sources for error include multipath signals, ionospheric and tropospheric delays, receiver and satellite clock differences, orbital errors, L1 and L2 phase errors, and user segment setup errors. All these must be accounted for when processing GPS data, making sure these are systematic and can be properly accounted for.

\subsection{GPS Data Collection}

Field work for the most recent GPS survey occurred during the summer of 2012, from May 31, 2012 to June 10, 2012, where 20 near-field stations and 4 continuous GPS (CGPS) were surveyed throughout Jordan (Figure 3.1). These data were compiled with previously collected survey-mode data from 2005-2010 (a total of 33-survey-mode stations), as well as other available GPS data from surveys within Israel (i.e. Le Beon et al. 2008; Sadeh et al. 2012) and regional CGPS stations throughout Eurasia and Arabia from UNAVCO (UNiversity NAVstar COnsortium) and SOPAC (Scripps Orbit and Permanent Array Center) 


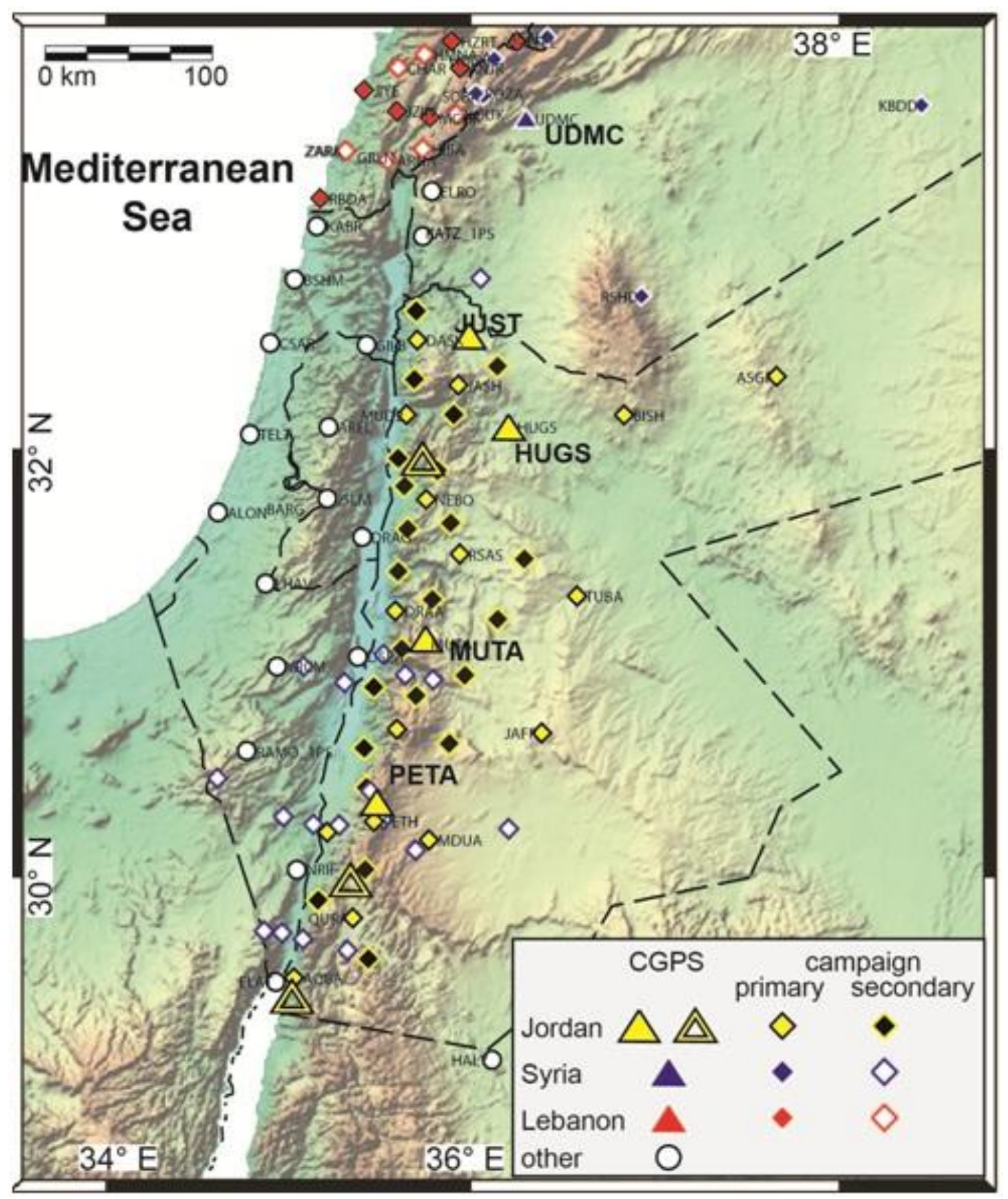

Figure 3.1. Survey-Mode and Continuous GPS stations for the Jordan surveys, including various GPS sites from the surrounding regions 
(Appendix A). Survey sites consisted of a $10 \mathrm{~cm}$ steel pin cemented into bedrock, while the CGPS sites are located atop buildings at various universities or government ran agencies. Our GPS data were collected using fixed-height antenna masts, Trimble R7 dual-frequency receivers and Zephyr geodetic antenna (Figure 3.2). Data was collected over 24 hrs to insure at least 8-10 hours on each UTC day, generating multiple epochs for each day.

\subsection{GPS Data Processing}

GAMIT/GLOBK (Herring et al. 2006) is a comprehensive software package designed for processing raw GPS measurements in order to calculate station coordinates and velocities, satellite orbital information, atmospheric delays, and post-seismic deformation (Herring et al. 2006). GAMIT is used to estimate station positions and Earth's rotation and orbital information by generating a covariance matrix from the raw GPS observables, and loosely constraining the GPS station site positions and velocities. The GPS stations input into GAMIT consists of the data from the Jordanian survey network and CGPS sites, other regional sites within the Arabian plate for our later defined reference frame, and other data from the ITRF2008 (International Terrestrial Reference Frame). These data are treated as a rigid body that can be rotated to fit the defined reference frame in the later steps of processing. The loosely constrained solutions are then input into a global Kalman filter (GLOBK) in order to combine epochs from previous surveys to achieve a more precise velocity solution and coordinates for each station. A conservative value of $1.3 \mathrm{~mm} / \mathrm{Vyr}$ random walk noise was applied to our solution, representing an average noise 


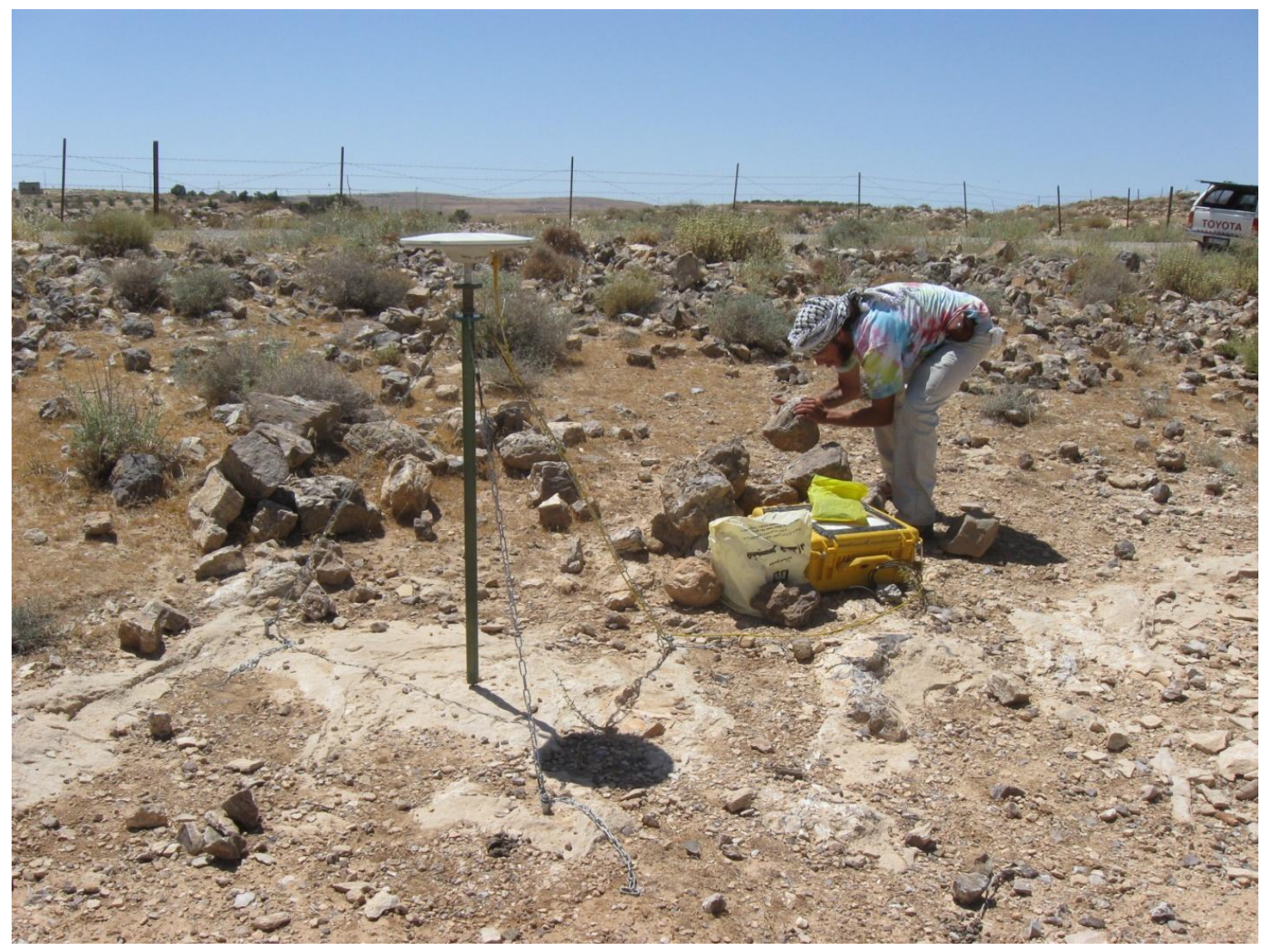

Figure 3.2. Trimble R7 dual-frequency GPS receiver with Zephyr Geodetic antenna. The Geodetic grade antenna is then connected to the receiver and left for a $24 \mathrm{hr}$ period. Site location DBUS, east of the Dead Sea. 
value for our CGPS sites (Reilinger et al. 2006). Subsequently, we transformed our data from the ITRF2008 no-net-rotation reference frame into our Arabia-fixed reference frame to analyze more local degrees of deformation. Six sites throughout the Arabian continent were used in defining our reference frame (Figure 3.4 - inset).

For a more comprehensive velocity field, GPS velocities reported by Le Beon et al. (2008) and Sadeh et al. (2012) were included in this study. These data were rotated into our Arabia-fixed reference frame by minimizing the residual misfit between sites common among the surveys (Figure 3.3). By incorporating these data into our analysis, not only does it increase the resolution throughout the near-field, but also increases the spatial coverage of GPS velocities.

\subsection{Resulting Velocity Field}

Once the raw GPS observables have been stabilized and rotated into the Arabia-fixed reference frame, the resulting GPS velocities with their respective 1$\sigma$ uncertainties ( $67 \%$ confidence) show the overall left-lateral motion along the southern DSF (Figure 3.4 and Figure 3.5). Figure 3.4 shows the GPS data processed in this study, while Figure 3.5 shows all the GPS data included in the final analyses. The GPS velocities show a gradual increase from east to west in the residual motion across the fault, indicating the accumulation of elastic strain along a locked fault zone. Far-field sites (> 100km from DSF) located in Arabia are effectively zero, whereas sites located as far as possible from the fault in Sinai are effectively at maximum velocity. Presently, all of the near-field sites 


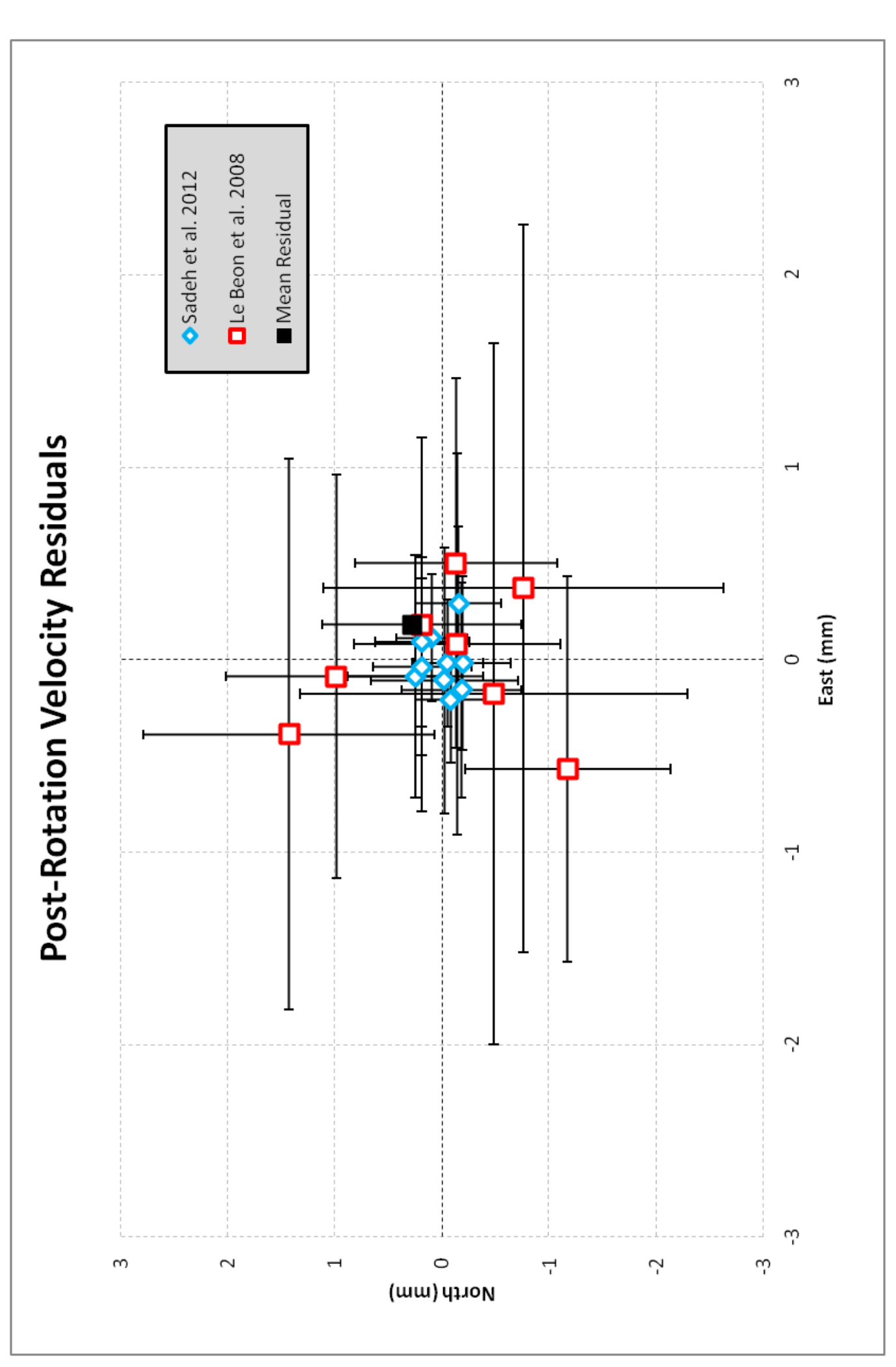

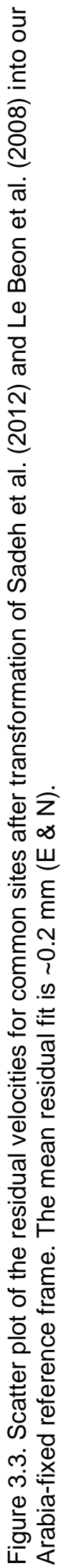




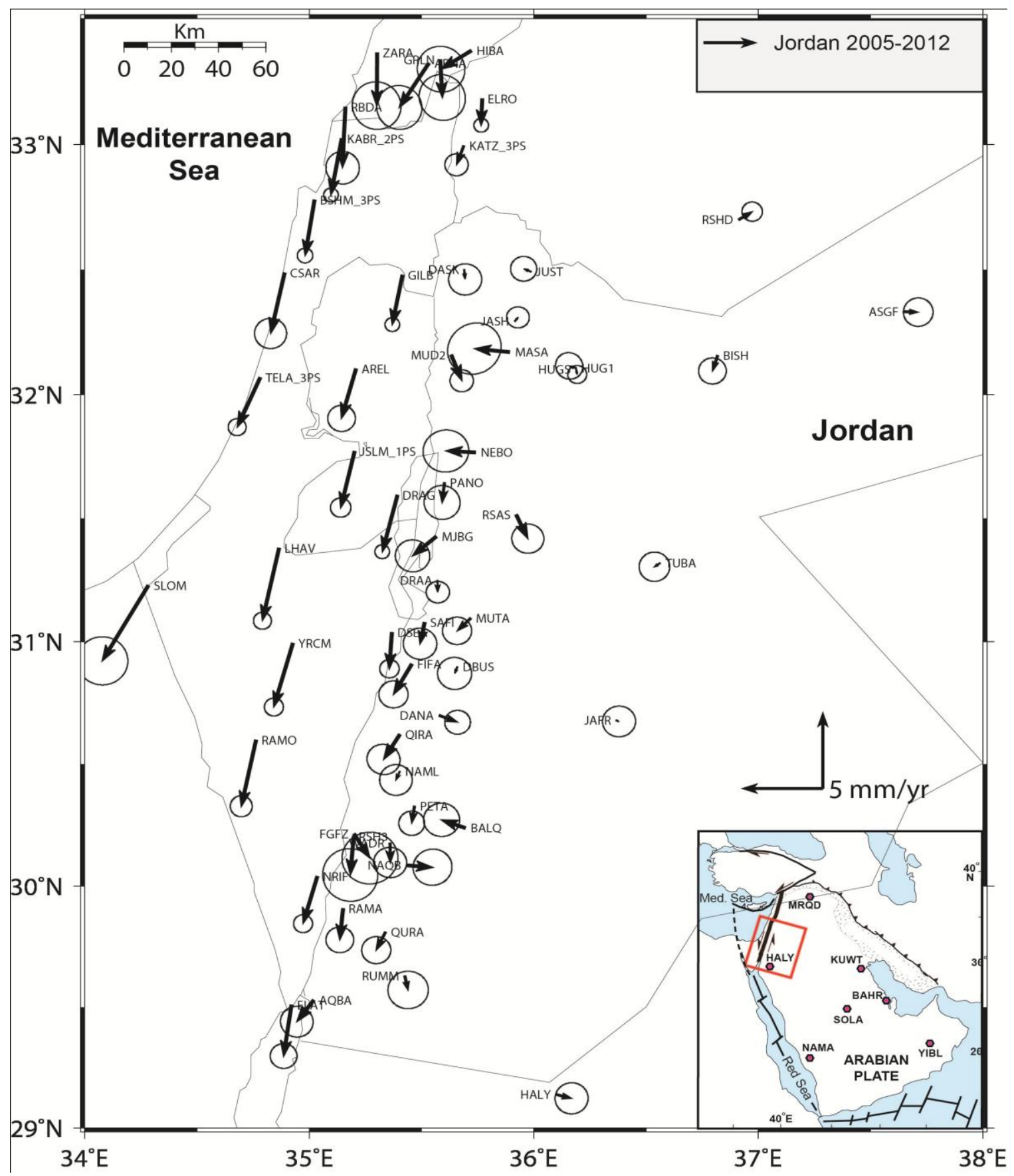

Figure 3.4. GPS velocities along the southern DSF processed in this study. Velocities are relative to an Arabia - fixed reference frame. 1- $\sigma$ uncertainties are represented by the circles at each site. Inset: Site locations for the regional GPS sites used for our Arabia - fixed reference frame. 


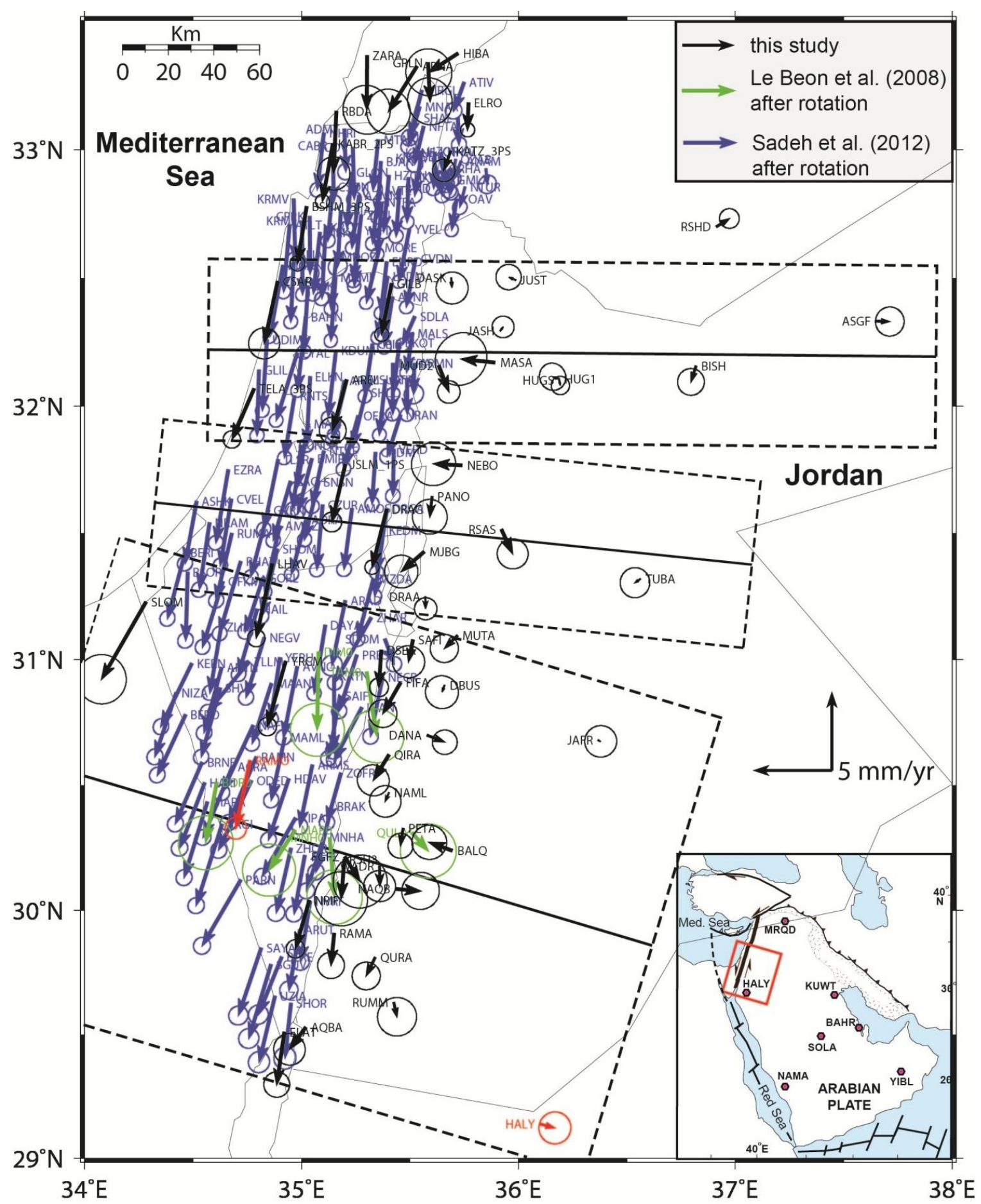

Figure 3.5. GPS velocities along the southern DSF. GPS velocities are shown relative to an Arabia-fixed reference frame. Raw GPS data from Sadeh et al. (2012) and Le Beon et al. (2008) were rotated into our reference frame for completeness. Circles represent $1-\sigma$ uncertainties. Inset: Regional GPS stations used to fix our Arabia reference frame. 
( 50-60 km from DSF) in the survey have initial velocities, with measurements spanning 4-5 years.

For a preliminary assessment of motion across the DSF, GPS velocities were projected along profiles drawn perpendicular to the fault (Figure 3.6). Three profiles were examined along the Jordan Valley and Wadi Araba faults, as well as across the Dead Sea Basin. The profiles break down the motion into faultperpendicular and fault-parallel motions. In all three profiles, strike-parallel velocities show progressive increase in the southward moving velocities across the transform from east to west. Although there are many transpresional/transtensional areas along the DSF, strike-perpendicular velocities are minimal. This correlates with a mainly strike-slip fault system.

\subsection{Modeling of GPS Velocities}

The resulting velocity field provides a basis for kinematic modeling and analysis along the southern DSF. While the locking depth is one parameter that is solved for, here we describe this parameter as "effective" locking depth, as the brittle-ductile transition is more of a coupling gradient than an abrupt change (e.g. Savage et al. 2006). Hence, modeling in this fashion provides a basis for more advanced modeling techniques. Modeling of the GPS velocities along the southern DSF uses two approaches: 

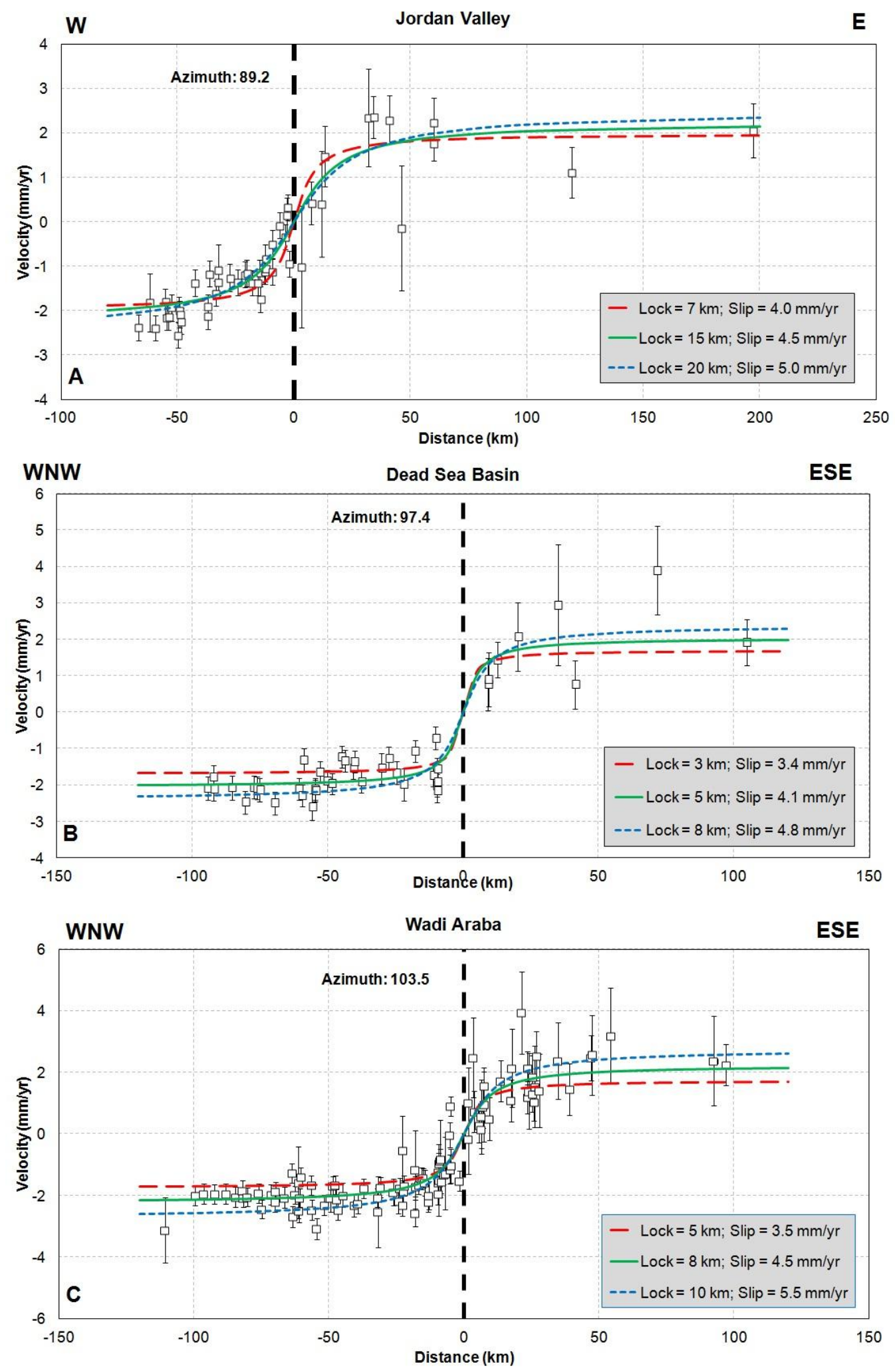

Figure 3.6. 1-D elastic dislocation models for a) Jordan Valley, b) Dead Sea Basin, and c) Wadi Araba. Locations are shown in figure 3.3. Dislocation models solves for a possible range of slip rates and locking depths, with our preferred values shown as the center lines. 
I.) 1- D elastic dislocation modeling: this model provides an initial estimate of fault parameters, including slip rate, "effective" locking depth, and a velocity solution at the fault in our Arabia reference frame.

II.) II.) 2-D elastic block modeling: this model assumes faults of a finite length, creating a series of fault blocks surrounding the region of interest. This model is more geometrically accurate than the 1-D dislocation models because it introduces plate motion as an additional constraint for fault slip.

\subsubsection{1-D Elastic Dislocation Model}

1-D elastic dislocation models were applied to three profiles across the southern DSF for an initial assessment of possible strike-parallel variations in slip rate and/or effective locking depth (Figure 3.6). Following the method described by Savage and Burford (1973), this model assumes an infinite fault length and displays the velocity at a point $\mathrm{V}$ as a function of distance from the fault $\mathrm{x}$ :

$$
\mathrm{V}(\mathrm{x})=\mathrm{b} / \pi^{*} \tan ^{-1}(\mathrm{x} / \mathrm{D})
$$

where $\mathrm{b}$ is the slip-rate and $\mathrm{D}$ is the depth of fault locking. Using a grid search we analyzed a range of values of possible slip rates $(0-7 \mathrm{~mm} / \mathrm{yr})$ and locking depths $(0-35 \mathrm{~km})$ to find the optimum set of parameters. These "optimum" values are the smallest WRMS (weighted root mean squared) solution of the faultparallel velocities. The fault perpendicular velocities are negligible. Weight is individually assigned to sites based on its uncertainty, as well as the spatial density of our sites. Subsequently, a Monte Carlo simulation was used to allow 
noise in our velocity data (Figure 3.7) (e.g. Sandvol and Hearn, 1994). Our results suggest a preferred slip rate and effective locking depth of $4.5 \mathrm{~mm} / \mathrm{yr}$ and $9 \mathrm{~km}$ for Wadi Araba fault, and $4.5 \mathrm{~mm} / \mathrm{yr}$ and $15 \mathrm{~km}$ for the Jordan Valley fault. These slip rates are statistically identical to values previously reported by alTarazi et al. (2011) along the southern DSF, as well as others (e.g. Le Beon et al. 2008; Sadeh et al. 2012; Widowinski et al. 2004). However, the locking depths reported here are not consistent with al-Tarazi et al. (2011), with a $8 \mathrm{~km}$ locking depth along the JVF and $15 \mathrm{~km}$ locking depth along the WAF. Furthermore, the large range in uncertainty associated with each profile gives precedence for modeling using the 2-D block model.

\subsubsection{2-D Elastic Block Model}

Although the 1-D dislocation models provide an initial solution of the fault parameters, the model does not account for plate motion, plate rotations, fault bends or fault dips to influence fault slip and locking depths. A more geometrically accurate approach to modeling GPS velocities involves using an elastic block model, following the methodology of Meade and Loveless (2009). This model describes each fault as a finite segment, rather than infinite length in the 1-D models, producing a series of blocks bounded by faults on all sides. Our model uses both strike-slip and thrust faulted blocks over the entire Dead Sea Fault system (i.e. a small thrust block off the Lebanon coast). However, the faults that define the southern DSF were relatively simple: a single fault trending N-S with a small left-step at the Dead Sea Basin (Figure 3.8). The block model solves for the best-fit Euler pole and slip rate solution for a given locking depth 


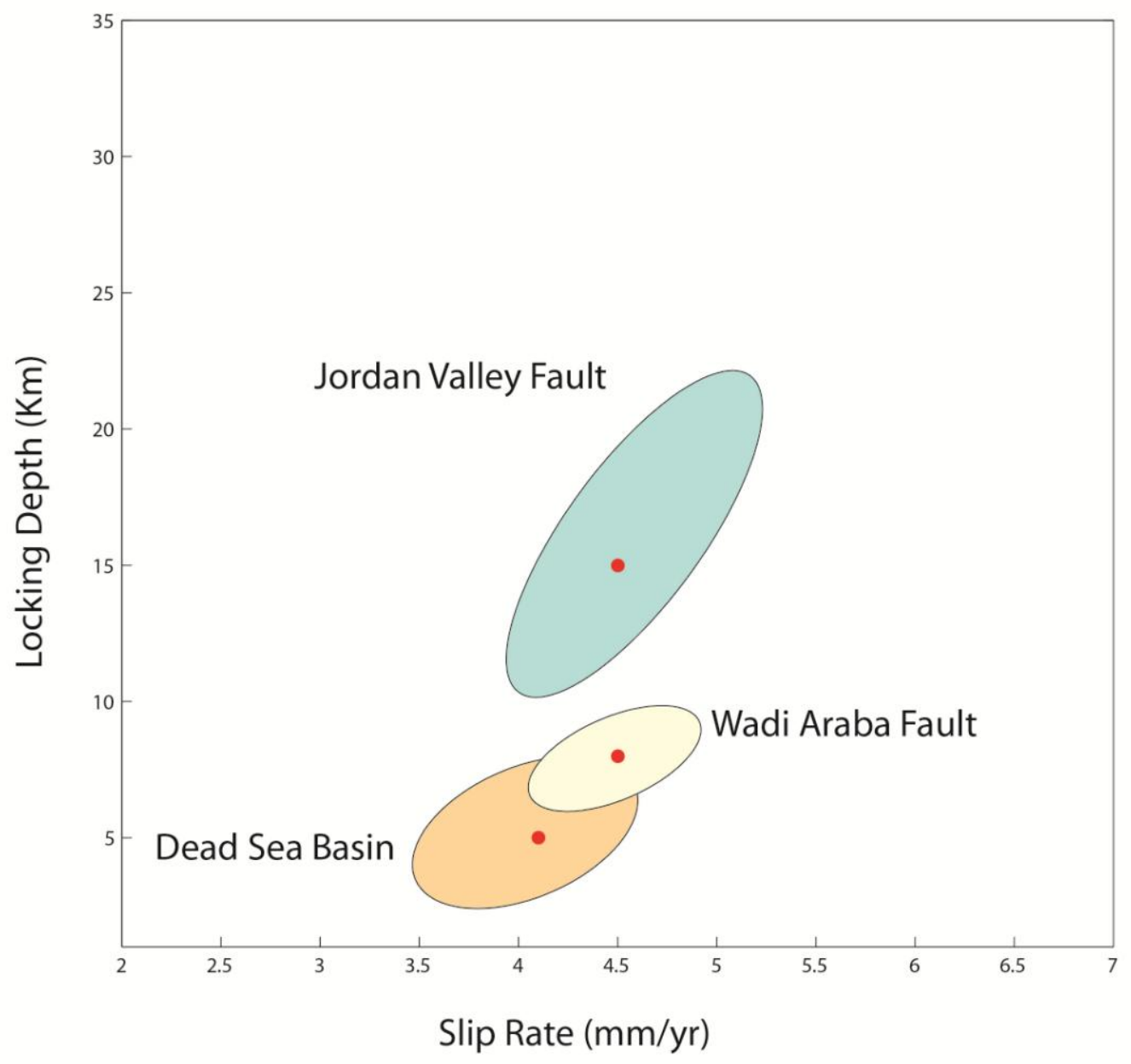

Figure 3.7. 1- $\sigma$ confidence limits (67\%) showing the distribution of possible slip rates and corresponding locking depths for each of the profiles in figure 3.5. Confidence ellipses estimated using a Monte Carlo simulation of the noise in the data. The best fit value was determined using a grid search of the lowest WRMS value of the data. 


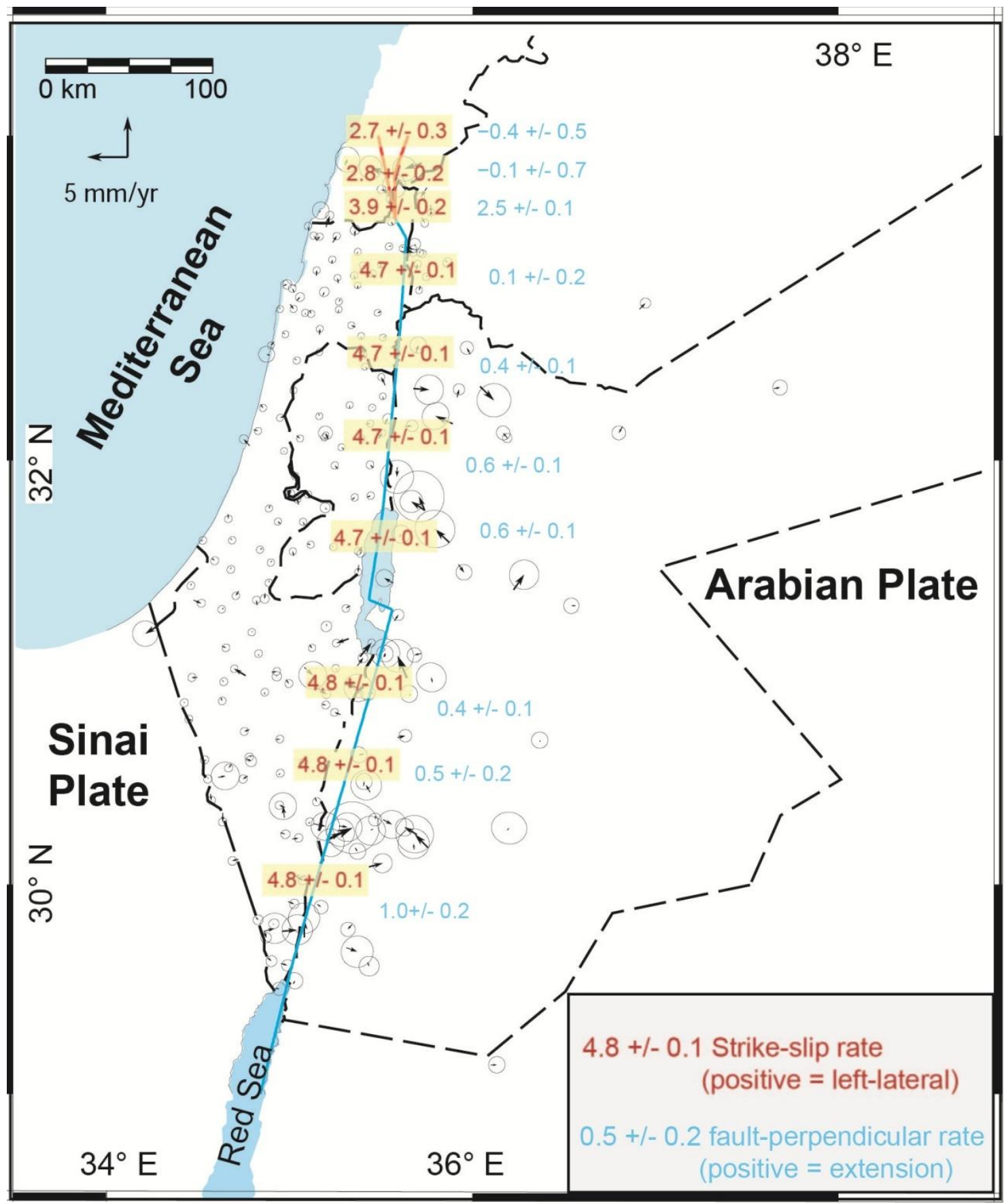

Figure 3.8. Block model solution showing the best fit velocities from our 2-D analysis. Each arrow has a relative magnitude of the residual velocity (misfit), with $1 \sigma$ uncertainties represented by the circles. Both fault-parallel and fault-perpendicular rates are represented in units of $\mathrm{mm} / \mathrm{yr}$. 
using a lineralized least square inverse method (Meade and Loveless, 2009). To minimize the residual velocity solutions, we included all the GPS sites from Sadeh et al. (2012) and Le Beon et al. (2008), in addition to our near-field sites within Jordan.

To find the optimal locking depth for each fault segment, I ran blocks over a range (i.e. grid search) of locking depths from 1-35 km, with a step value of 1 $\mathrm{km}$ for the JVF and WAF. All other faults in the model were fixed at $15 \mathrm{~km}$. Solving for locking depths using this method is only warranted if there is sufficient near-field data ( 50-60 km from DSF). Additionally, processing time increases exponentially with each fault segment added to the model.

After running the models, the best fit slip rate solution is $4.8 \pm 0.1 \mathrm{~mm} / \mathrm{yr}$ and $4.7 \pm 0.1 \mathrm{~mm} / \mathrm{yr}$ for the Wadi Araba and Jordan Valley Faults, respectively. These values are statistically identical to the solutions found the al-Tarazi et al. (2011), producing a lower uncertainty of $\pm 0.1 \mathrm{~mm} / \mathrm{yr}$ compared with $\pm 0.2 \mathrm{~mm} / \mathrm{yr}$. This value is also in agreement with surveys throughout Israel (e.g. Le Beon et al. 2008; Sadeh et al. 2012). The best fit effective locking depths for these faults agrees with our 1-D models, suggesting a $9 \mathrm{~km}$ and $15 \mathrm{~km}$ locking depth for the WAF and JVF, respectively. Our effective locking depths, however, do not correlate with the shallower locking depths of the JVF relative to the WAF (i.e. 8 $\mathrm{km}$ to $15 \mathrm{~km}$ ) reported by al-Tarazi et al. (2011). Additionally, Sadeh et al. (2012) also suggest a decrease in effective locking depths from south to north. By combining and updating the GPS site velocities from both of the aforementioned works; the results show different solutions for effective locking 
depths. This could be a consequence of the rotation of the common GPS sites, or a difference in how the raw observables were processed.

\subsection{Discussion}

The above elastic models provide a comprehensive look at short-term crustal deformation along the southern DSF. GPS station velocities vary across the fault and imply present-day, interseismic strain accumulation (e.g. Thatcher, 1993). The fault slip rates along the southern DSF are comparable to previously reported slip rates along the Yammouneh fault along the central Dead Sea fault of 4-6 mm/yr (Gomez et al. 2007b).

Another set of block models were tested by adding another fault block, corresponding with the Sinai-Carmel fault. However, the Euler pole for the small block bounded by the Carmel fault had large uncertainties (e.g., \pm 100 degrees in longitude). This suggests the block model becomes unstable with this additional parameter, or that the data do not require a block to be present. Therefore, within the uncertainties of our GPS velocities, the Carmel fault likely accounts for a very small amount of slip $(<0.5 \mathrm{~mm} / \mathrm{yr})$, at the most.

As noted above, our elastic models for southern DSF kinematics suggests along-strike variation in both slip rates and effective locking depths along this segment of the transform. The slight variation in slip rate is controlled by the Euler pole describing the relative motion of the Arabian and Sinai plates. Variations in effective locking depths may suggest different seismogenic characteristics for each of the two fault segments, including rheology, lowercrustal viscosity (e.g. thermal properties), and lithologies. 
Spatial variations in effective locking depths are also seen along other continental transforms, including the San Andreas Fault. Smith-Konter et al. (2011) estimates along-strike variation in locking depths along the San Andreas Fault from $6-22 \mathrm{~km}$, and is generally consistent with earthquake hypocenters. High heat flow seen along the southern San Andreas Fault correlates with the shallower geodetic locking depths, suggesting the thermal properties of the lower crust and mantle lithosphere influence the fault locking depths (Smith-Konter et al. (2011). The suggested inverse correlation between high heat flow and locking depths, however, is not seen in this study of the southern DSF. The previously mentioned high attenuation values and recent mafic volcanism suggests a higher heat flow along the JVF relative to the WAF. However, deeper locking depths are found along the JVF, suggesting other properties may be more influential on locking depths than the thermal properties seen. 


\section{Chapter 4}

\section{Statistical Analysis of Quaternary Slip Rates}

\subsection{Introduction}

The following section documents available Quaternary slip rate data for the southern DSF and applies a consistent statistical methodology to analyze perturbations in slip rates for landforms younger than $\sim 350 \mathrm{ka}$. The aim is to assess previously reported raw observations from a statistical standpoint, remaining internally constant. Over the previous 15 years, multiple studies have reported Quaternary slip rates along the southern DSF (e.g. Klinger et al. 2000a; Niemi et al. 2001; Ferry et al. 2007; Ferry et al. 2011; Le Beon et al. 2012; Le Beon et al. 2010). Each study's observations, however, introduce a new set of errors with a wide variety of values for slip rates $(2-20 \mathrm{~mm} / \mathrm{yr})$, as well as use a different statistical method of analyses to produce a slip rate. Herein I reevaluate and analyze the raw observations, both the offsets and radiometric dates with their respective uncertainties, propagate the uncertainties throughout the slip rate calculation, and assess temporal variations of the slip rates produced. When appropriate, we also standardized the age of offset landforms if two or more studies have dates for that specific feature. For a more complete view of statistical analysis and error propagation, please refer to Taylor (1982) and Tsoulfanidis (1995).

\subsection{Observational Data}

Figure 4.1 shows the site locations for each of the aforementioned studies. These observations include: 1) the measured offsets with their respective 


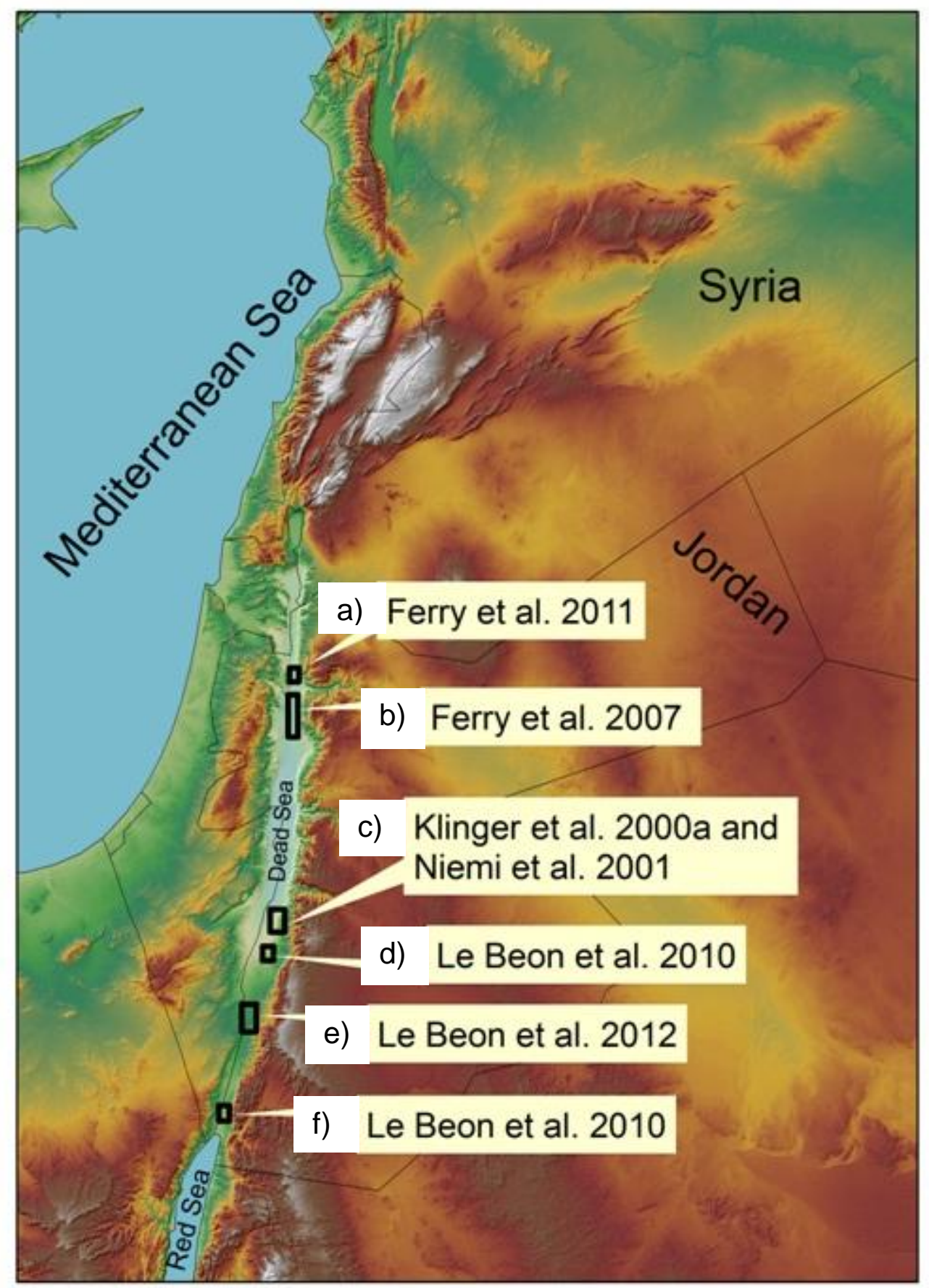

Figure 4.1. Site locations for the each study of Quaternary slip rates along the southern DSF. Within each study are site localities which correlate with Table 4.1: a) Tell Saidiyeh; b) K'tar ElMunkataates, Ghor Katar, and Ghor Al-Mendessa; c) Dahal fan, El Ghor site; d) Al-Fidan bajada; e) Risha fans, Wadi al-Dhawi fan, and Mazla site; and f) Al- Muhtadi fan. 
uncertainties of the geomorphic feature cut by the fault, and 2) the radiometric dates with their respective uncertainties for these features. Site locations were found by mapping in detail the fault trace. Each study bases the offset of geomorphic features (i.e. alluvial fans, abandoned channels, and offset ephemeral channels) using photogrammetric techniques (e.g. air photographs) and field observations. The raw data from each study, including the stream offsets and the inferred ages, are provided in Appendix B.

Dating techniques for these studies consisted of ${ }^{10} \mathrm{Be} \mathrm{CRN}$ (cosmogenic radio-nuclide) dating, ${ }^{14} \mathrm{C}$ dating of stratigraphic units cut by the fault, and the use of lake level curves (Bartov et al. (2002) demonstrating widespread lake level fluctuations of the paleo-lake Lake Lisan (present-day Dead Sea). ${ }^{10} \mathrm{Be}$ CRN measures the amount of cosmogenic isotopes (e.g. ${ }^{3} \mathrm{He},{ }^{10} \mathrm{Be},{ }^{21} \mathrm{Ne},{ }^{36} \mathrm{Cl}$ ) produced from the bombardment of cosmic rays on clasts exposed on the surface. ${ }^{10} \mathrm{Be}$ is produced through the isotopic decay of ${ }^{16} \mathrm{O}$ atoms in quartz. The number of ${ }^{10} \mathrm{Be}$ atoms $\left(\mathrm{N}_{10 \mathrm{Be}(\mathrm{t}, \mathrm{z})}\right)$ produced as a function of time $(\mathrm{t})$ and depth (z) is:

$$
N_{10 B e(t, z)}=N_{10 B e(t, 0)}+[P \exp (-u z) /(\lambda+u \varepsilon)]^{*}\{1-\exp [-(\lambda+u \varepsilon) * t]\}
$$

where $\mathrm{N}_{10 \mathrm{Be}(\mathrm{t}, 0)}$ is the inherited ${ }^{10} \mathrm{Be}$ value, $\mathrm{P}$ is the production rate of ${ }^{10} \mathrm{Be}(\mathrm{at} / \mathrm{g}$ of quartz/year), $\lambda$ is the decay constant, $u$ is the ratio of the sediment density to attenuation length of the cosmic rays, and $\varepsilon$ is the erosion rate at the surface. All of the above values were taken directly from the previous studies, provided the values were defined. 
All organic materials have both stable $\left({ }^{12} \mathrm{C},{ }^{13} \mathrm{C}\right)$ and unstable $\left({ }^{14} \mathrm{C}\right)$ carbon isotopes. Radiocarbon dating utilizes the radioactive beta decay of the ${ }^{14} \mathrm{C}$ to ${ }^{14} \mathrm{~N}$ estimate age by:

$$
\mathrm{N}(\mathrm{t})=\mathrm{N}(0){ }^{*} \exp (-\lambda \mathrm{t})
$$

where $N(t)$ is the amount of $14 \mathrm{C}$ at time $t, N(0)$ is the initial amount of ${ }^{14} \mathrm{C}, \lambda$ is the decay constant, and $t$ is the time elapsed. While the organic materials are alive, ${ }^{14} \mathrm{C}$ is constantly being replenished. However, as soon as the organism dies, the amount of ${ }^{14} \mathrm{C}$ steadily decreases, allowing an estimation of the age of the materials using the constant half-life of 5730 years. Making sure that the organic material is in-situ and has not been remobilized is essential for calculating accurate ages.

\subsection{Statistical Methods}

Although the sources of these data compare their resulting slip rates with previously documented results, statistical treatment of the data varied between studies. In the analysis, each study was subjected to the same statistical approach by first propagating the uncertainties of either the measured offset or age, and finding the average uncertainty using,

$$
\sigma_{\text {ave }}=\left(1 / \sigma_{1}^{2}+1 / \sigma_{2}^{2}+\ldots 1 / \sigma_{n}{ }^{2}\right)^{-0.5}
$$

where $\sigma_{\mathrm{n}}$ is the uncertainty associated with each measurement and $\sigma_{\text {ave }}$ is the average of the uncertainty (Tsoulfanidis, 1995). To find the average value of the measurement in question, whether it is an average slip rate or an average age, we used,

$$
\mu_{\text {ave }}=\left(\sigma_{\text {ave }}{ }^{2} x\left(\mu_{1}{ }^{2} / \sigma_{1}{ }^{2}+\mu_{2}{ }^{2} / \sigma_{2}{ }^{2}+\ldots \mu_{n}{ }^{2} / \sigma_{n}{ }^{2}\right)\right)^{0.5}
$$


where $\mu_{n}$ is the measurement of either the slip rate or radiometric age and $\mu_{\text {ave }}$ is the best solution for the given range of values (Tsoulfanidis, 1995). Furthermore, in order to determine outliers within the data, I used Chauvenet's criterion which is simply a means of assessing whether an outlier within a given data set is likely to be spurious. A value suspected of deviating to far from the mean $\left(\mathrm{x}_{\text {sus }}\right)$ due to undetected mistakes, is subject to this test to determine its accuracy of the data measurements,

$$
\mathrm{t}_{\text {sus }}=\left(\mathrm{x}_{\text {sus }}-\mathrm{x}_{\text {mean }}\right) / \sigma_{\mathrm{x}}
$$

where $\mathrm{x}_{\text {mean }}$ is the mean of the data set, $\sigma_{\mathrm{x}}$ is the standard deviation of the data set, and $t_{\text {sus }}$ is the number of standard deviations by which $\mathrm{x}_{\text {sus }}$ differs from $\mathrm{x}_{\text {mean }}$ (Taylor, 1982). The probability that an accurate measurement will deviate from the data set by so many standard deviations was found using,

$$
n\left(\text { worse than } x_{\text {sus }}\right)=N P\left(\text { outside } t_{\text {sus }} \sigma_{x}\right)
$$

where $\mathrm{n}$ is the number of measurements expected to be as bad as $\mathrm{x}_{\text {sus }}$ (Taylor, 1982). If $\mathrm{n}$ is $>1 / 2$, the value was considered as spurious and removed from the data set. Generally, the spurious values in this study coincided with rejected data from the previous studies.

\subsection{Results}

Along the Jordan Valley fault, Ferry et al. (2007) obtained multiple measurements of offset streams ranging from $17-240 \mathrm{~m}$, and dated the gully incisions based on climatic fluctuation curve from Bartov et al. (2002) and Bookman et al. (2004). The incision events were dated at $47.5 \mathrm{ka}, 37.5 \mathrm{ka}, 13 \mathrm{ka}$, 
$9 \mathrm{ka}, 7 \mathrm{ka}$, and $5 \mathrm{ka}$ using ${ }^{14} \mathrm{C}$ and $\mathrm{U}$-series isotopic dating methods. Three locations (Appendix B) were found to have the different aged units of the Lisan formation offset by the JVF. In our analysis, each location was treated as its own data set, averaging stream offsets of the same age to find a mean offset value, as opposed to finding the average ages in subsequent calculations of other studies (e.g. Le Beon et al. 2010). An average slip rate for the K'tar ElMunkataates, Ghor Katar, and Ghor Al-Mendessa are $4.65 \pm 0.29 \mathrm{~mm} / \mathrm{yr}, 4.32 \pm$ $0.37 \mathrm{~mm} / \mathrm{yr}$, and $4.65 \pm 0.58 \mathrm{~mm} / \mathrm{yr}$, respectively. A mean slip rate of $4.54 \pm 0.21$ $\mathrm{mm} / \mathrm{yr}$ was calculated for all three site locations, with a standard deviation of all the calculated slip rates of 0.77 . This value is statistically similar to previously reported value of $4.9 \pm 0.2 \mathrm{~mm} / \mathrm{yr}$. In addition to the 2007 study, Ferry et al. (2011) included a slip rate into their paleoseismic investigation along the Jordan Valley fault. This value, found to be $4.9 \pm 0.3 \mathrm{~mm} / \mathrm{yr}$, also correlates well with the previous slip rate. A mean slip rate of $4.7 \pm 0.2 \mathrm{~mm} / \mathrm{yr}$ was determined using all the available data for the Jordan Valley Fault. This slip rate represents an average rate over the past $47.5 \mathrm{ka}$, and compares well with our GPS results (Table 4.1).

Compared to the JVF, the Wadi Araba Fault has been much more frequently studied in terms of late Quaternary slip rates. The four studies reanalyzed here interpreted the slip history along this section of the southern DSF using offset alluvial fans and beheaded and offset drainage systems. Two of these studies, Klinger et al. (2000a) and Niemi et al. (2001), evaluated correlative alluvial terraces and therefore the ages were statistically combined to reduce the 
Table 4.1. Summary of the Standardized Ages and Slip Rates Calculated in this study.

Summary of Statistical Results

\begin{tabular}{|c|c|c|c|}
\hline \multirow[t]{2}{*}{ Reference } & \multirow[t]{2}{*}{ Ages (ka) } & \multicolumn{2}{|c|}{ Slip Rates (mm/yr) } \\
\hline & & Minimum & Maximum \\
\hline \multirow[t]{2}{*}{ Ferry et al. (2007/2011) } & $47.5 \pm 0.5$ & $4.7 \pm 0.2$ & - \\
\hline & & & - \\
\hline \multirow[t]{3}{*}{ Klinger et al. (2000a) } & $13.4 \pm 0.1$ & $2.7 \pm 0.1$ & - \\
\hline & $105 \pm 35$ & $5.7 \pm 3.4$ & - \\
\hline & & & - \\
\hline \multirow[t]{2}{*}{ Niemi et al. (2001) } & $13.4 \pm 0.1$ & $4.8 \pm 0.4$ & - \\
\hline & & & - \\
\hline \multirow[t]{4}{*}{ Le Beon et al. (2010) } & $9.8 \pm 0.4$ & $4.9 \pm 0.7$ & $\begin{array}{c}\text { statistically identical } \\
\text { to minimum }\end{array}$ \\
\hline & $42.4 \pm 1.5$ & $3.8 \pm 0.2$ & $\begin{array}{c}\text { statistically identical } \\
\text { to minimum }\end{array}$ \\
\hline & $53.2 \pm 3.4$ & $5.2 \pm 0.4$ & $4.8 \pm 0.4$ \\
\hline & $85.3 \pm 1.8$ & $7.3 \pm 0.5$ & $6.5 \pm 0.4$ \\
\hline \multirow[t]{6}{*}{ Le Beon et al. (2012) } & $70.7 \pm 2.7$ & $6.2 \pm 0.3$ & $5.5 \pm 0.3$ \\
\hline & $93.1 \pm 3.9$ & $9.3 \pm 6.5$ & $7.9 \pm 6.6$ \\
\hline & $116.2 \pm 3.7$ & $9.7 \pm 1.7$ & $7.7 \pm 3.2$ \\
\hline & $\begin{array}{c}314 \pm 17.7 \\
\text { (maximum erosion } \\
\text { age of } 601 \mathrm{ka} \text { ) }\end{array}$ & $8.8 \pm 3.8$ & $5.1 \pm 1.8$ \\
\hline & $328.8 \pm 16.4$ & & \\
\hline & $\begin{array}{c}\text { (maximum erosion } \\
\text { age of } 636 \mathrm{ka} \text { ) }\end{array}$ & $9.3 \pm 3.4$ & $4.3 \pm 1.9$ \\
\hline
\end{tabular}


uncertainty in the slip rate measurement (Table 4.1). The ages for these features were found to have an average age of $4.3 \mathrm{ka}, 9.1 \mathrm{ka}$, and $13.4 \mathrm{ka}$. The offsets, however, were not comparable to one another, resulting in different slip rates for the same feature. From the Klinger et al. (2000a) data set, a mean slip rate of $2.7 \pm 0.1 \mathrm{~mm} / \mathrm{yr}$, while the Niemi et al. (2001) data set generated a $4.8 \pm 0.4$ $\mathrm{mm} / \mathrm{yr}$. The latter is more comparable to the GPS slip rates found in this study, as well as with the rates along the Jordan Valley Fault. Furthermore, Klinger et al. (2000a) also dated an offset alluvial fan (Dahal Fan) using cosmogenic radionuclide dating, and found an age of $105 \pm 35 \mathrm{ka}$ (preferred age of $120 \mathrm{ka}$ ). Using the offset of $600 \pm 300 \mathrm{~m}$ (preferred $500 \mathrm{~m}$ ) results in a slip rate of $5.7 \pm 3.4$ $\mathrm{mm} / \mathrm{yr}$. This value is comparable with the Klinger et al. (2000a) range of 2-6 $\mathrm{mm} / \mathrm{yr}$.

More recently along the WAF, Le Beon et al. (2010/2012) used offset geomorphic features ranging in age from $9-330$ years before present (Appendix B), and reported slip rates ranging from 0-20 mm/yr. With the extensive data collected within each study, a closer look at the raw data provided more insight on Quaternary slip rates. Each study reported the raw ${ }^{10} \mathrm{Be} C R N$ ages as both a minimum and maximum age, depending on whether they assumed zero erosion or a maximum erosion rate of $2.1 \mathrm{~m} / \mathrm{yr}$. In Le Beon et al. (2012), however, the surfaces older than 300 ka do not have maximum reported rates. Thus, calculations of these ages using a maximum erosion rate are introduced in this study, which will be used in the discussion section of this chapter. Figures 4.2 4.3 show the interpreted alluvial surfaces for each of the study sites (i.e. F1, 
$\mathrm{F} 2, \ldots \mathrm{Fn}$ ), and give context for the discussion below. Furthermore, the production rate reported in Le Beon et al. (2010) is assumed be the same for Le Beon et al. (2012), since the values were not reported in the 2012 study.

Le Beon et al. (2010) looked at two offset features along the WAF: the AlMuhtadi alluvial fan (originally observed by Galli et al. (1999)) located $\sim 30 \mathrm{~km}$ north of Aqaba, and the Al-Fidan bajada located $\sim 50 \mathrm{~km}$ south of the Dead Sea (Figure 4.1). For the Al-Muhtadi site, ages ranged from $9.8 \pm 0.4 \mathrm{ka}$ and $53.2 \pm$ 3.4 ka for surfaces F2 and F3, respectively, with corresponding slip rates of $4.9 \pm$ $0.7 \mathrm{~mm} / \mathrm{yr}$ and $5.2 \pm 0.4 \mathrm{~mm} / \mathrm{yr}$. It is interesting to note that when the maximum erosion rate is used, a slip rate of $4.8 \pm 0.4 \mathrm{~mm} / \mathrm{yr}$ is found for the $53 \mathrm{ka}$ surface. At the Al-Fidan site, surfaces F2 (not the same F2 as the Al-Muhtadi site) and F4 yield a standardized age of $42.4 \pm 1.5 \mathrm{ka}$ and $85.3 \pm 1.8 \mathrm{ka}$, respectively. These correspond to slip rates of $3.8 \pm 0.2 \mathrm{~mm} / \mathrm{yr}$ and $7.3 \pm 0.5 \mathrm{~mm} / \mathrm{yr}$. The slip rates younger than $\sim 53 \mathrm{ka}$ yield a mean slip rate of $4.3 \pm 0.2 \mathrm{~mm} / \mathrm{yr}$, and are generally consistent with our GPS solution.

Le Beon et al. (2012) assessed offset alluvial fans along the central section of the WAF (Figure 4.1). Main observations within this study included mapping the sedimentary cover and alluvial surfaces, interpreting 7 depositional surfaces (F1-F7; youngest to oldest); of these, only F3 (F3a,b,c) and F5 surfaces had reported ${ }^{10} \mathrm{Be} \mathrm{CRN}$ ages. At the Risha site, two surfaces were dated and found to have a standardized age of $70.7 \pm 2.7 \mathrm{ka}$ and $314.4 \pm 17.7 \mathrm{ka}$ for the F3c and F5 surfaces, respectively. These ages yield slip rates of $6.2 \pm 0.3 \mathrm{~mm} / \mathrm{yr}$ and $8.8 \pm 3.8 \mathrm{~mm} / \mathrm{yr}$. At surface F3c, a maximum erosion rate yields a slip rate 


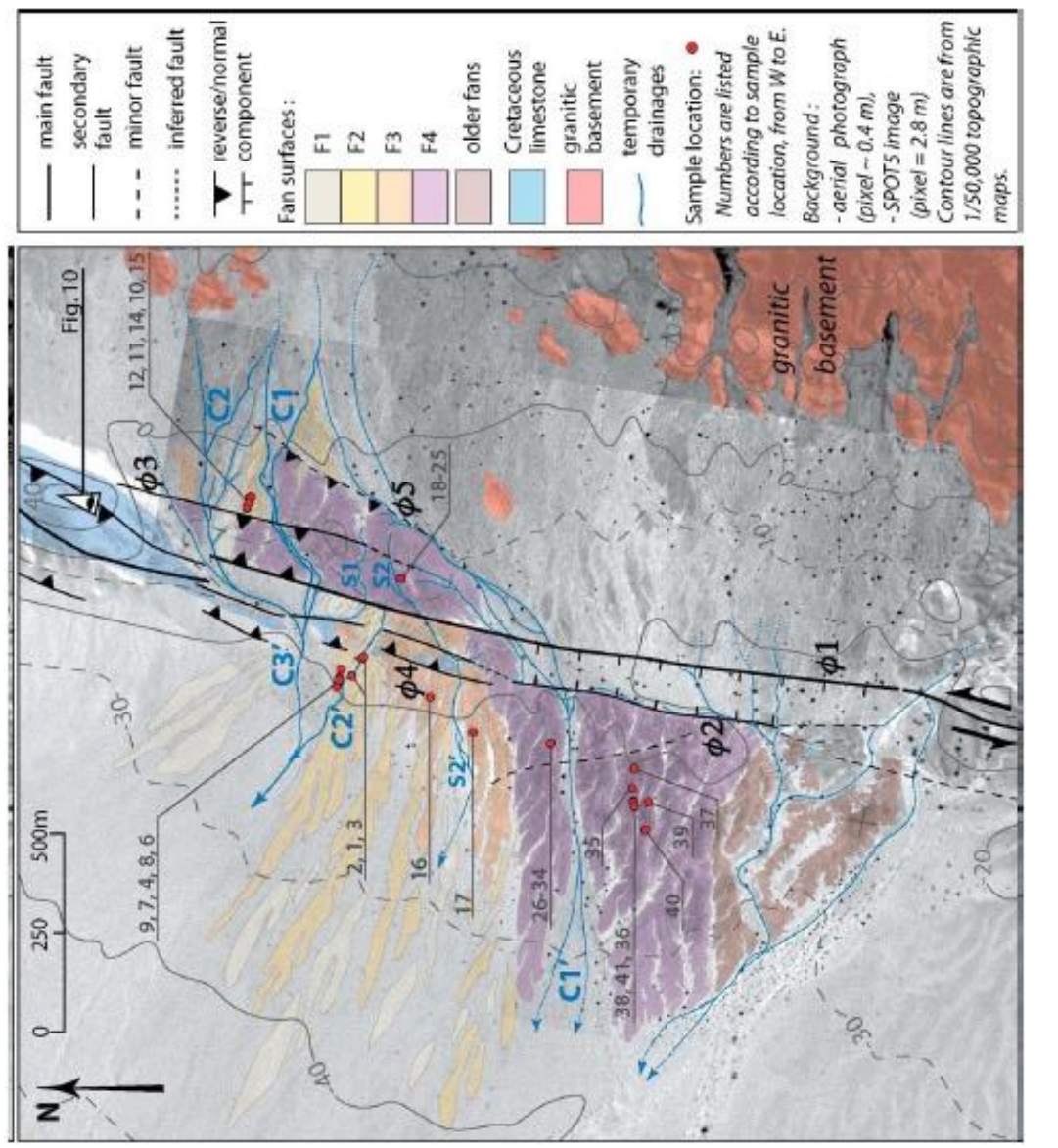

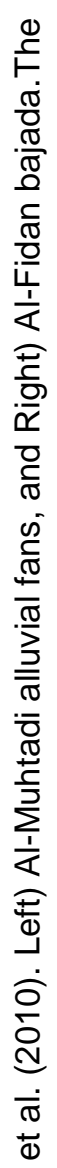

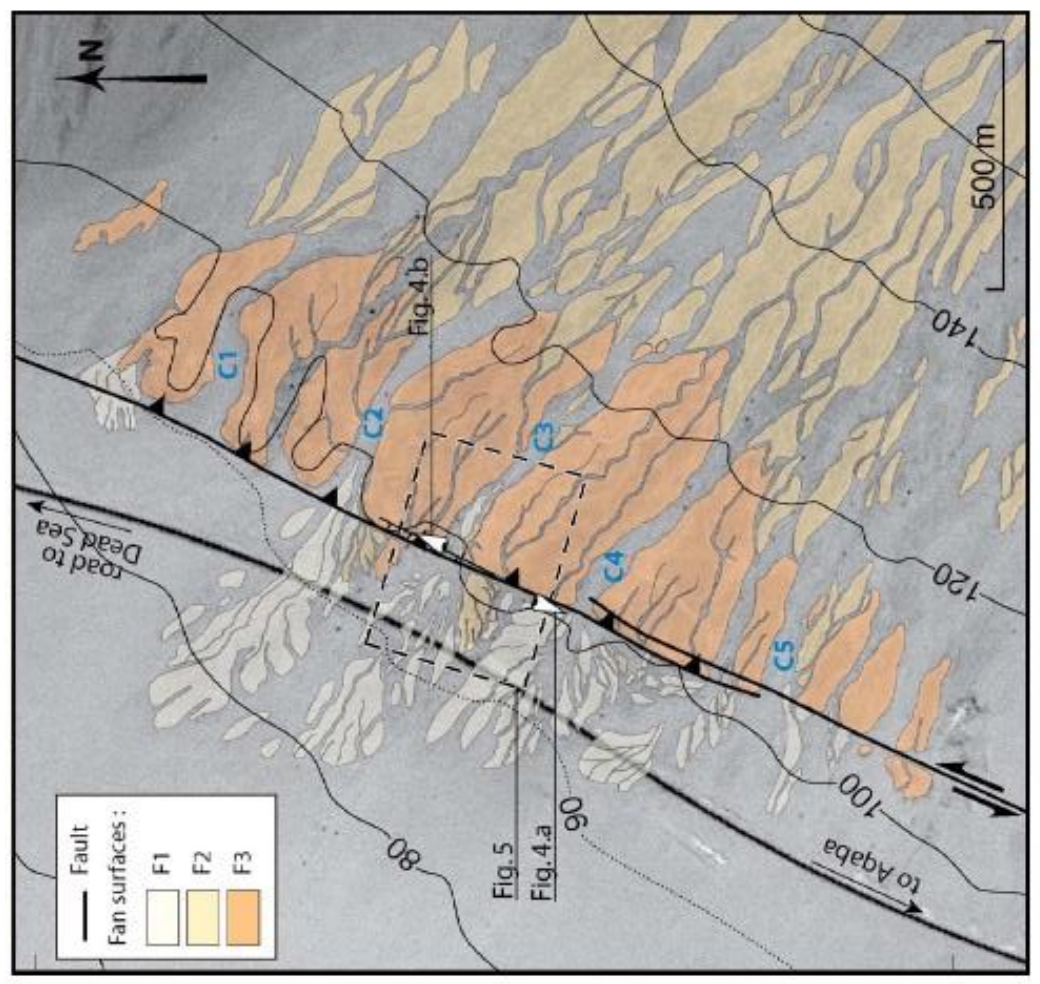

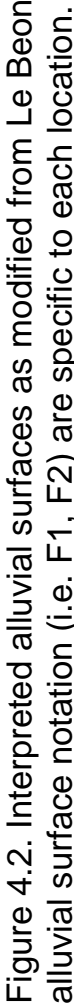



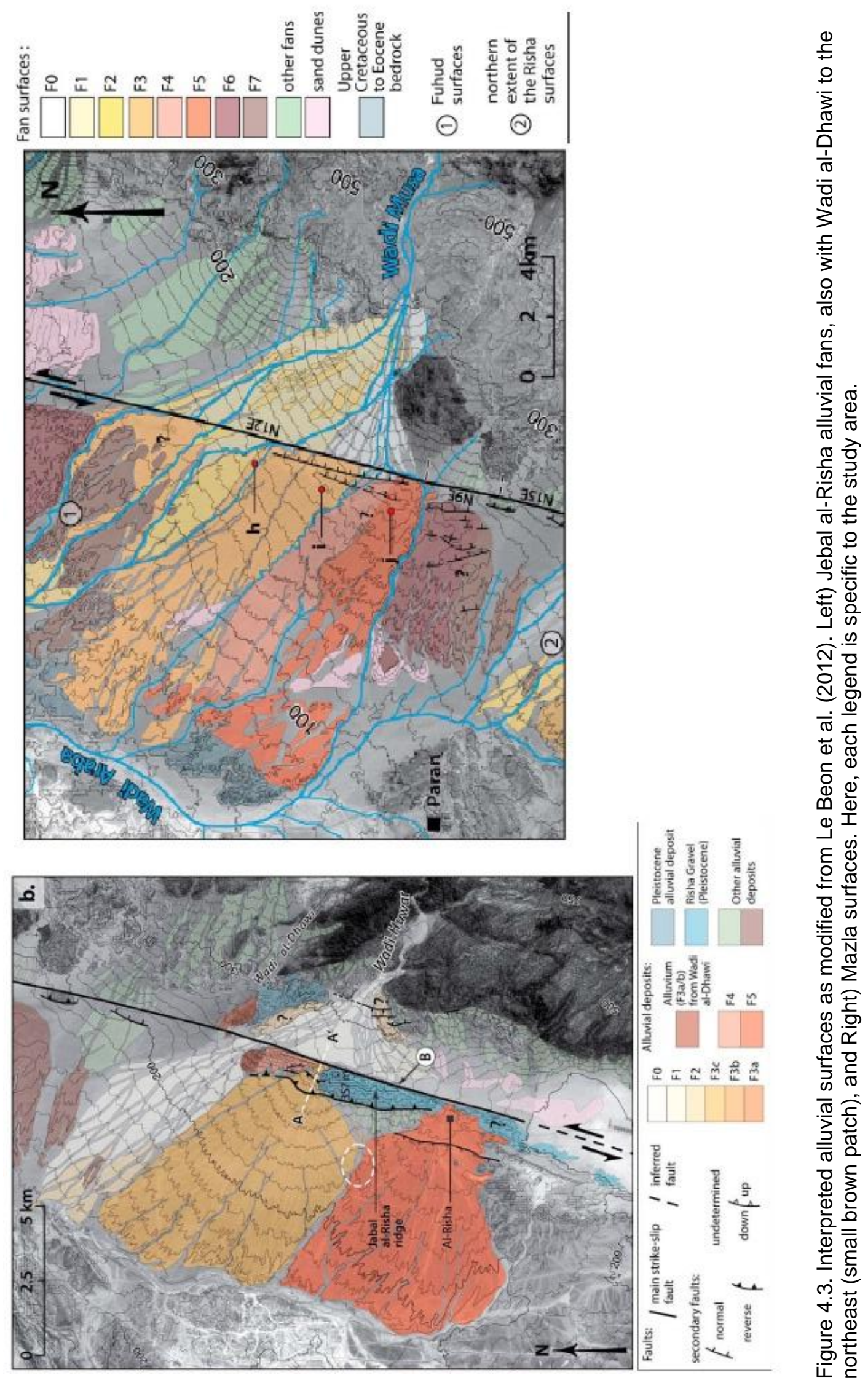
of $5.5 \pm 0.3 \mathrm{~mm} / \mathrm{yr}$, which is slightly higher but still comparable to modern day rates.

At the Wadi al-Dhawi site, F3 was the suggested feature to be offset by the WAF by matching the ephemeral gully systems associated with the F3 surface. In the interpretation, however, Le Beon et al. suggest that the surface offset is actually two different surfaces, F3a (west) and F3b (east). Since there is a clustering of data around $\sim 108 \mathrm{ka}$ and $\sim 130 \mathrm{ka}$ for the eastern and western surfaces, respectively, deposition continued along the eastern surface while the western surface was abandoned due to faulting, thus making the eastern surface younger (Le Beon et al. 2012). This study, however, assumes the two surfaces are the same age. Given that the ages are statistically similar (Appendix B), the data should be evaluated as a single age. Therefore, a mean age of $116.2 \pm 3.7$ ka yielded a slip rate of $9.7 \pm 1.7 \mathrm{~mm} / \mathrm{yr}$ for the $\mathrm{F} 3 a+b$ surface. Again, important to note is a slip of $7.7 \pm 3.2 \mathrm{~mm} / \mathrm{yr}$ was found using maximum erosion. This value has a larger uncertainty but the slip rate itself is more comparable than the minimum value.

Finally, statistical calculations of the Mazla site suggests ages of $93.1 \pm$ $3.9 \mathrm{ka}$ and $328.8 \pm 16.4 \mathrm{ka}$ for surfaces F3 and F5, respectively. With the offsets having such a large uncertainty associated with the reconstruction of the ephemeral stream channels at this site, slip rates of $9.3 \pm 6.5 \mathrm{~mm} / \mathrm{yr}$ and $9.3 \pm$ $3.4 \mathrm{~mm} / \mathrm{yr}$ found here are questionable. The slip rates from the three site locations described above all have rates within the mean values reported by Le Beon et al. (2012): Risha, 4.6-13.5 mm/yr (F5) and 5.5-6.9 mm/yr (F3c); al- 
Dhawi, 6.2-12.2 mm/yr (F3a+b); and Mazla, 5.5-13.5 mm/yr (F5) and 0-21.8 $\mathrm{mm} / \mathrm{yr}$ (F3). Table 4.1 summarizes the standardized ages and the corresponding slip rate derived from that feature.

\subsection{Discussion}

Plotting the standardized offsets and ages permits assessing possible time-variability of slip rates (Figure 4.4). In this plot, cosmogenic nuclide ages are shown assuming zero erosion. Data younger than 50 ka are generally consistent with a slip rate of $4.5-5 \mathrm{~mm} / \mathrm{yr}$. Offset landforms older than $50 \mathrm{ka}$, however, seem to suggest an increase in slip rate by about 200\% (9-10 mm/yr). Although the uncertainties are large, the data are consistent. The dashed lines delimit a $5-12 \mathrm{~mm} / \mathrm{yr}$ enveloped that encompasses the data from the oldest fans, namely those fans from $\sim 315 \mathrm{ka}$ and $\sim 330 \mathrm{ka}$.

An alternative to the interpretation of faster slip rate after $\sim 50$ ka may involve non-zero erosion rates. In particular, assuming a zero-erosion rate scenario for the past 350 ka seems unlikely. Areas adjacent to the DSF (Paran Plains) estimate the rate of erosion to be low (0.3 m/Ma) (Matmon et al. 2009). This value, however, is estimate for a low-dipping $\left(<1^{\circ}\right)$, tectonically inactive area, whereas the sites presented here have a considerable dip $\left(>3^{\circ}\right)$ and are fed by ephemeral streams. Therefore, a more robust estimation of age should introduce a maximum erosion rate in the calculation of the older alluvial surfaces (i.e. these values were not reported in Le Beon et al. (2010/2012) (Figure 4.5). In both Le Beon et al. (2010/2012), a maximum age is given for each surface assuming an erosion rate of $2.1 \mathrm{~m} / \mathrm{Ma}$. By applying the same erosion rate to the 


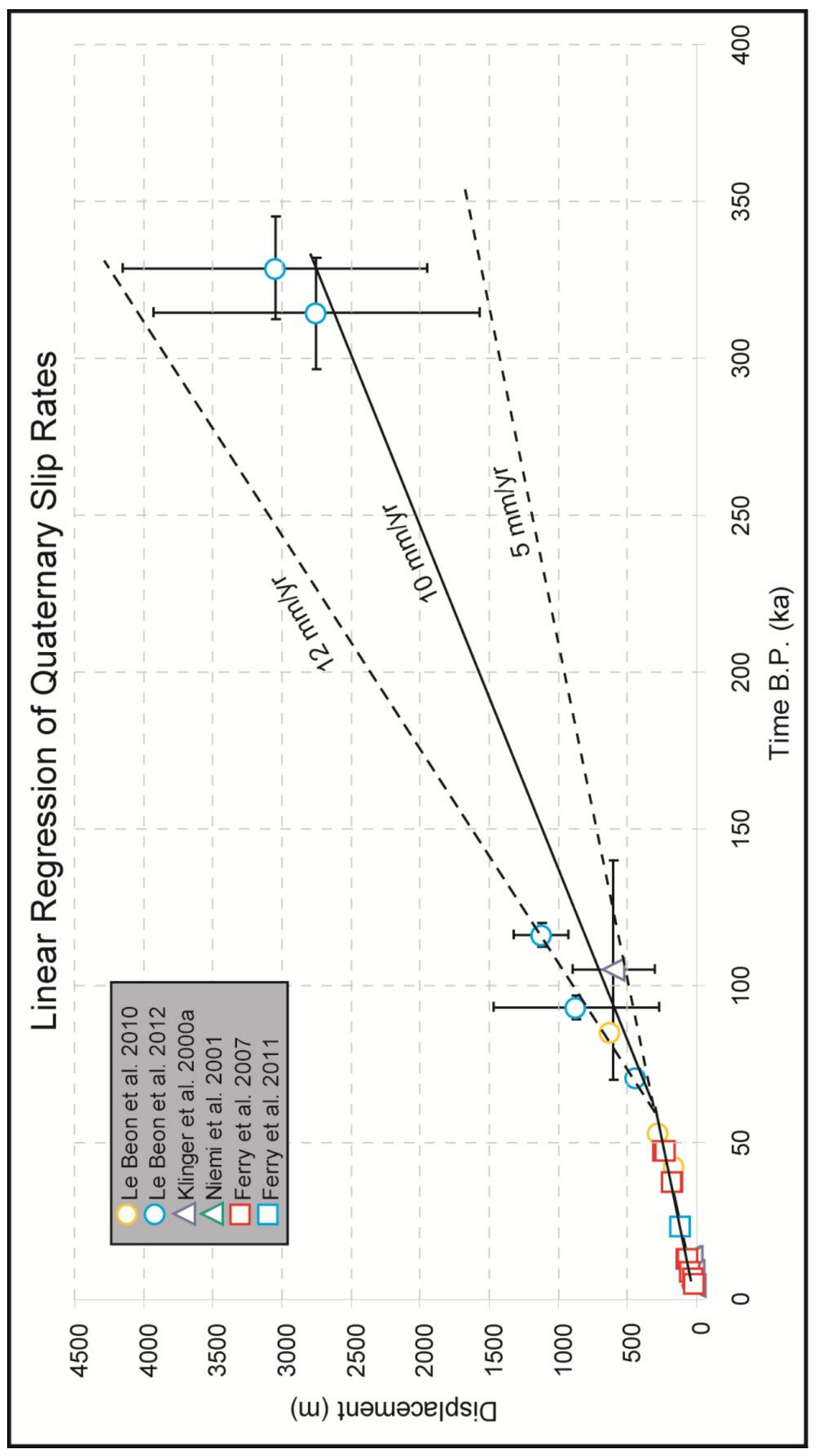

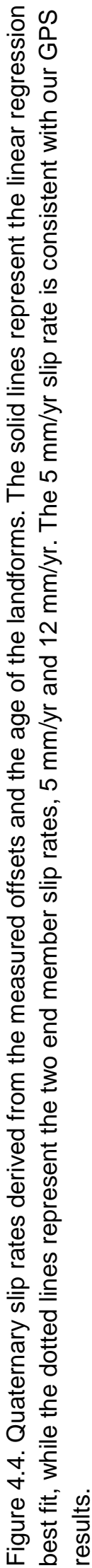




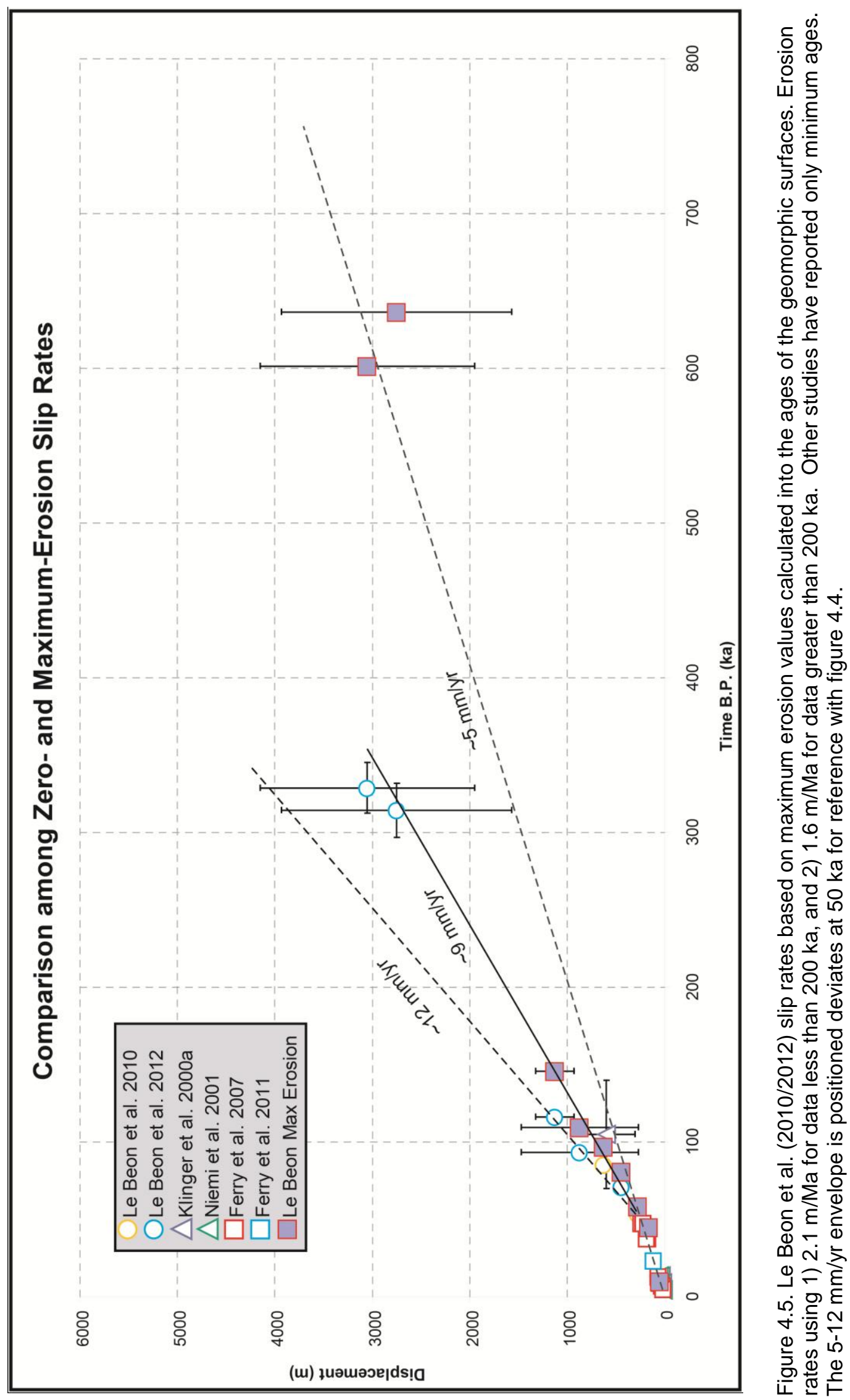


$\sim 300$ ka surfaces, the calculation results in taking the natural $\log (\ln )$ of a negative number (equation 1). Hence, I applied a variable erosion rate of 2.1 $\mathrm{m} / \mathrm{Ma}$ (i.e. Le Beon et al. 2010) to surfaces less than $200 \mathrm{ka}$ and $1.6 \mathrm{~m} / \mathrm{Ma}$ rate to surfaces older than $200 \mathrm{ka}$. This suggests that a constant erosion rate cannot be extrapolated past $200 \mathrm{ka}$, and in order to obtain a consistent slip rate through the late Quaternary, the surfaces range from 400 to $800 \mathrm{ka}$, with a best-fit value of $600 \mathrm{ka}$. Slip rates for these older surfaces range from $4.3-5.1 \mathrm{~mm} / \mathrm{yr}$. For comparison, geologic slip rates along the central DSF system (i.e. the Yammouneh fault) show similar results to the theoretical slip rates (i.e. when using maximum erosion). Gomez et al. (2007a) suggested Holocene slip rates ranging from 3.8 to $6.1 \mathrm{~mm} / \mathrm{yr}$. Daeron et al. (2004) suggested a late Pleistocene to Holocene slip rate of $3.8-6.4 \mathrm{~mm} / \mathrm{yr}$. Being in close proximity to the southern DSF, these results suggest a conservation of slip between the southern and central DSF segments. 


\section{Chapter 5}

\section{Discussions and Scientific Implications}

\subsection{Short-Term vs. Long Term Slip Rates}

Theoretical models of the earthquake cycle predict possible variations in strain accumulation rates during the interseismic period; that these values may vary from long-term strain rates, in cases of relatively weak (i.e., low viscosity) lower crust. The results presented in the previous two chapters indicate that, overall, the GPS-derived (i.e., elastic dislocation) slip rates and late Quaternary slip rates are statistically consistent for the past $\sim 600$ ka (Figure 5.1 ), assuming a maximum erosion rate hypothesis for the Wadi Araba fault. In other words, the crust is well approximated as an elastic half-space, with the lower crust along the southern DSF being relatively strong. Furthermore, geophysical observations suggest the transform cuts through the mantle-lithosphere along a narrow fault (Weber et al. 2009). These observations are thus applicable to a "Deep-Slip" model, suggesting that the depth of coseismic faulting is shallower than the total thickness of seismogenic depth, and that the interseismic strain accumulation is due to steady-state aseismic slip within the lower crust (e.g. Thatcher, 1993). In this model, the interseismic strain accumulation is loaded by slip in the lower crust and mantle lithosphere (Scholz, 2002).

\subsection{Seismic Hazard Implications}

These studies play an important role in the development of seismic hazard mitigation operations adopted by surrounding countries. In Jordan, many devastating earthquakes have been shown to destroy cities (e.g. Ferry et al. 


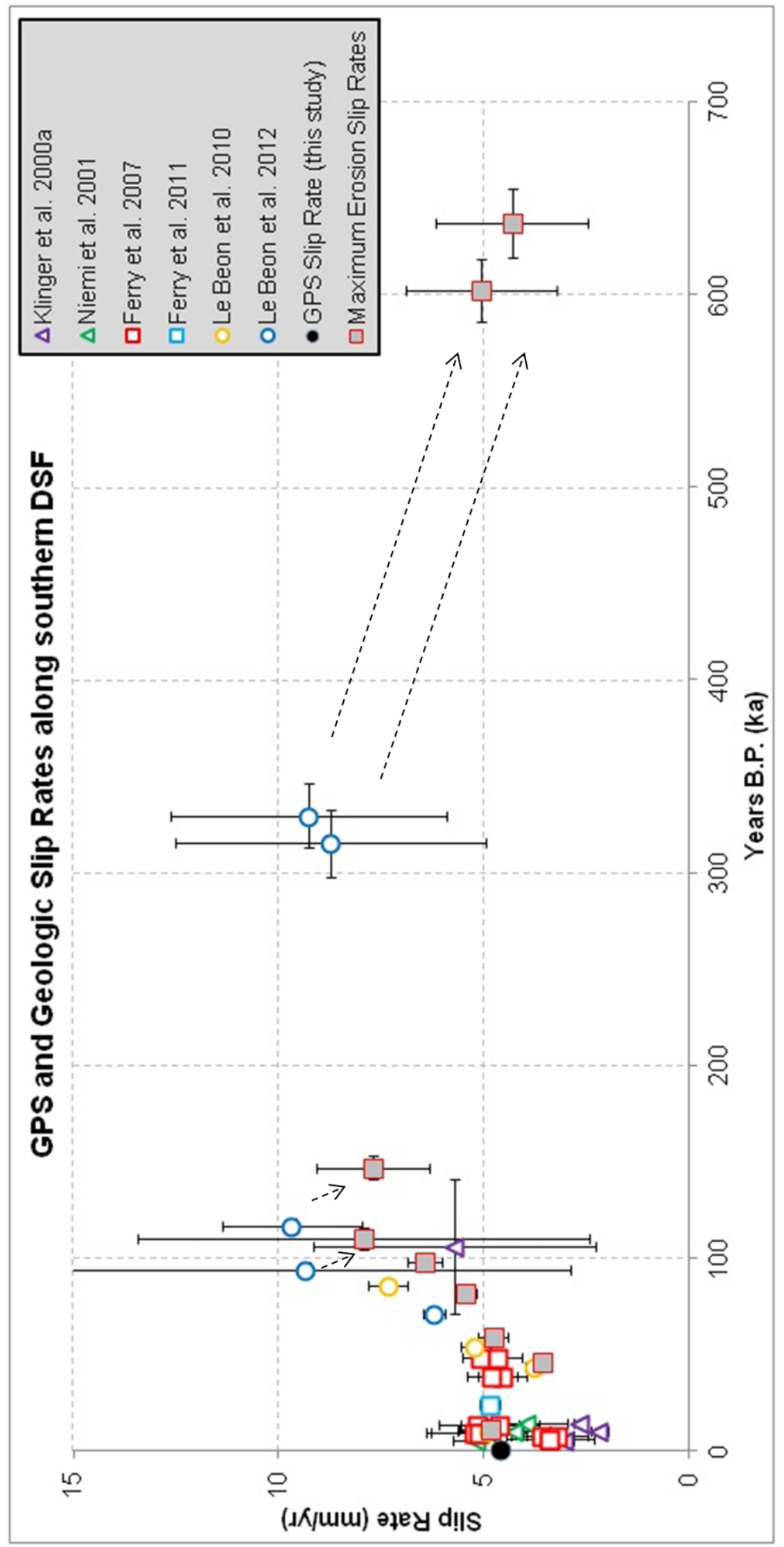

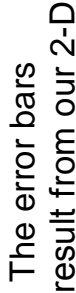

¿்

बण

过

$\stackrel{0}{ \pm}$

등

ฮิ \&

め) 응

का क

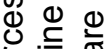

워

की है

응 중

을흥

E $₫$

잏

흥 항

흥하

हํㅠㅁ

엉잉

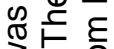

उ. 은

퐁

음

ญ்

응

岗?

的言

증

(1) 응

흘

후 중 है

乩 。

ᄃ

동

实 $\frac{\overline{5}}{\omega}$

응

(1)

뚜

웡 잉

음 든

达

징요

응의

क 눈

두웡

(1)

$\overline{0}$

㨁 $\frac{0}{0}$ 
2011). Addressing questions of earthquake hazard results in the calculation of the peak magnitude earthquake (moment magnitude $~ M w)$ that could be produced along the JVF and WAF. The relationship to slip deficit and moment magnitude is:

$$
\begin{aligned}
& M_{0}=\mu{ }^{*} A{ }^{*} D_{a v} \\
& M w=2 / 3{ }^{*} \log M_{0}-10.7
\end{aligned}
$$

where $\mu$ is the rigidity modulus for the crust ( $32 \mathrm{GPa}), \mathrm{D}_{\mathrm{av}}$ is the slip during the event, and $A$ is the total area of the fault rupture. This relationship is valuable when assessing incremental slip events and calculating slip deficits along fault zones. Furthermore, empirical relationships (Wells and Coppersmith, 1994) among average displacement and moment magnitude are also utilized to determine peak magnitude events:

$$
M=7.04+0.89 * \log (A D)
$$

where $M$ is the moment magnitude and $A D$ is the average displacement. The slip deficit (i.e. average displacement), then, is simply the product of the time elapsed since the last event and the slip rate.

An example of an incremental slip event previously studied Qasr Tilah site (see figure 1.2 for location) is shown in figure 5.2 (Klinger et al. 2000b; Haynes et al. 2006). Figure 5.3-5.5 shows the final product of using Photomodeler Scanner Software package to generate orthorectified photogrammetric photos, and using Arc Scene to create the 3D surface model. Here, the fault trace is well expressed at the surface by an offset late Byzantine water reservoir and 


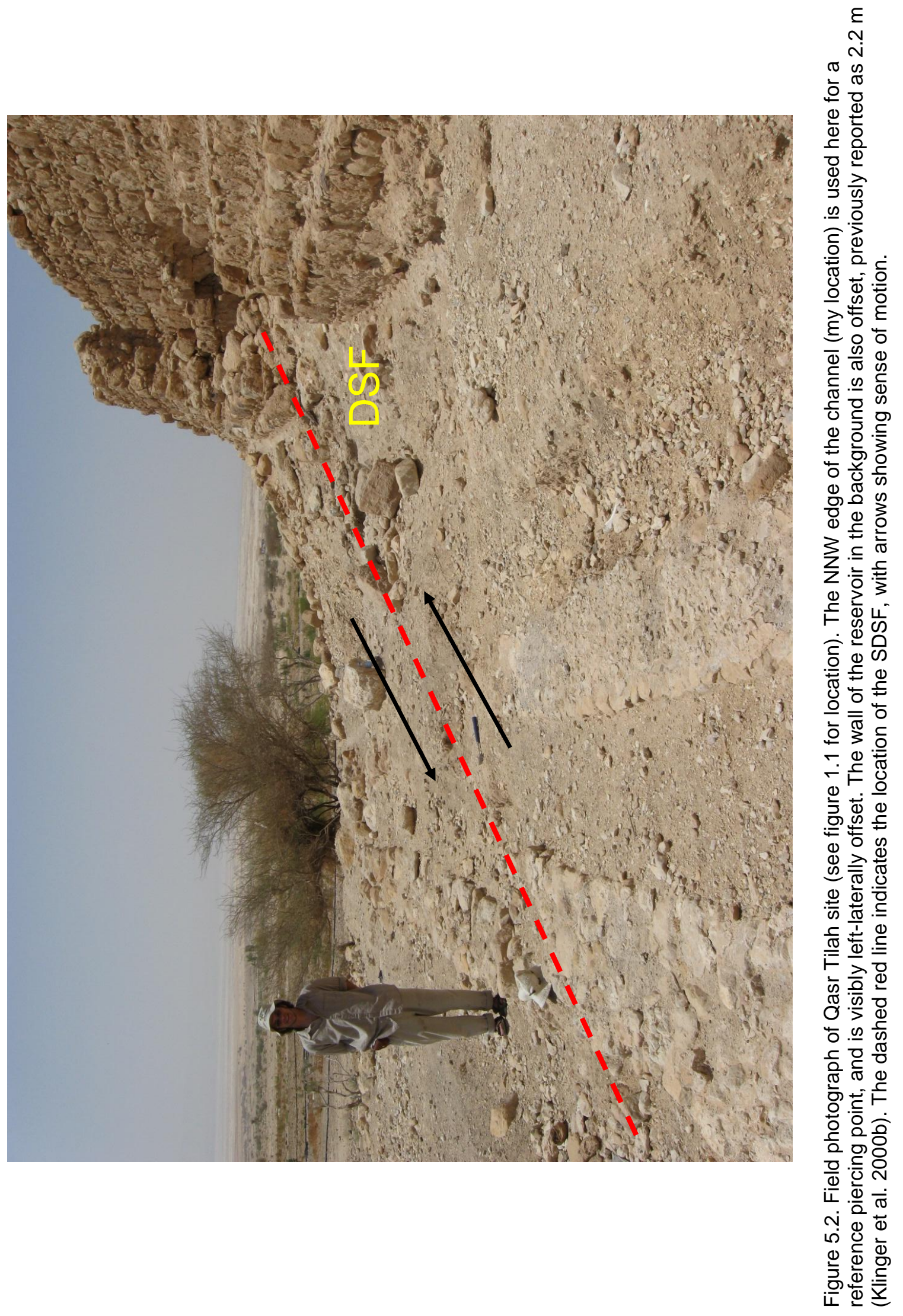




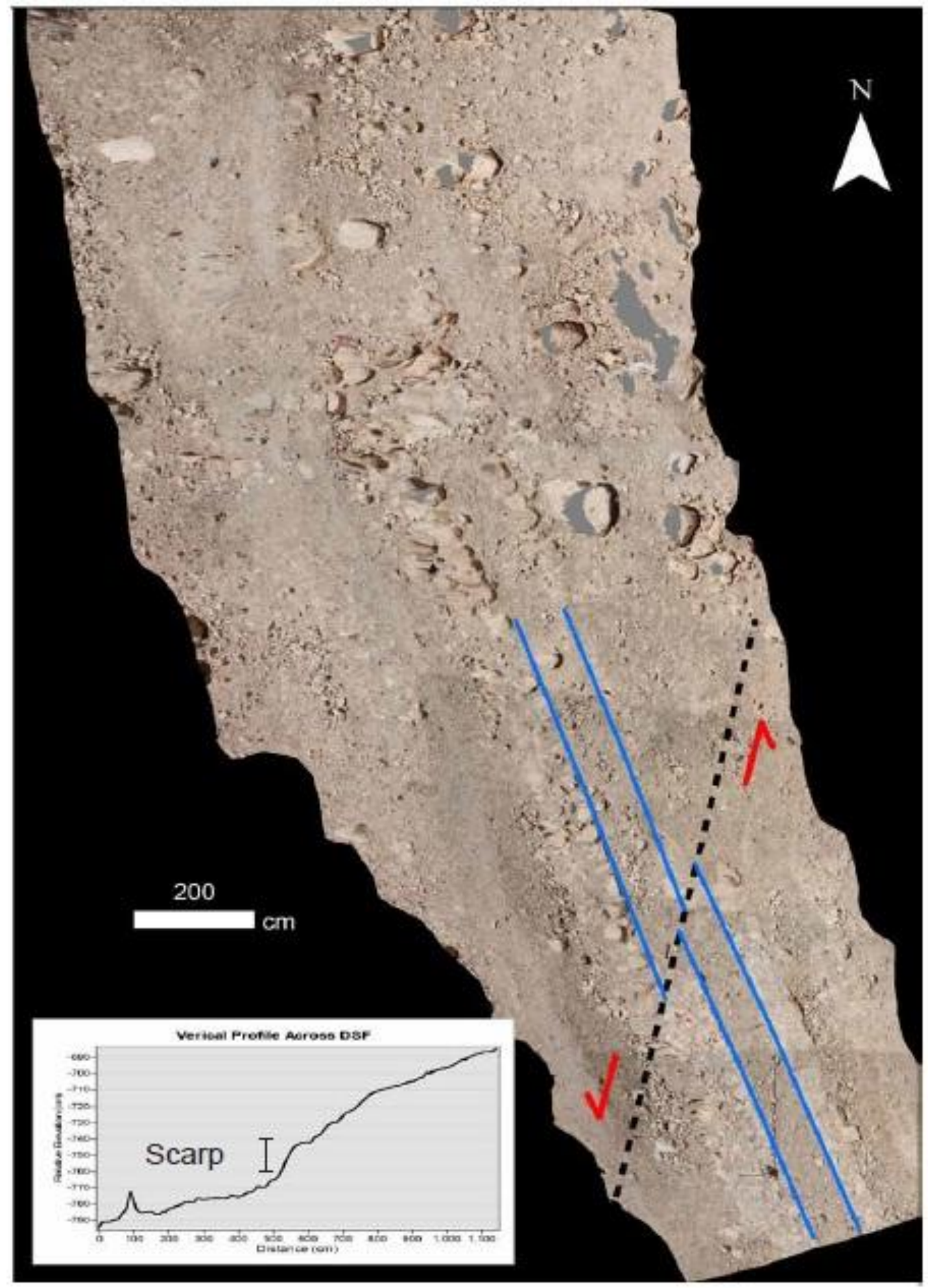

Figure 5.3. Orthorectified photograph generated from Photomodeler Scanner Software of Qasr Tilah aqueduct. Here the inside walls of the aqueduct (blue lines) serve as piercing points for assessing slip. Profile is taken from north to south, parallel with the aqueduct, showing vertical displacement across the DSF. The scarp height is $\sim 20 \mathrm{~cm}$. 


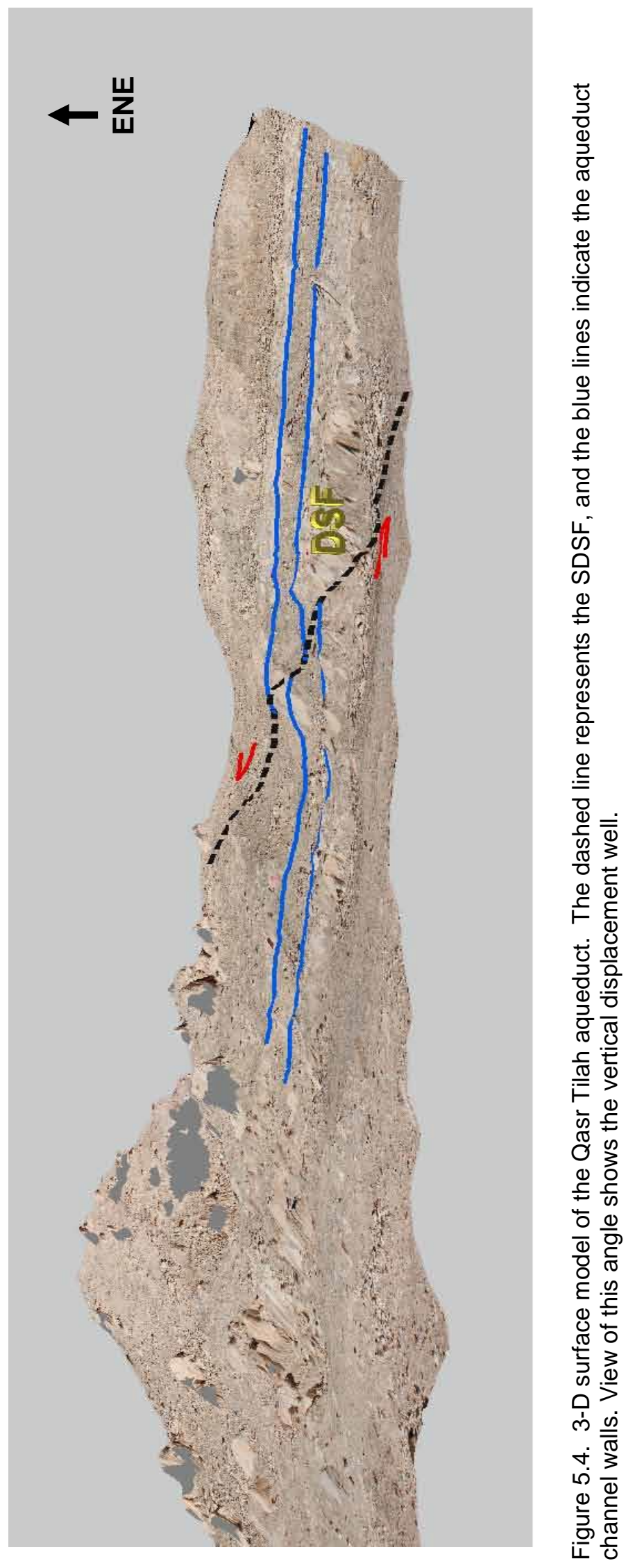




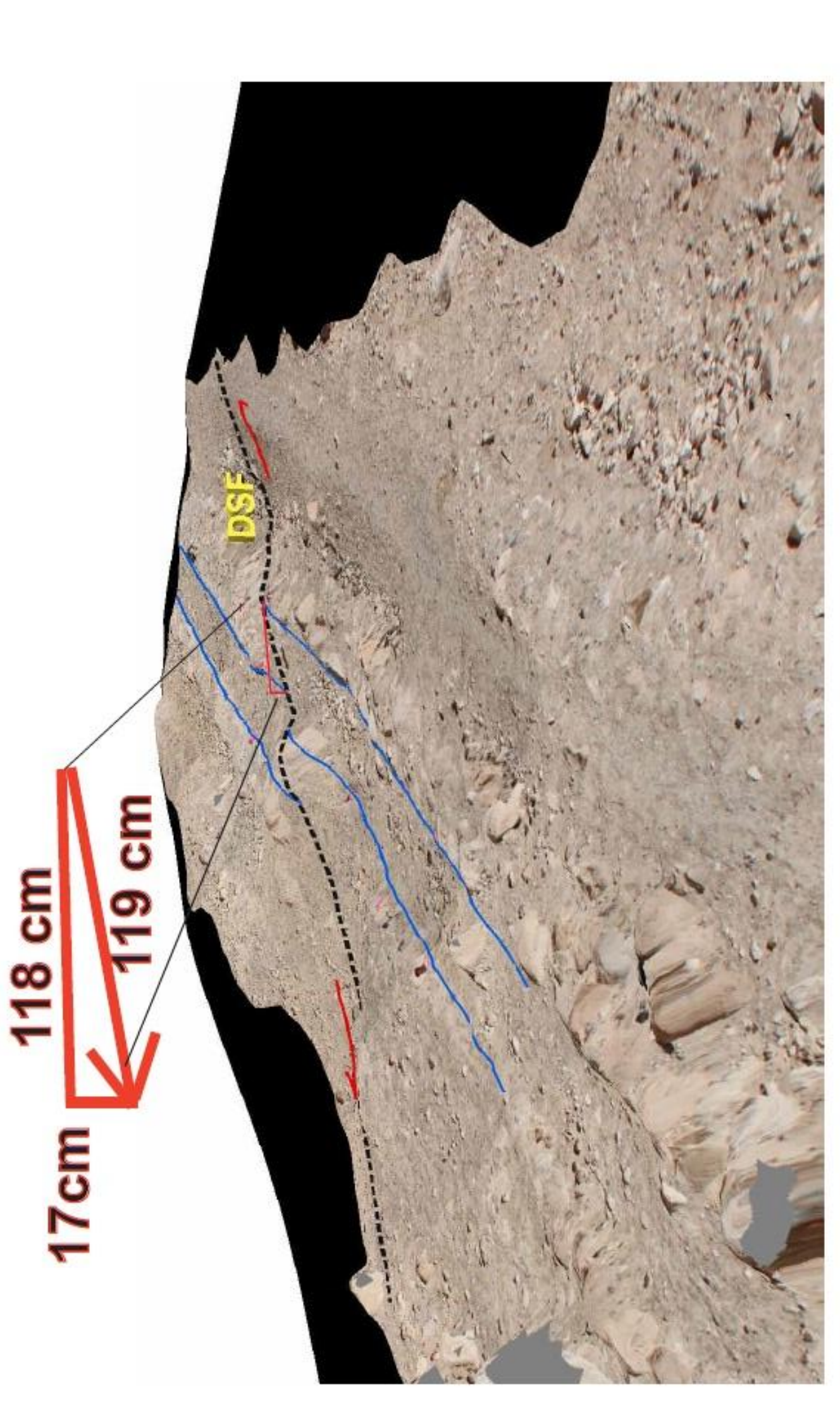

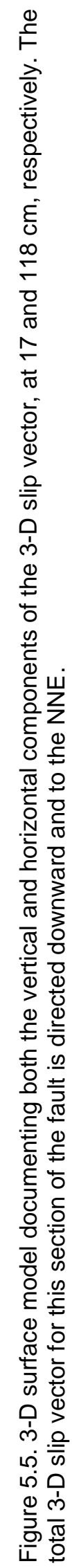


aqueduct. Although the earthquakes likely to cause this rupture have been previously documented (Haynes et al. 2006), and the lateral offsets have been estimated, this study presents a three-dimensional slip vector a magnitude of $\sim 120 \mathrm{~cm}$ (horizontal) and $\sim 20 \mathrm{~cm}$ (vertical). The horizontal displacement corresponds well with the $1.6 \pm 0.4 \mathrm{~m}$ offset of Haynes et al. (2006), but is slightly smaller than the documented $2 \mathrm{~m}$ offset reservoir wall to the NE (Klinger et al. 2000b). The vertical displacement visible at the Qasr Tilah site is consistent with the small amounts of opening produced from our block model, and is expressed all along the southern DSF by transtensional basins.

Using the empirical relationships by Wells and Coppersmith (1994) which relates surface rupture to moment magnitude, the lateral displacement correlates with a $\mathrm{Mw} \sim 7.0$. This magnitude is slightly greater than the 1546 event suggested by Haynes et al. (2006). There exists ambiguity of whether the 1546 event was large enough to produce this rupture (Ambraseys and Karcz, 1992). Therefore, I believe that the event was caused by the 1458 A.D. WAF earthquake, well documented to have occurred near the Qasr Tilah site (e.g. Ambraseys 2006).

Under the assumptions the last event was in 1458 A.D for the WAF and 1033 A.D. for the JVF (e.g. Ferry et al. 2011); here I calculate peak moment magnitudes using our GPS solution ( $\sim 5 \mathrm{~mm} / \mathrm{yr}$ ), the effective locking depths of 9 and $15 \mathrm{~km}$ with $90^{\circ}$ dips, and fault lengths of $160 \mathrm{~km}$ for WAF and $120 \mathrm{~km}$ for JVF. Empirical relationships (Wells and Coppersmith, 1994) suggest peak moment magnitudes of $\mathrm{Mw} \sim 7.4$ and $\mathrm{Mw} \sim 7.6$ for the WAF and JVF, 
respectively. Calculations relating moment deficit to magnitude produces the similar results. Also note that moderate seismicity releases strain on a regular basis, so the true magnitudes for these faults would be lower. For the megacities located within 20-50 km of these faults (e.g. Jerusalem, Amman, Jericho), earthquake hazard assessment is necessary to reduce the risk and prepare for such catastrophes.

\subsection{Conclusions}

Combined results of GPS and neotectonic studies herein show the absence of the time-variability of crustal deformation along southern DSF. This study presents present - day slip rates of $4.6-4.9 \mathrm{~mm} / \mathrm{yr}$, and suggests a similar slip rate through late Quaternary. When maximum erosion rates are introduced into the age calculation, deviation from our $\sim 5 \mathrm{~mm} / \mathrm{yr}$ slip rate occurs at $\sim 100 \mathrm{ka}$. Marco et al. (1996) showed that earthquake clustering tends occurs every $10 \mathrm{ka}$, implying that earthquake clustering cyclicity should not contribute to variations in slip as we see with the Quaternary data, since we have averaged over many earthquake cycles. Thus, our statistically similar slip rates through the late Quaternary are comparable with earthquake recurrence models for a "Deep-Slip" strike slip fault. 


\section{References Cited}

Alchalbi, A., Daoud, M., Gomez, F., et al., 2010, Crustal deformation in northwestern Arabia from GPS measurements in Syria: Slow slip rate along the northern Dead Sea Fault: Geophys. J. Int., v. 180, p. 125-135.

Al-Damegh, K., E. Sandvol, A. Al - Lazki, and M. Barazangi (2004), Regional seismic wave propagation ( $\mathrm{Lg}$ and $\mathrm{Sn}$ ) and $\mathrm{Pn}$ attenuation in the Arabian Plate and surrounding regions, Geophys. J. Int., v. 157, p. 775-795.

Al-Lazki, A. I., E. Sandvol, D. Seber, M. Barazangi, N. Turkelli, and R. Mohamad (2004), Pn tomographic imaging of mantle lid velocity and anisotropy at the junction of the Arabian, Eurasian and African plates, Geophys. J. Int., v. 158 , p. $1024-1040$

Al-Tarazi, E., J. Abu Rajab, F. Gomez, W. Cochran, R. Jaafar, and M. Ferry (2011),GPS measurements of near-field deformation along the southern Dead Sea Fault System, Geochem. Geophys. Geosyst., v. 12, p. Q12021.

Al-Tarazi, E., E. Sandoval, and F. Gomez (2006), The February 11, 2004 Dead Sea earthquake $\mathrm{Ml}=5.2$ in Jordan and its tectonic implication, Tectonophysics, v. 422, p. 149-158.

Al-Zoubi, A. and Ben Avraham, Z., 2002, Structure of the earth's crust in Jordan from potential field data: Tectonophysics, v. 346, p. 45-59.

Ambraseys, N. N. and Karcz, I, (1992) The earthquake of 1546 in the Holy Land. Terra Nova 4:254-263.

Ambraseys, N. N., C. P. Melville, and R. D. Adams (1994), The Seismicity of Egypt, Arabia, and the Red Sea: A Historical Review, 181 pp., Cambridge Univ. Press, Cambridge, U. K.

Ambraseys, N. N. and Jackson, J.A., 1998, Faulting Associated with Historical and Recent Earthquakes in the Eastern Mediterranean Region: Geophys. J. Int., v. 133, p. 390-406.

Ambraseys, N. N., 2006, Comparison of frequency of occurrence of earthquakes with slip rates from long-term seismicity data: the cases of Gulf of Corinth, Sea of Marmara and Dead Sea Fault Zone: Geophys. J. Int., v. 165, p. 516-526.

Bao, X., et al. (2011), Pg attenuation tomography within the northern Middle East, Bull. Seismol. Soc. Am., v. 101(4), p. 1496-1506, 
Barberi, F., G. Capaldi, P. Gasperini, G. Marinelli, R. Santacroce, R. Scandone, M. Treuil, and J. Varet (1980), Recent basaltic volcanism of Jordan and its implications on the geodynamic history of the Dead Sea shear zone, in Geodynamic Evolution of the Afro-Arabian Rift System, edited by A. Carrelli, p. 667-683, Accad. Naz. dei Lincei, Rome.

Bartov, Y., Stein, M., Enzel, Y., Agnon, A., Reches, Z.E., 2002. Lake Levels and Sequence Stratigraphy of Lake Lisan, the Late Pleistocene Precursor of the Dead Sea. Quat. Res., v. 57, p. 9-21.

Bookman, R., Enzel, Y., Agnon, A., Stein, M., 2004. Late Holocene lake levels of the Dead Sea. Geol. Soc. Amer. Bull., v. 116, p. 555-571.

Chang, S.-J., and S. Van der Lee (2011), Mantle plumes and associated flow beneath Arabia and East Africa, Earth Planet. Sci. Lett., v. 302, p. 448454.

Daeron, M., Benedetti, L., Tapponnier, P., Sursock, A. and Finkel, R.C. 2004. Constraints on the post $\sim 25$-ka slip rate of the Yammouneh fault (Lebanon) using in situ cosmogenic $\mathrm{Cl}$ dating of offset limestone-clast fans, Earth and Planetary Science Letters, v. 227, p. 105-119.

Eyal M, Eyal Y, Bartov Y, Steinitz G. 1981. Tectonic development of the western margin of the Gulf of Elat (Aqaba) rift. Tectonophysics, v. 80, p. 39-66.

Ferry, M., Meghraoui, M., Karaki, N., Al-Taj, M., and Khalil L., 2011, Episodic Behavior of the Jordan Valley Section of the Dead Sea Fault Inferred from a 14-Ka-Long Integrated Catalog of Large Earthquakes: Bull. Seis. Soc. America. v. 101, No. 1, p. 39-67.

Freund, R., Z. Garfunkel, I. Zak, M. Goldberg, T. Weisbrod, and B. Derin, 1970, The shear along the Dead Sea rift: Philos. Trans. R. Soc. London, Ser. A, v. 267 , p. $107-130$.

Garfunkel, Z., I. Zak, and R. Freund (1981), Active faulting in the Dead Sea rift: Tectonophysics v. 80, p. 1-26.

Garfunkel Z. 1989, Tectonic setting of Phanerozoic magmatism in Israel: Isr. J. Earth Sci., v. 38, p. 51-74.

Garfunkel, Z., and Z. Ben-Avraham (2001), Basins along the Dead Sea Transform, in Peri-Tethyan Rift/Wrench Basins and Passive, Peri-Tethys Mem., vol. 6, edited by W. C. P. A. Ziegler, A. H. F. Robertson, and S. Crasquin-Soleau, Mem. Mus. Natl. Hist. Nat., v. 186, p. 607-627. 
Gomez, F., Nemer, T., Tabet, C. et al., 2007a, Strain partitioning of active transpression within the Lebanese restraining bend of the Dead Sea Fault (Lebanon and SW Syria): Geologic Society of London, Special publications 2007, v. 290, p. 285-303.

Gomez, F., et al. 2007b, Global Positioning System measurements of strain accumulation and slip transfer through the restraining bend along the Dead Sea Fault System in Lebanon, Geophys. J. Int., v. 168, p. 10211028.

Haynes, J., T. Niemi, and M. Atallah (2006). Evidence for ground-rupturing earthquakes on the Northern Wadi Araba fault at the archaeological site of Qasr Tilah, Dead Sea Transform fault system, Jordan, J. Seismol., v. 10, p. $415-430$.

Hempton, M. R., 1987, Constraints on Arabian Plate motion and extensional history of the Red Sea: Tectonics, v.6, p. 687-705.

Herring, T.A., King, R.W., and McClusky, S.C., 2006. Introduction to GAMIT/GLOBK. Release 10.2.

Ilani S, Harlavan Y, Tarawneh K, Rabba I,Weinberger R, et al. 2001, New K-Ar ages of basalts from Harrat Ash Shaam volcanic field in Jordan: Implications for span and duration of the upper-mantle upwelling beneath the western Arabian plate: Geology, v.29, p. 171-74.

Khair, K., Karakaisis, G.F., and Papadimitriou, E.E., 2000, Seismic Zonation of the Dead Sea Transform Fault Area: Annali Di Geofisica, v. 43, N.1, p. 6179.

Klinger, Y., J. P. Avouac, N. Abou Karaki, L. Dorbath, D. Bourles, and J. L. Reyss, 2000a, Slip rate on the Dead Sea transform fault in northern Araba Valley (Jordan): Geophys. J. Int., v. 142, p.755 -768.

Klinger, Y., J. P. Avouac, L. Dorbath, N. Abou Karaki, and N. Tisnerat, 2000b, Seismic behaviour of the Dead Sea fault along Araba Valley Jordan: Geophys. J. Int., v. 142, p. $769-782$.

Laske, G., M. Weber, and the DESSERT Working Group (2008), Lithosphere structure across the Dead Sea Transform as constrained by Rayleigh waves observed during the DESERT experiment, Geophys. J. Int., v. 173, p. 593-610.

Le Beon, M. Klinger, Y., et al., 2008, Slip Rate and Locking Depth from GPS Profiles across the southern Dead Sea Transform: J. Geophys. Research, v. 113, N. B11403, p. 1-19. 
Le Béon, M., Y. Klinger, A.-S. Mériaux, M. Al-Qaryouti, R. C. Finkel, O. Mayyas, and P. Tapponnier (2012), Quaternary morphotectonic mapping of the Wadi Araba and implications for the tectonic activity of the southern Dead Sea fault, Tectonics, 31, TC5003.

Marco, S., M. Stein, A. Agnon, and H. Ron (1996), Long-term earthquake clustering: A 50,000-year paleoseismic record in the Dead Sea Graben, J. Geophys. Res., v. 101(B3), p. 6179-6191.

Matmon, A., O. Simhai, R. Amit, I. Haviv, N. Porat, E. McDonald, L. Benedetti, and R. Finkel (2009), Desert pavement-coated surfaces in extreme deserts present the longest-lived landforms on Earth, Geol. Soc. Am. Bull., v. 121, p. $688-697$.

McClusky, S., R. Reilinger, S. Mahmoud, D. B. Sari, and A. Tealeb (2003), GPS constraints on Africa (Nubia) and Arabia plate motions, Geophys. J. Int., v. 155 , p. $126-138$.

Meade, B. J., and J. P. Loveless (2009), Block modeling with connected faultnetwork geometries and a linear elastic coupling estimator in spherical coordinates, Bull. Seismol. Soc. Am., v. 99, p. 3124-3139.

Mechie, J., Abu-Ayyash, K., Ben-Avraham, Z., El-Kelani, R., Qabbani, I., Weber, M., DESIRE Group. 2009.Crustal structure of the southern Dead Sea basin derived from project DESIRE wide-angle seismic data, Geophys. J. Int., v. 160, p. 910-924.

Niemi, T. M., Zhang, H., Atallah, M., and Harrison, J., 2001, Late Pleistocene and Holocene slip rate of the Northern Wadi Araba Fault, Dead Sea Transform, Jordan: Jour. Seis., v. 5, p. 449.

Paschke, M., Stiller, M., Ryberg, T., Weber, M., and DESIRE Group, 2012, The shallow P-velocity structure of the southern Dead Sea basin derived from near-vertical incidence reflection seismic data in project DESIRE: Geophys. J. Ing., v. 188, p. 524-534.

Quennell, A.M, 1958, The Structural and Geomorphic Evolution of the Dead Sea Rift: Q. J. Geol. Soc. London, v. 114, p. 1-24.

Quennell, A.M., 1984, The Western Arabian Rift System: Geological Society, London, Special Publications 1984; v. 17; p. 775-788.

Reilinger, R., et al. (2006), GPS constraints on continental deformation in the Africa-Arabia-Eurasia continental collision zone and implications for the dynamics of plate interactions: J. Geophys. Res., v. 111, p. B05411. 
Sadeh, M., Y. Hamiel, A. Ziv, Y. Bock, P. Fang, and S. Wdowinski (2012), Crustal deformation along the Dead Sea Transform and the Carmel Fault inferred from 12 years of GPS measurements, J. Geophys. Res., v. 117, p. B08410.

Sandvol, E. \& Hearn, T., 1994. Bootstrapping shear-wave splitting errors. Bulleting of the Seismological Society of America, v. 84, p. 1971-1977.

Scholz, C. (2002), The Mechanics of Earthquakes and Faulting, 2nd ed., 496 pp., Cambridge Univ. Press, Cambridge, U. K.

Segall, P. and Davis, J. L., 1997. GPS applications for geodynamics and earthquake studies. Earth Planet. Sci., v. 25, p. 301-36.

Shaw, J. E., J. A. Baker, M. A. Menzies, M. F. Thirlwall, and K. M. Ibrahim (2003), Petrogenesis of the largest intraplate volcanic field in the Arabian Plate (Jordan): A mixed lithosphere-asthenosphere source activated by lithospheric extension, J. Petrol., v. 44, p. 1657-1679.

Smith-Konter, B., D. Sandwell, and P. Shearer (2011), Locking depths estimated from geodesy and seismology along the San Andreas Fault System: Implications for seismic moment release, J. Geophys. Res., v. 116, p. B06401.

Steinitz G, Bartov Y. 1991, The Miocene-Pliocene history of the Dead Sea segment of the rift in light of K-Ar ages of basalts: Isr. J. Earth Sci, v. 40, p.199-208.

Taylor, J., 1982, An Introduction to Error Analysis. Mill Valley, CA, University Science Books, Oxford University Press.

ten Brink, U.S., Al-Zoubi, A.S., Flores, C.H., Rotstein, Y., Qabbani, I., Harder, S.H. \& Keller, G.R., 2006. Seismic imaging of deep low-velocity zone beneath the Dead Sea basin and transform fault: implications for strain localization and crustal rigidity, Geophys. Res. Lett., v. 33, p. L24314.

Thatcher, W., 1993, The earthquake cycle and its role in the long-term deformation of the continental lithosphere: Annali di Geofisica, v. xxxvi, N.2, p. 13-24.

Tsoulfanidis. N., 1995, Measurement and Detection of Radiation, Second edition. Washington DC, Taylor \& Francis Publishing.

Weber, M., et al. (2009), Anatomy of the Dead Sea Transform from lithospheric to microscopic scale, Rev. Geophys., v. 47, p. RG2002. 
Weber, M., et al. 2011. Results of geophysical studies across the Dead Sea Transform: the Arava/Araba Valley and the Dead Sea Basin, Isr. J. Earth Sci.,v. 58, p. 147-161.

Wdowinski, S., Bock, Y., Baer, G., et. al., 2004, GPS measurements of current crustalmovements along the Dead Sea Fault: J. Geophys. Research, v. 109, No., B05403, p.1-16. 


\section{Appendix A}

Velocities for GPS sites shown in Figure $3.1^{a}$

\begin{tabular}{|c|c|c|c|c|c|c|c|c|c|c|c|c|}
\hline Site & Longitude & Latitude & $\begin{array}{c}\mathrm{Ve} \\
\text { (ITRF) }\end{array}$ & $\begin{array}{c}\mathrm{Vn} \\
\text { (ITRF) }\end{array}$ & $\begin{array}{l}\text { Ve } \\
(\mathrm{Ar})\end{array}$ & $\begin{array}{l}\mathrm{Vn} \\
(\mathrm{Ar}) \\
\end{array}$ & Sig. E & Sig. $N$ & Corr. & $\begin{array}{l}\text { First } \\
\text { (Date) }\end{array}$ & $\begin{array}{c}\text { Last } \\
\text { (Date) }\end{array}$ & $\begin{array}{l}\text { Span } \\
\text { (year) }\end{array}$ \\
\hline \multicolumn{13}{|c|}{ Jordan Sites } \\
\hline AQBA & 35.019 & 29.528 & 20.93 & 18.70 & -1.02 & -1.38 & 0.67 & 0.67 & -0.0190 & 2005.6 & 2010.5 & 4.9 \\
\hline ASGF & 37.648 & 32.333 & 22.01 & 21.24 & 0.88 & -0.03 & 0.61 & 0.62 & 0.0060 & 2005.6 & 2010.5 & 4.9 \\
\hline BALQ & 35.695 & 30.239 & 20.89 & 20.92 & -1.45 & 0.52 & 0.74 & 0.73 & -0.0050 & 2006.5 & 2012.5 & 6.0 \\
\hline $\mathrm{BISH}$ & 36.818 & 32.156 & 20.79 & 19.91 & -0.31 & -0.99 & 0.57 & 0.57 & 0.0040 & 2005.6 & 2010.5 & 4.9 \\
\hline DANA & 35.580 & 30.698 & 24.09 & 19.91 & 1.11 & -0.43 & 0.53 & 0.52 & 0.0030 & 2008.5 & 2012.5 & 4.0 \\
\hline DASK & 35.691 & 32.501 & 20.67 & 19.76 & 0.05 & -0.63 & 0.68 & 0.68 & 0.0060 & 2005.6 & 2010.5 & 4.9 \\
\hline DBUS & 35.659 & 30.897 & 21.68 & 19.95 & -0.16 & -0.43 & 0.70 & 0.70 & -0.0150 & 2008.5 & 2012.5 & 4.0 \\
\hline DRAA & 35.572 & 31.249 & 21.56 & 19.56 & 0.01 & -0.77 & 0.48 & 0.47 & -0.0010 & 2005.6 & 2.5 & 6.9 \\
\hline FGFZ & 35.200 & 30.214 & 25.24 & 19.30 & 0.97 & -1.57 & 1.15 & 1.13 & 0.0090 & 2010.5 & 2012.5 & 2.0 \\
\hline FIFA & 35.456 & 30.907 & 20.68 & 18.33 & -1.11 & -1.95 & 0.60 & 0.59 & -0.0080 & 2007.5 & 2.5 & 5.0 \\
\hline HUG1 & .189 & 32.107 & 22.50 & 18.71 & -0.43 & 0.13 & 0.56 & 0.58 & -0.0550 & 200 & 2.5 & 7.0 \\
\hline HUGS $^{b}$ & 36.189 & 32.101 & 20.59 & 20.75 & 0.06 & -0.33 & 0.39 & 0.39 & 0.0010 & 2005.5 & 2012.5 & 7.0 \\
\hline IRHB & 6.041 & 32.343 & 21.08 & 20.29 & 1.70 & -2.22 & 1.40 & 1.38 & 0.0020 & & & 2.0 \\
\hline JAFR & 36.368 & 30.680 & 22.51 & 18.33 & 0.16 & -0.09 & 0.68 & 0.67 & 0.0060 & 2005.6 & 10.5 & 4.9 \\
\hline JASH & & 32.294 & 22.29 & 20.61 & 0.20 & 0.26 & 0.47 & 0.46 & & & & 6.9 \\
\hline JUST $^{b}$ & .987 & 32.493 & 21.02 & 20.75 & -0.44 & 0.19 & 0.54 & 0.54 & 0.0000 & 8.4 & 2.5 & 4.1 \\
\hline KRMA & 35.588 & 31.968 & 20.75 & 17.23 & -0.26 & -3.11 & 1.37 & 1.37 & 0.0100 & & 2.5 & 2.0 \\
\hline MJBG & 35.565 & 31.426 & 19.98 & 19.08 & -1.44 & -1.25 & 0.71 & 0.70 & -0.0110 & 2008.5 & 12.5 & 4.0 \\
\hline MUD2 & 35.632 & 32.158 & 21.52 & 18.70 & 0.65 & -1.66 & 0.48 & 0.48 & -0.0020 & & 2012.5 & 6.9 \\
\hline MUTA $^{b}$ & 35.718 & 31.095 & 20.88 & 19.58 & -0.82 & -0.82 & 0.60 & 0.60 & 0.0020 & 200 & 2012.5 & 5.3 \\
\hline NAML & 35.403 & 30.469 & 21.88 & 19.72 & -0.23 & -0.54 & 0.67 & 0.67 & -0.0 & 2008.5 & & 4.0 \\
\hline NAQB & 5.433 & 30.086 & 24.01 & 20.14 & 1.60 & -0.14 & 0.80 & 0.79 & 0.0220 & & & 4.0 \\
\hline NEB2 & 35.739 & 31.766 & 20.33 & 21.14 & -0.86 & 0.73 & 2.08 & 2.10 & -0.0200 & 2008.5 & 2010.5 & 2.0 \\
\hline NEBO & 35.739 & 31.766 & 19.40 & 20.51 & -1.79 & 0.10 & 0.94 & 0.92 & 0.0210 & & 0.5 & 4.9 \\
\hline PANO & 35.602 & 31.644 & 21.12 & 19.07 & -0.14 & -1.28 & 0.74 & 0.74 & -0.0130 & 2008.5 & 2012.5 & 4.0 \\
\hline PETA $^{b}$ & 35.469 & 30.327 & 22.06 & 19.19 & -0.17 & -1.10 & 0.53 & 0.53 & 0.0000 & 2008.2 & 2.5 & 4.3 \\
\hline PETH & & & 21.87 & & -0.41 & -0.84 & 1.23 & 1.20 & & & & 1.9 \\
\hline QIRA & 35.403 & 30.621 & 21.01 & 18.64 & -0.99 & -1.62 & 0.68 & 0.66 & -0.0420 & 2007.5 & 2012.5 & 5.0 \\
\hline QURA & 35.340 & 29.810 & 22.03 & 19.06 & -0.57 & -1.17 & 0.60 & 0.59 & 0.0020 & & 0.5 & 4.9 \\
\hline RAMA & 35.151 & 29.907 & 22.29 & 18.11 & -0.20 & -2.03 & 0.57 & 0.56 & -0.0010 & 2007.5 & 2012.5 & 5.0 \\
\hline RSAS & 35.922 & 31.514 & 22.13 & 18.96 & 0.71 & -1.54 & 0.66 & 0.64 & & 2005.6 & 2010.5 & 4.9 \\
\hline $\mathrm{RSH} 3$ & 35.197 & 30.202 & 22.08 & 17.68 & -0.20 & -2.48 & 1.13 & 1.15 & -0.0220 & 2010.5 & 2012.5 & 2.0 \\
\hline RUMM & 35.426 & 29.630 & 22.95 & 19.35 & 0.20 & -0.92 & 0.83 & 0.82 & 0.0040 & 2007.5 & 2010.5 & 3.0 \\
\hline SAFI & 35.514 & 31.078 & 21.39 & 18.92 & -0.28 & -1.39 & 0.69 & 0.68 & -0.0150 & 2008.5 & 2012.5 & 4.0 \\
\hline TUBA & 36.562 & 31.319 & 21.35 & 20.55 & -0.34 & -0.24 & 0.63 & 0.64 & 0.0040 & 2005.6 & 2010.5 & 4.9 \\
\hline WADR & 35.359 & 30.176 & 22.35 & 18.98 & 0.02 & -1.26 & 0.68 & 0.66 & -0.0120 & 2008.5 & 2010.5 & 2.0 \\
\hline ZFRN & 35.872 & 31.617 & 19.56 & 21.46 & -1.77 & 0.99 & 1.65 & 1.55 & -0.0430 & 2008.5 & 2010.5 & 2.0 \\
\hline
\end{tabular}




\begin{tabular}{|c|c|c|c|c|c|c|c|c|c|c|c|c|}
\hline Site & Longitude & Latitude & $\begin{array}{c}\mathrm{Ve} \\
\text { (ITRF) }\end{array}$ & $\begin{array}{c}\mathrm{Vn} \\
\text { (ITRF) }\end{array}$ & $\begin{array}{l}\mathrm{Ve} \\
(\mathrm{Ar})\end{array}$ & $\begin{array}{l}\mathrm{Vn} \\
(\mathrm{Ar})\end{array}$ & Sig. E & Sig. $N$ & Corr. & $\begin{array}{l}\text { First } \\
\text { (Date) }\end{array}$ & $\begin{array}{c}\text { Last } \\
\text { (Date) }\end{array}$ & $\begin{array}{l}\text { Span } \\
\text { (year) }\end{array}$ \\
\hline \multicolumn{13}{|c|}{ Southern Lebanon and Syria Survey Sites } \\
\hline ANJR & 35.922 & 33.740 & 19.15 & 18.78 & -0.57 & -1.71 & 0.49 & 0.49 & -0.0090 & 2002.4 & 2007.8 & 5.4 \\
\hline HZRT & 35.880 & 33.859 & 18.51 & 18.69 & -1.11 & -1.79 & 0.41 & 0.41 & -0.0010 & 2002.4 & 2007.8 & 5.4 \\
\hline JIYE & 35.401 & 33.641 & 18.26 & 17.08 & -1.43 & -3.17 & 0.65 & 0.66 & -0.0320 & 2002.4 & 2007.8 & 5.4 \\
\hline JZIN & 5.579 & 33.545 & 19.18 & 17.50 & -0.62 & -2.84 & 0.58 & 0.58 & -0.0090 & 2002.4 & 2007.8 & 5.4 \\
\hline KBDD & 38.437 & 33.571 & 21.64 & 22.41 & 1.29 & 0.79 & 0.46 & 0.45 & -0.0230 & 2001.1 & 2008.7 & 7.6 \\
\hline CHK & 5.761 & 33.516 & 19.27 & 18.83 & -0.59 & -1.59 & 50 & 50 & 0.0050 & & & 5.4 \\
\hline RBDA & 35.162 & 33.149 & 19.84 & 16.21 & -0.18 & -3.93 & 0.69 & 0.71 & -0.0110 & 2002.4 & 2007.8 & 5.4 \\
\hline & & 32. & 21.53 & 21. & 32 & 0.51 & & 42 & & & & 7.6 \\
\hline TFEL & 36.235 & 33.860 & 18.95 & 19.91 & -0.74 & -0.73 & 54 & 0.55 & -0.0260 & 2002.4 & 2007.8 & 5.4 \\
\hline \multicolumn{13}{|c|}{ Other Regional Sites } \\
\hline $\operatorname{NKR} R^{b}$ & 32.758 & 39.887 & -1.80 & 9.00 & -15.96 & -10.02 & 0.28 & 0.28 & -0.0050 & 2000.9 & 2012.5 & 11.6 \\
\hline $\mathrm{REL}^{\mathrm{b}}$ & 35.209 & 32.102 & 19.95 & 16.97 & -0.89 & -3.20 & 0.57 & 0.57 & -0.0010 & 2005.2 & 2008.6 & 3.4 \\
\hline $\mathrm{BAHR} \mathrm{R}^{\mathrm{b}}$ & 50.608 & 26.209 & 28.20 & 26.14 & 0.20 & -0.29 & 0.33 & 0.33 & 0.0000 & 2000.9 & 2008.6 & 7.7 \\
\hline $\mathrm{BSHM}^{\mathrm{b}}$ & 35.023 & 32.779 & 19.71 & 16.48 & -0.57 & -3.60 & 0.32 & 0.32 & 0.0010 & 2000.9 & 2012.5 & 11.6 \\
\hline $\operatorname{CSAR}^{b}$ & 34.890 & 32.488 & 19.63 & 16.09 & -0.85 & -3.93 & 0.66 & 0.66 & -0.0010 & 2004.4 & 2012.5 & 8.1 \\
\hline DRAG ${ }^{b}$ & 35.392 & 31.593 & 20.34 & 16.59 & -0.92 & -3.66 & 0.30 & 0.30 & 0.0010 & 2000.9 & 2012.5 & 11.6 \\
\hline DSEA $^{b}$ & 35.369 & 31.037 & 21.52 & 17.88 & -0.16 & -2.36 & 0.40 & 0.40 & 0.0020 & 2005.2 & 2012.5 & 7.3 \\
\hline $\mathrm{ELAT}^{\mathrm{b}}$ & 34.921 & 29.509 & 22.27 & 16.73 & -0.48 & -3.31 & 0.55 & 0.54 & -0.0010 & 2001.1 & 2012.5 & 11.4 \\
\hline ELRO $^{b}$ & 35.771 & 33.182 & 20.05 & 18.72 & -0.07 & -1.71 & 0.30 & 0.30 & 0.0000 & 2000.9 & 2010.6 & 9.7 \\
\hline GILB $^{b}$ & 35.416 & 32.479 & 19.96 & 17.05 & -0.63 & -3.21 & 0.30 & 0.30 & 0.0010 & 200 & 2012.5 & 11.6 \\
\hline JSLM $^{b}$ & 35.202 & 31.771 & 20.24 & 16.51 & -0.85 & -3.66 & 0.42 & 0.42 & 0.0010 & 2002.3 & 2012.5 & 10.2 \\
\hline $\mathrm{KABR}^{\mathrm{b}}$ & 35.145 & 33.023 & 19.46 & 16.50 & -0.66 & -3.64 & 0.30 & 0.30 & 0.0010 & 2000.9 & 2012.5 & 11.6 \\
\hline $\mathrm{KATZ}$ & 35.688 & 32.995 & 19.80 & 19.17 & -0.44 & -1.22 & 0.48 & 0.48 & -0.0020 & 2000.9 & 2012.5 & 11.6 \\
\hline LAUG $^{b}$ & 35.674 & 34.115 & 18.25 & 17.30 & -1.12 & -3.08 & 0.34 & 0.34 & 0.0020 & 2002.8 & 2010.7 & 7.9 \\
\hline LHAV $^{b}$ & 34.866 & 31.378 & 20.31 & 15.31 & -1.02 & -4.70 & 0.37 & 0.37 & 0.0000 & 2001.1 & 2008.9 & 7.8 \\
\hline MERS $^{b}$ & 34.256 & 36.566 & 11.18 & 13.05 & -5.98 & -6.67 & 0.35 & 0.35 & 0.0000 & 2002.4 & 2012.5 & 10.1 \\
\hline $\mathrm{NICO}^{b}$ & 33.396 & 35.141 & 16.98 & 11.35 & -1.14 & -7.97 & 0.38 & 0.38 & 0.0000 & 2000.9 & 2012.5 & 11.6 \\
\hline $\mathrm{NRIF}^{\mathrm{b}}$ & 35.036 & 30.038 & 21.50 & 17.04 & -0.87 & -3.05 & 0.39 & 0.39 & 0.0010 & 2005.2 & 2012.5 & 7.3 \\
\hline $\mathrm{NSSP}^{\mathrm{b}}$ & 44.503 & 40.226 & 26.00 & 13.72 & 9.26 & -10.42 & 0.34 & 0.34 & 0.0010 & 2001.1 & 2010.5 & 9.4 \\
\hline SLOM $^{b}$ & 34.284 & 31.228 & 18.52 & 14.84 & -2.82 & -4.90 & 1.05 & 1.05 & -0.0050 & 2004.7 & 2012.5 & 7.8 \\
\hline TELA ${ }^{b}$ & 34.781 & 32.068 & 19.38 & 16.75 & -1.40 & -3.22 & 0.37 & 0.37 & 0.0000 & 2000.9 & 2012.5 & 11.6 \\
\hline TRAB $^{\mathrm{b}}$ & 39.776 & 40.995 & 22.85 & 9.87 & 7.95 & -12.32 & 0.39 & 0.39 & 0.0000 & 2000.9 & 2007.9 & 7.0 \\
\hline UDMC $^{b}$ & 36.285 & 33.510 & 19.66 & 19.90 & -0.30 & -0.76 & 0.37 & 0.37 & 0.0000 & 2002.3 & 2010.9 & 8.6 \\
\hline $\mathrm{YRCM}^{\mathrm{b}}$ & 34.928 & 30.992 & 20.46 & 15.91 & -1.17 & -4.13 & 0.39 & 0.39 & 0.0010 & 2005.5 & 2010.5 & 5.0 \\
\hline ZECK ${ }^{b}$ & 41.565 & 43.788 & 23.24 & 8.17 & 10.08 & -14.77 & 0.31 & 0.31 & 0.0020 & 2000.9 & 2012.5 & 11.6 \\
\hline
\end{tabular}




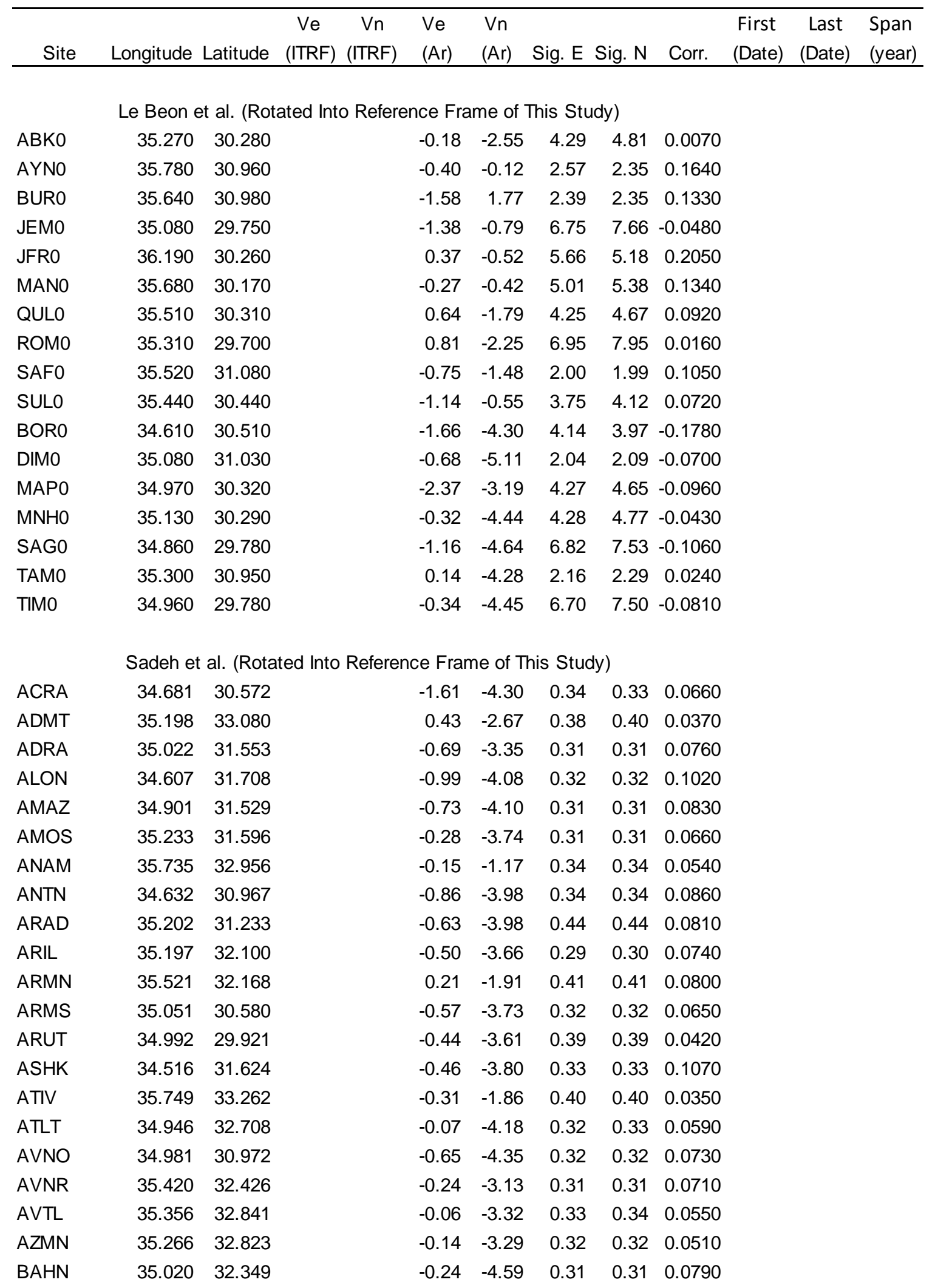




\begin{tabular}{|c|c|c|c|c|c|c|c|c|}
\hline Site & Longitude & Latitude & $\begin{array}{cc}\mathrm{Ve} & \mathrm{Vn} \\
\text { (ITRF) } & \text { (ITRF) }\end{array}$ & $\begin{array}{l}\mathrm{Ve} \\
(\mathrm{Ar})\end{array}$ & $\begin{array}{l}\mathrm{Vn} \\
(\mathrm{Ar})\end{array}$ & Sig. E & Sig. N & Corr. \\
\hline \multicolumn{9}{|c|}{ Sadeh et al. (cont.) } \\
\hline $\mathrm{BAHR}^{\mathrm{b}}$ & 50.608 & 26.209 & & 14.74 & 9.49 & 21.53 & 20.39 & -0.0590 \\
\hline BERE & 34.908 & 29.812 & & -1.21 & -3.43 & 0.43 & 0.42 & 0.0340 \\
\hline BERI & 34.463 & 31.423 & & -0.86 & -4.04 & 0.33 & 0.34 & 0.1070 \\
\hline BERO & 34.465 & 30.781 & & -1.53 & -3.69 & 0.34 & 0.33 & 0.0810 \\
\hline BJAN & 35.367 & 32.955 & & 0.11 & -3.52 & 0.33 & 0.33 & 0.0420 \\
\hline ВKOT & 35.452 & 32.247 & & -0.16 & -3.20 & 0.30 & 0.30 & 0.0670 \\
\hline BMIR & 35.048 & 31.793 & & -0.63 & -3.26 & 0.31 & 0.31 & 0.0780 \\
\hline BRAK & 35.138 & 30.414 & & -0.76 & -3.96 & 0.33 & 0.33 & 0.0630 \\
\hline BRKA & 35.029 & 32.470 & & 0.04 & -4.13 & 0.32 & 0.32 & 0.0760 \\
\hline BRNE & 34.542 & 30.590 & & -1.45 & -3.73 & 0.35 & 0.34 & 0.0690 \\
\hline BSOR & 34.475 & 31.346 & & 0.12 & -4.20 & 0.34 & 0.34 & 0.1040 \\
\hline CABR & 35.145 & 33.017 & & 0.40 & -3.56 & 0.35 & 0.35 & 0.0320 \\
\hline CADM & 35.341 & 31.817 & & 0.02 & -3.18 & 0.30 & 0.31 & 0.0630 \\
\hline CBIR & 35.328 & 32.243 & & -0.22 & -3.25 & 0.30 & 0.30 & 0.0710 \\
\hline CNDA & 34.999 & 31.846 & & -0.28 & -3.95 & 0.31 & 0.31 & 0.0820 \\
\hline CPRK & 35.038 & 32.741 & & 0.35 & -3.60 & 0.40 & 0.40 & 0.0710 \\
\hline CSON & 35.145 & 32.855 & & 0.02 & -3.36 & 0.33 & 0.34 & 0.0480 \\
\hline CVDN & 35.527 & 32.576 & & -0.31 & -3.04 & 0.31 & 0.30 & 0.0660 \\
\hline CVEL & 34.677 & 31.634 & & -0.45 & -4.09 & 0.32 & 0.32 & 0.0970 \\
\hline CZUR & 35.097 & 31.610 & & -0.12 & -3.99 & 0.30 & 0.31 & 0.0730 \\
\hline DAYA & 35.109 & 31.136 & & -0.48 & -4.20 & 0.30 & 0.30 & 0.0640 \\
\hline DRGA & 35.395 & 31.597 & & -0.44 & -3.97 & 0.30 & 0.30 & 0.0530 \\
\hline ECOV & 35.236 & 33.009 & & 0.42 & -3.24 & 0.35 & 0.35 & 0.0360 \\
\hline ELKN & 35.039 & 32.114 & & 0.04 & -4.26 & 0.30 & 0.31 & 0.0810 \\
\hline ENRD & 35.393 & 32.565 & & -0.08 & -3.22 & 0.31 & 0.31 & 0.0670 \\
\hline EYAL & 34.980 & 32.207 & & -1.06 & -4.19 & 0.31 & 0.31 & 0.0830 \\
\hline EZRA & 34.662 & 31.749 & & -0.52 & -4.50 & 0.32 & 0.32 & 0.0990 \\
\hline GLIL & 34.804 & 32.141 & & 0.15 & -4.07 & 0.31 & 0.32 & 0.0910 \\
\hline GLON & 35.230 & 32.912 & & 0.04 & -3.50 & 0.34 & 0.33 & 0.0440 \\
\hline GMLA & 35.692 & 32.884 & & 0.27 & -0.86 & 0.33 & 0.33 & 0.0570 \\
\hline GORL & 34.823 & 31.323 & & -0.88 & -3.28 & 0.32 & 0.32 & 0.0850 \\
\hline GTIT & 35.387 & 32.102 & & -0.13 & -3.42 & 0.30 & 0.30 & 0.0670 \\
\hline GVRN & 34.848 & 31.589 & & -0.86 & -4.09 & 0.30 & 0.31 & 0.0860 \\
\hline HAIL & 34.796 & 31.199 & & -0.94 & -3.99 & 0.31 & 0.31 & 0.0830 \\
\hline HALY ${ }^{b}$ & 36.100 & 29.139 & & 1.00 & -1.36 & 0.72 & 0.68 & 0.0790 \\
\hline HARI & 34.553 & 30.508 & & -1.33 & -3.96 & 0.35 & 0.34 & 0.0630 \\
\hline HDAV & 34.941 & 30.524 & & -1.05 & -3.68 & 0.33 & 0.33 & 0.0640 \\
\hline HKUK & 35.494 & 32.892 & & 0.22 & -2.82 & 0.32 & 0.32 & 0.0510 \\
\hline HZON & 35.403 & 32.900 & & -0.01 & -3.56 & 0.33 & 0.33 & 0.0490 \\
\hline HZOR & 35.555 & 32.994 & & -0.13 & -2.84 & 0.35 & 0.34 & 0.0470 \\
\hline IDAN & 35.277 & 30.808 & & -1.54 & -3.16 & 0.32 & 0.32 & 0.0600 \\
\hline KATN & 35.150 & 30.935 & & 0.21 & -4.60 & 0.35 & 0.35 & 0.0710 \\
\hline KBIA & 35.182 & 32.764 & & 0.11 & -3.51 & 0.42 & 0.43 & 0.0740 \\
\hline
\end{tabular}




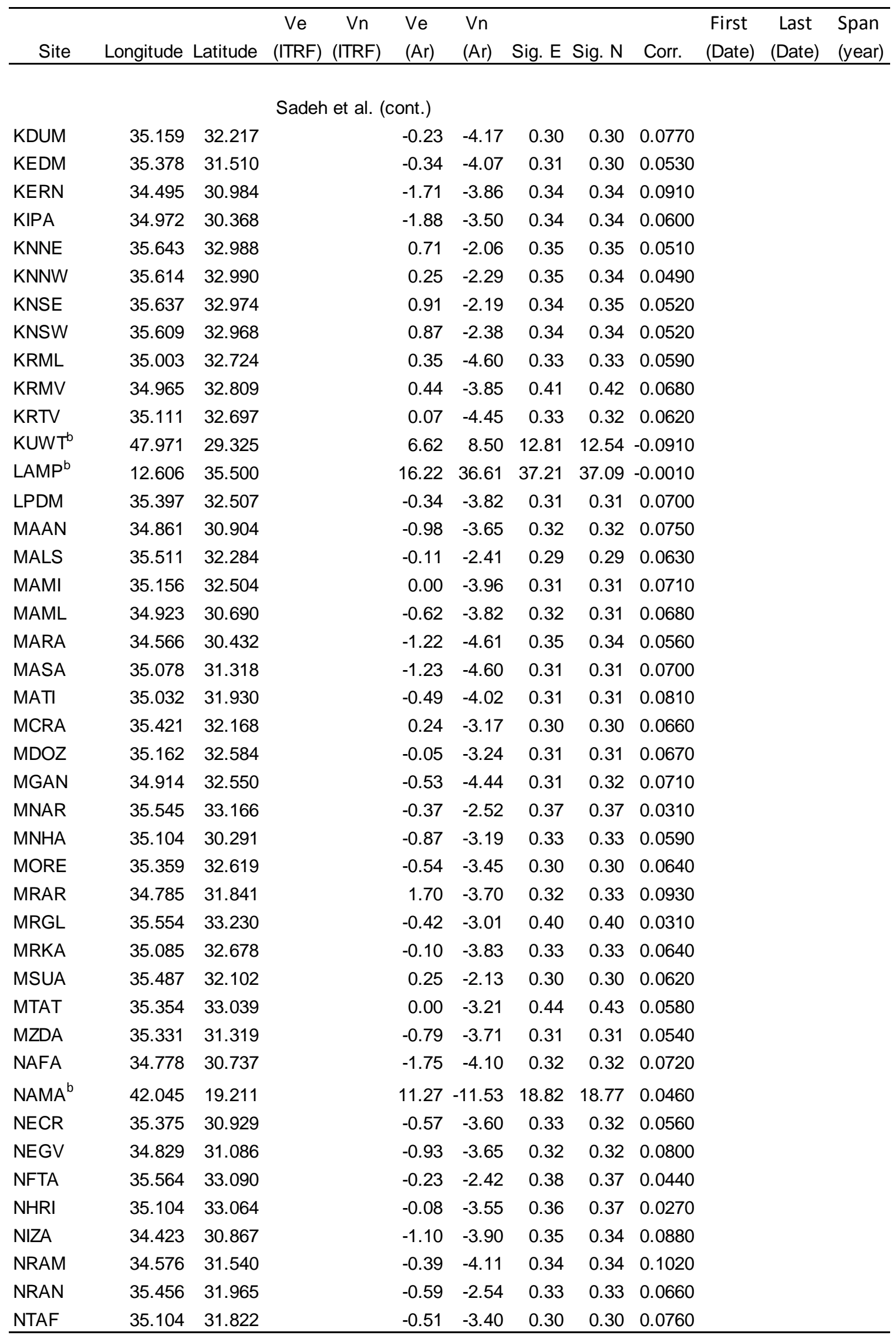




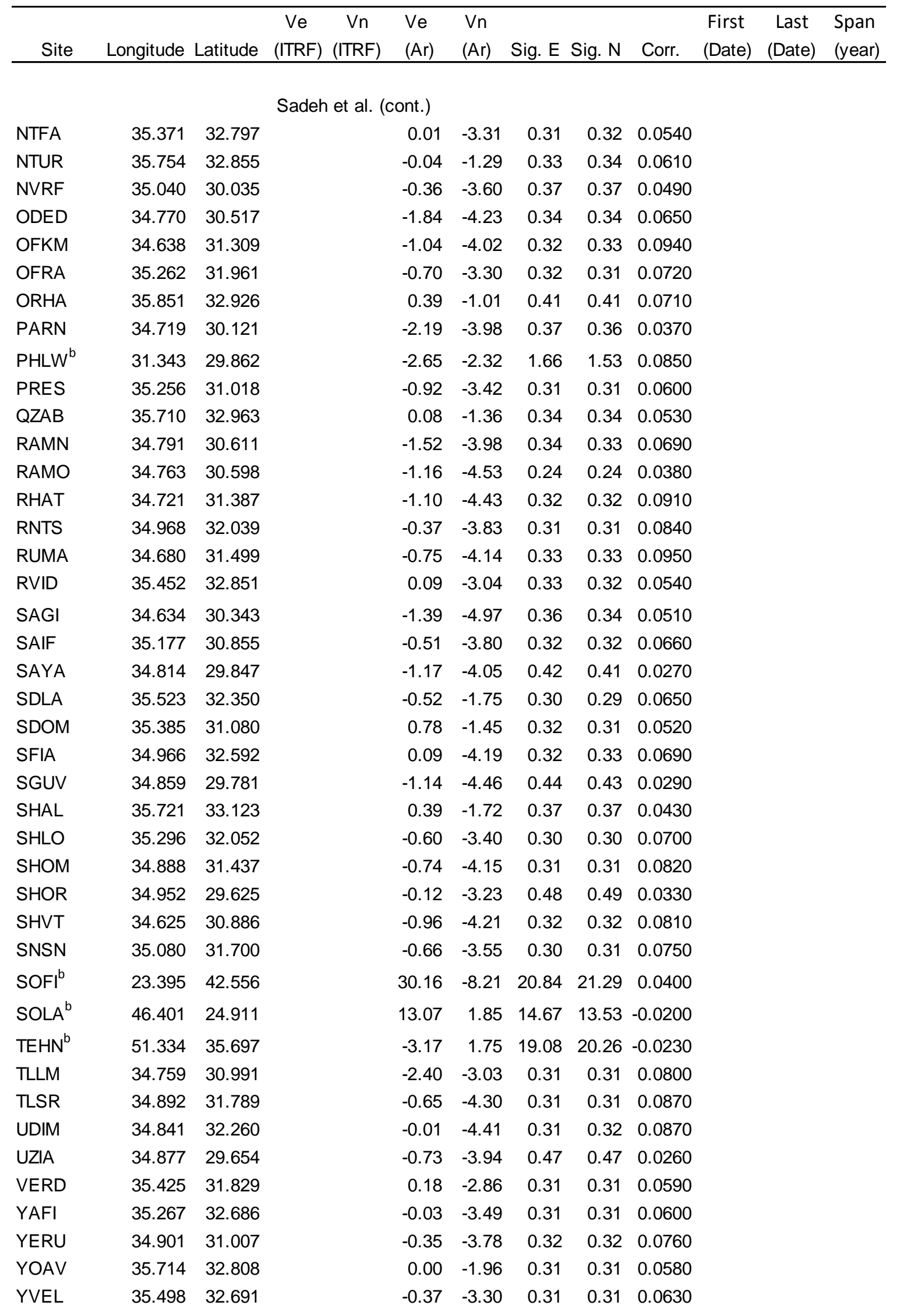




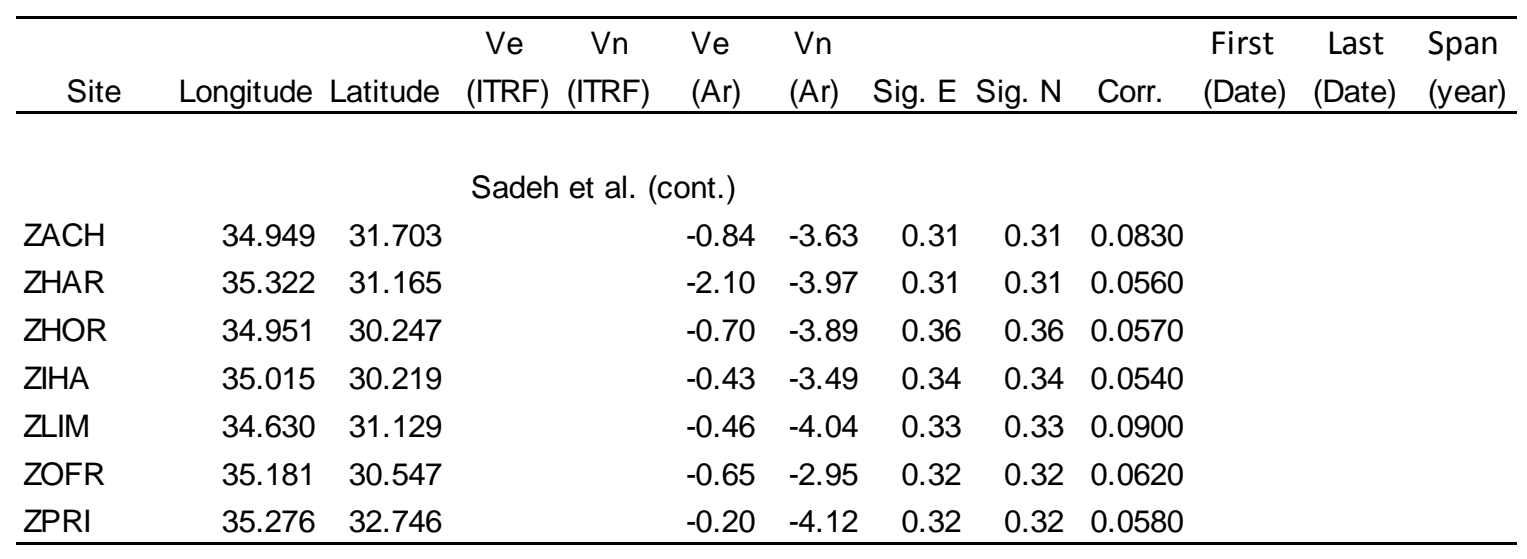

${ }^{a}$ Velocities are presented in ITRF2008 and Arabia-fixed reference frame.

${ }^{b}$ Denotes continuous GPS stations 

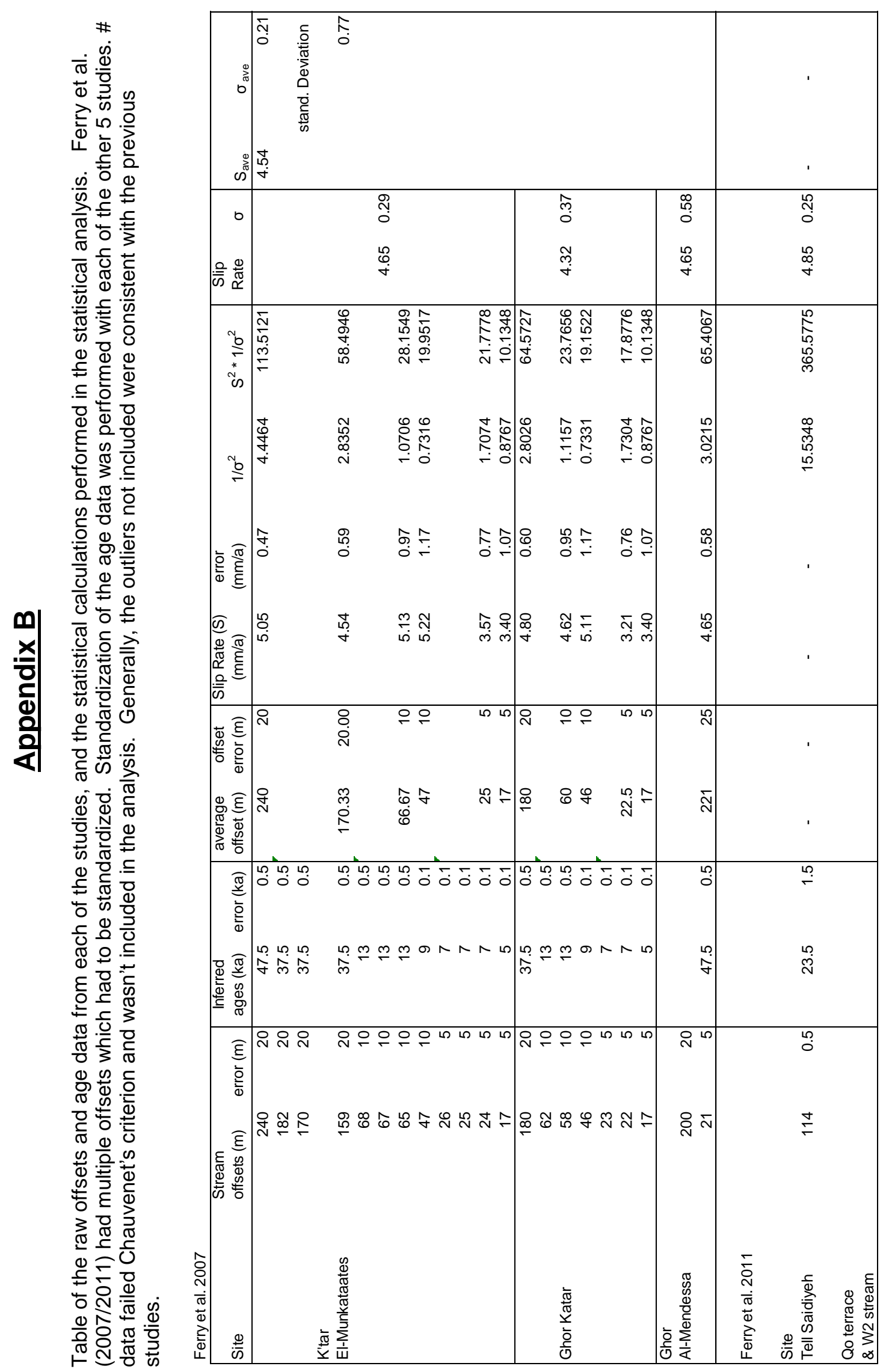


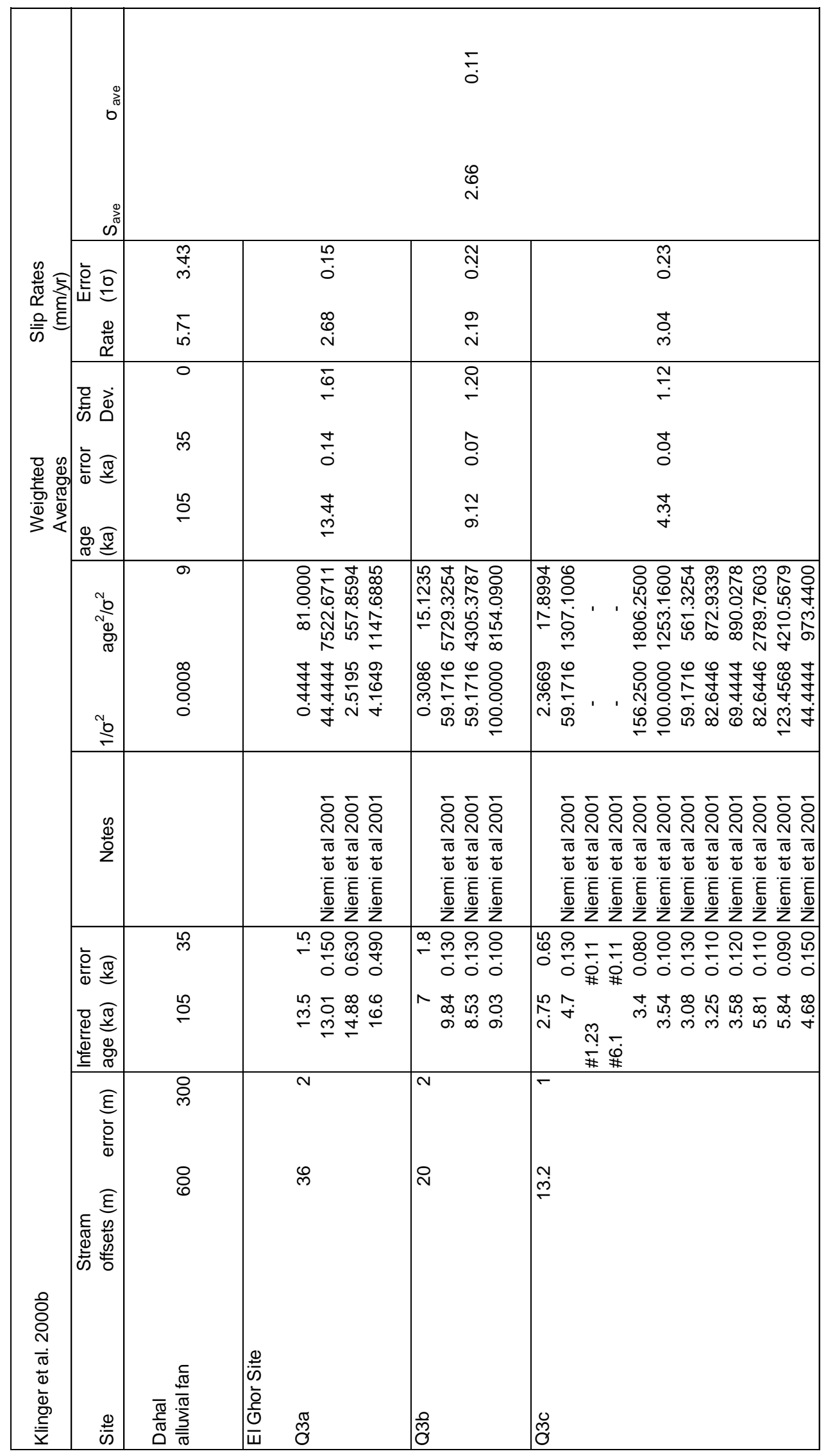




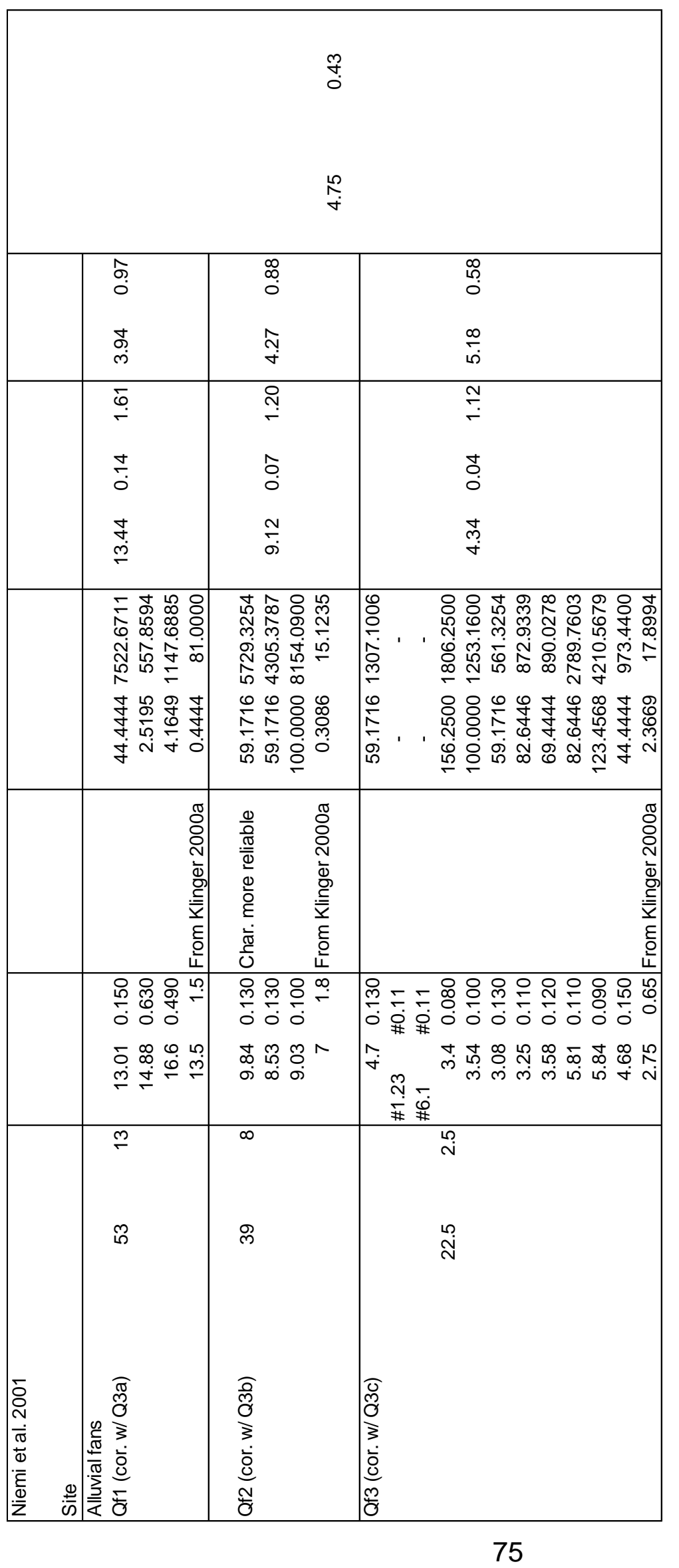




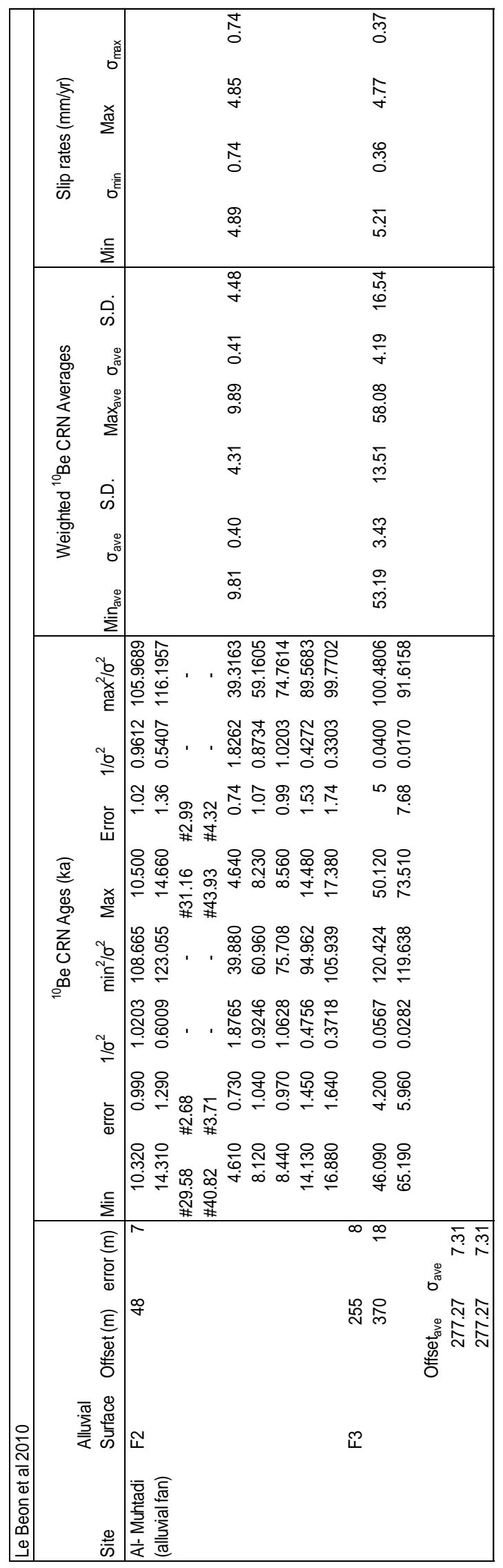




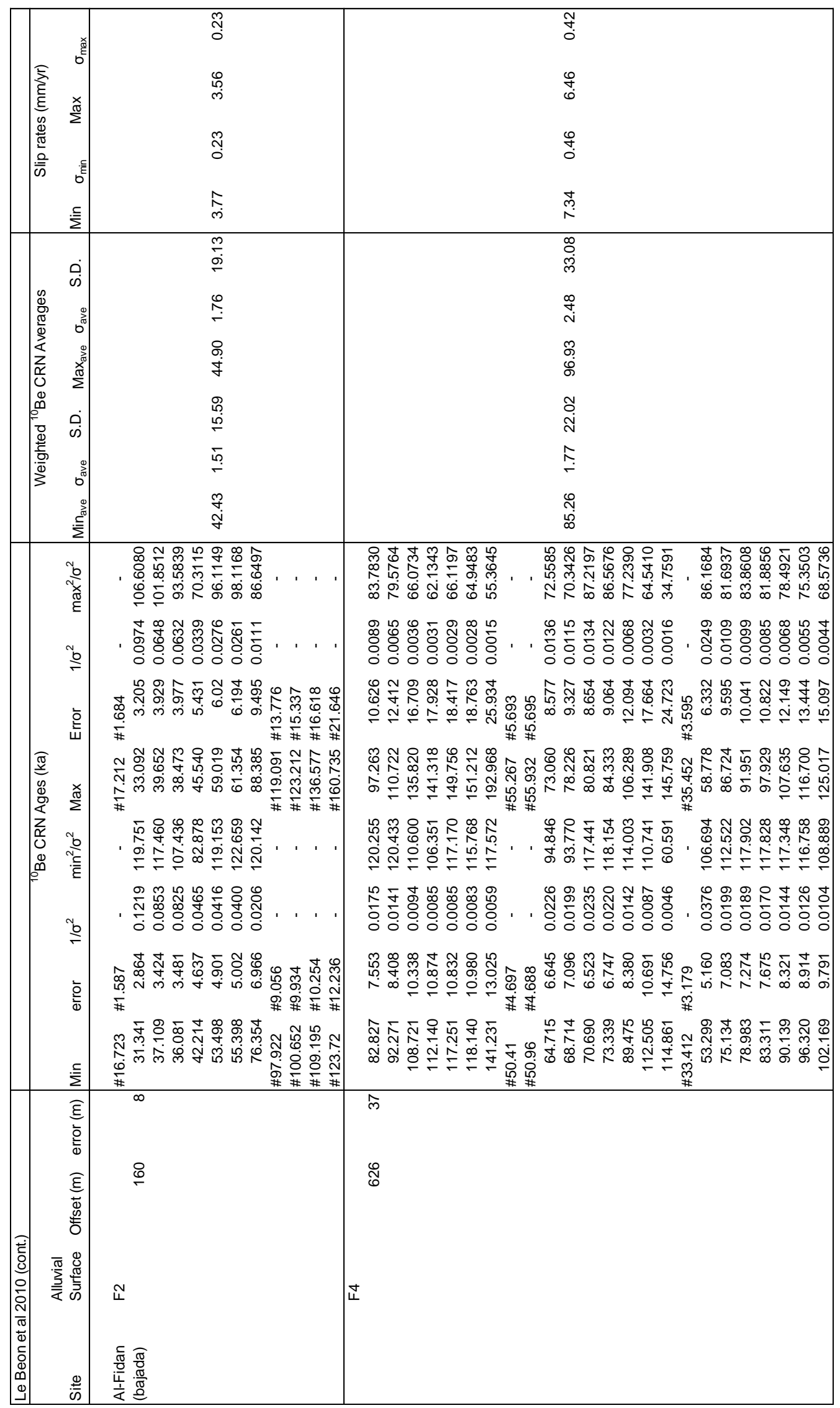




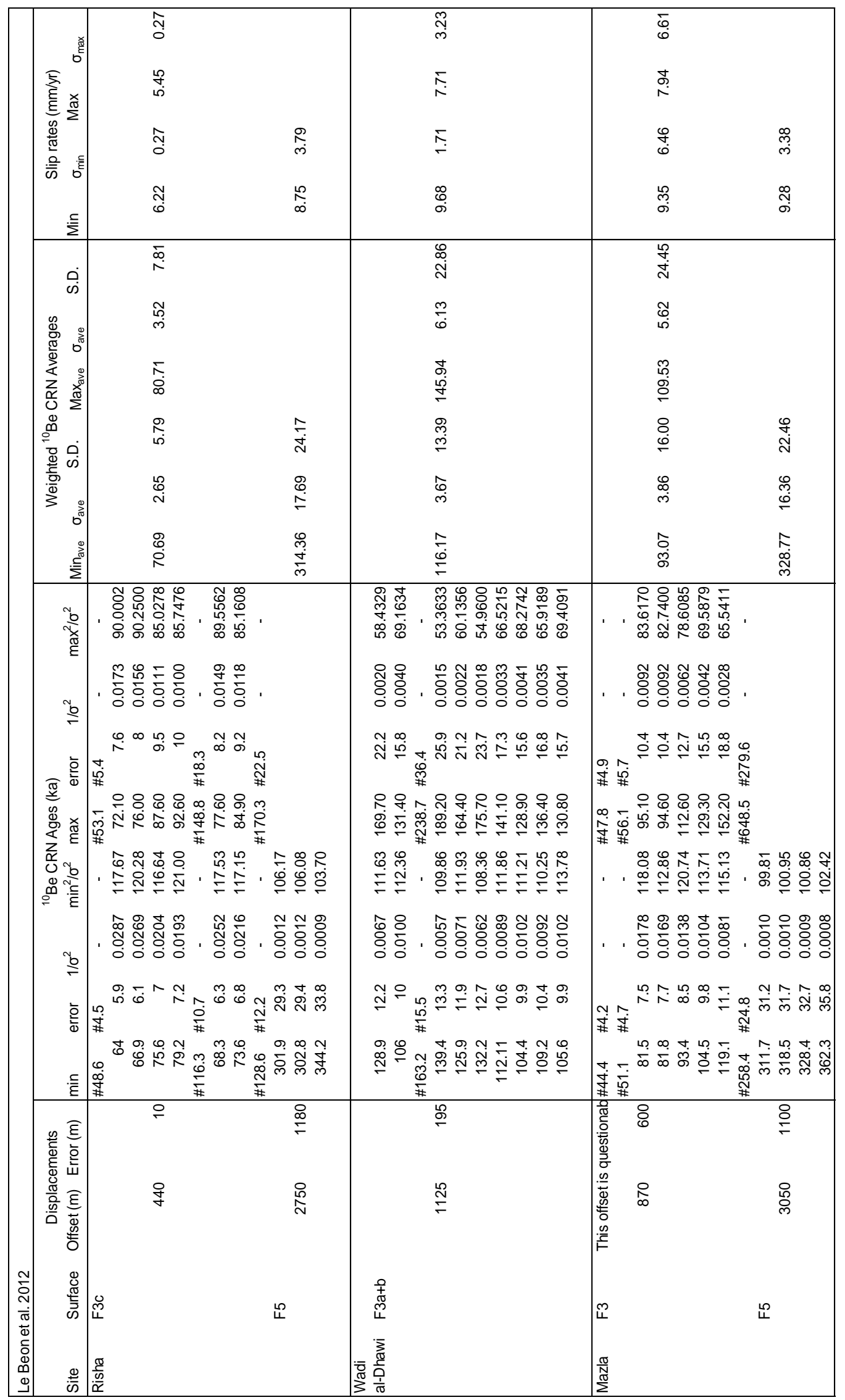

